\title{
Tannin containing legumes as a model for nutraceuticals against digestive parasites in livestock
}

Article

Accepted Version

Hoste, H., Torres-Acosta, J. F. J., Sandoval-Castro, C. A., Mueller-Harvey, I., Sotiraki, S., Louvandin, H., Thamsborg, S. M. and Terrill, T. H. (2015) Tannin containing legumes as a model for nutraceuticals against digestive parasites in livestock. Veterinary Parasitology, 212 (1-2). pp. 5-17. ISSN 0304-4017 doi: https://doi.org/10.1016/j.vetpar.2015.06.026 Available at https://centaur.reading.ac.uk/40566/

It is advisable to refer to the publisher's version if you intend to cite from the work. See Guidance on citing.

To link to this article DOI: http://dx.doi.org/10.1016/j.vetpar.2015.06.026

Publisher: Elsevier

All outputs in CentAUR are protected by Intellectual Property Rights law, including copyright law. Copyright and IPR is retained by the creators or other copyright holders. Terms and conditions for use of this material are defined in the End User Agreement. 


\section{CentAUR}

Central Archive at the University of Reading

Reading's research outputs online 


\section{Elsevier Editorial System(tm) for Veterinary Parasitology}

Manuscript Draft

Manuscript Number: Vetpar-D-15-9343R1

Title: TANNIN CONTAINING LEGUMES AS A MODEL FOR NUTRACEUTICALS AGAINST DIGESTIVE PARASITES IN LIVESTOCK

Article Type: Review Article

Keywords: Nutraceuticals / Condensed tannins/ Polyphenols / Gastrointestinal nematodes / Antiparasitic effects / Small ruminants

Corresponding Author: Dr. HOSTE Hervé, DVM, Phd,HDR

Corresponding Author's Institution: INRA

First Author: HOSTE Hervé, DVM, Phd,HDR

Order of Authors: HOSTE Hervé, DVM, Phd,HDR; TORRES-ACOSTA J.F.J.; SANDOVAL-CASTRO C.A.; MUELLER-HARVEY I.; SOTIRAKI S.; LOUVANDINI H.; THAMSBORG S.M.; TERRILL T.H.

Abstract: Parasitic infections with gastrointestinal nematodes (GINs) still represent a worldwide major pathological threat associated with the outdoor production of various livestock species. Because of the widespread resistance to synthetic chemical anthelmintics, there is a strong impetus to explore novel approaches for a more integrated management of the infections. The use of nutraceuticals in the control of GINs is one of the alternatives which has been widely studied for 20 years.

The objective of this review are: i) to define and illustrate the concept of 'nutraceutical' in the context of veterinary parasitology based on data obtained on the most studied GIN models in small ruminants, the tannin-containing legumes (Fabaceae); ii) to illustrate how the 'nutraceutical concept' could be expanded to other plants, other livestock production systems and other GI parasitic diseases, and iii) to explain how this concept is opening up new research fields for better understanding the interactions between the host, the digestive parasites and the environment 
Dr Hervé HOSTE

Unité Associée 1225 INRA / ENVT

«Interactions Hôte Agents Pathogènes »

Ecole Nationale Vétérinaire de Toulouse

23, Chemin de Capelles

31076 TOULOUSE Cedex

Tel 0561193875 Fax 0561193944

E mail h.hoste@envt.fr

Toulouse, the 08th June 2015.

Dear colleague,

Please find enclosed a revised version of the article "Tannin containing legumes as a model for nutraceuticals against digestive parasites in livestock" by Hoste $\mathrm{H}$ and collaborators which is submitted for publication to Veterinary Parasitology. This review was invited for the Special Issue in preparation for the next WAAVP 2015 meeting in Liverpool.

By comparison to the first version, main changes have been made on i) the main text li) the figure 3 and its caption and iii) 10 references have been added to address some of the referees'comments.

We wish to thank the 2 referees for their inputs and we hope to have addressed their comments. In particular, we have paid special attention to the definition of nutraceutical in the section 2 in order to take into account the comments of the 2 referees

This revised manuscript has been approved by all co-authors.

We are looking forward to receiving your comments

Yours sincerely

Hervé HOSTE 
Reviewer \#1: This review manuscript is very well written and very thorough on the experimental approach to determine the nutraceutical effect of plants, specifically condensed tannin (CT) containing plants, on small ruminant gastrointestinal nematode (GIN) infections. It is so thorough that it could be condensed, as there is much repetitive information throughout. It would be very useful information in a textbook for veterinary students studying parasitology or animal science students studying production issues. In some instances though, the literature could have been more thoroughly researched rather than only including the authors work. An example of this can be found in Lines 180-184 and L346-348. Some papers that were missed in this discussion include those from Utah State University (even though this is not a tropical area, they do use irrigation and might consider this a model for self-medication - Villalba and Provenza, 2007; Villalba et al., 2010, 2012; Lisonbee et al., 2009; and also, Hutchings et al., 2003 to name another). Minor comments appear below.

The different references mentioned by the referee (and some others) have been now added in the section 5.3 dedicated to the subject of self medication

L80-82: I found this sentence, almost word for word on Wikipedia. I was curious because research and patent regulation concerning nutraceuticals occurred before 1998. See DeFelice, 1995 (Trends in Food Sci. Tech.) or Linko and Hayakawa, 1996 (same journal), or Mee, 1994, Hunt, 1994 concerning regulatory issues.

Because of the comments of the 2 referees, we tried to better defined and clarify in the section 2 the definition of the concept of nutraceuticals in medical and vet sciences and to make clear that we will focus on one subcategory of nutraceuticals, namely those based on PSM containing resources either when directly present or when added to animal feed.

This will be found in section 2 of the current Revised Manuscript (REVMAN)

Text throughout: There seems to be missing "t", "I" and "f" typically in either bold or italicized text throughout on my pdf copy. We have checked these errors throughout the Revised Manuscript (REVMAN)

L199-204: On the other hand, is it worth noting that non-native species are considered invasive by environmentalists and ecologists? The comment has been included in section 3.1.2. of the REVMAN (see line 212-213)

L390: (e.g., packed cell volume): This has been added (line $\mathbf{4 6 2}$ in the revised manuscript)

L386-401: Should effects on toxicology be considered at some point in the experimental protocol?

As stated in the title of section 3.2, we intend and decided to focus only on the efficacy issue

L438, 617: Should non-peer reviewed papers be cited in review articles?

For the references 50 (Klongsiriwet, C., et al 2015) and the reference 85 (Quijada et al. 2015) in the Revised Manuscript $=$ We have now replaced the previous reference to a summary for a conference by a reference to an accepted or submiited article. 
For the references 19 (Castañeda-Ramírez, G.S et al. 2014); ref 22 (Covarrubias-Cárdenas, A.G. et al 2013); ref 23 (Desrues et al 2012); ref 30: (Girard et al, 2013), and ref 104 (Vargas-Magaña, J.J. et al, 2014), we will respect the editorial rules and advices of the editor

L450: Not just iso-proteic, but also similar in bypass protein as well. We agree with the referee that this should be a task. However, it is difficult to assess the amount of increased by-pass proteins because of the presence of CT. We could only say that CT could alter (increase) the quantity of bypass proteins in the diets (see section 4.1.1. (line 522) and section 4.1.2 (lines 534), in the RevMan).

L452-459: Already been alluded to in previous paragraph.

L596: "...based on nutritional..." CORRECTED

L633: sporulation. CORRECTED

L647-648: Burke et al., 2013 fed before and at weaning. Has been added on line $\mathbf{7 4 4}$ in the Revised Manuscript

L661: spp. CORRECTED (line 671)

L666: However and ,L666-667: Is there something missing after this sentence? We think to have clarified this sentence now (line 731 to 739 in the Revised Manuscript)

L668-688: Does not fit the objective of the paper. The referee is right; however, we wished to illustrate in this section 5.2 that the concept of nutraceutical can be applied to other plant families in relation with other PSM (see the title of section 5.2) (line 726 in the revised manuscript)

References: Some are not formatted correctly and contain misspellings. We had checked thoroughly the references and have corrected several errors.

Figures 2, 3: Why is the male worm depicted as being larger than the female? The referee is right

This has been corrected now in the REVMAN

Reviewer \#2: General comments are as follows:

This is an interesting review, which summarises a complicated area and makes many valid points. However, it seeks to redefine bioactive forages as nutraceuticals, and in doing so it becomes confusing. The authors defines all nutraceuticals as plant based products containing PSM, and the rest of the paper follows from th is inaccurate assumption. It is broadly accepted that a nutraceutical is a food product or a product derived from food (e.g. vitamins and minerals) which is added to the diet and is perceived to have added health benefits. Usually the beneficial compounds in nutraceuticals do not have pharmacological action against pathogens, rather they help improve host health. Hence bioactive forages presented in this context simply does not work for me. Another broad issue with the review, is that it gives few facts and figures regarding the efficacy of these 'nutraceuticals' and hence leaves you with little sense of how efficacious these plants actually are. To be of interest to a wider audience I would suggest adding in some basic information regarding CT containing forages and their efficacy. For these reasons I suggest moderate revision before acceptance. I suggest that either the definition of nutraceutical is changed, and it is acknowledged that bioactive forages are a very specific type of nutraceutical, or the term nutraceutical is removed altogether. 
WE TRIED TO MAKE CLEAR in the TITLE AND in the SECTION 2, THAT IN THIS REVIEW WE WERE FOCUSSING ON BIOACTVE PLANTS USED AS NUTRACEUTICALS

IN ADDITION, TO ADRRESS ONE OF THE REFEREE, ONE CAN EXPECT THAN ANY EFFECT AGAINST PATHOGENS WILL HELP AT IMPROVING ANIMAL HEALTH

Specific points are as follows:

Line 25 - 'nutraceuticals', should be plural

NOW CORRECTED

Line 26 - 'alternatives', should be plural

NOW CORRECTED

Line 26 - suggest change 'since 20 years' to 'for 20 years' better grammar

NOW CORRECTED

Line 27 - 'objectives', should be plural

NOW CORRECTED

Line 62-63 - This sentence is unclear, consider re-phrase.

THIS HAS BEEN REPHRASED

Line 72-73 - Not sure this sentence quite makes sense - it infers the fabaceae are a GIN model. Suggest rephrase.

THE SENTENCE HAS BEEN MODIFIED

Line 80-92 - I think that the definition of a veterinary nutraceutical here is too narrow. Nutraceuticals are not all bioactive plants with PSMs. Some are derived from other biological materials e.g. glucosamine from shellfish. More accurately bioactive forages are a sub-category of nutraceuticals.

WE HAVE TAKEN INTO ACCOUNT THE REFEREE'S COMMENT AND INCLUDED IT IN THE TEXT (LINE 9192 in the REVISED MANUSCRIPT)

Line 98-110 - Following on from the point above, referring to bioactive forage as 'nutraceuticals' could be construed as inaccurate

WE HAVE ALSO ADDED SOME PRECISION IN THE TEXT TO CLARIFY THE FACT THAT WE ARE FOCUSSING ON BIOACTIVE FORAGES AS A SUB CATEGORY OF NUTRACEUTICALS

Line 149 - What is IVDMD?

EXPLANATIONS ARE NOW PROVIDED

Line 152 - I'm not sure this is strictly true. Many nutraceuticals are added to animals feeds in specific amounts and their intake is not voluntary. E.g. joint supplements, vitamins and fatty acids

WE HAVE NOW MADE CLEAR THAT THE FOCUS WAS ON BIOACTIVE PLANTS (SEE LINE 91/92 AND 118). IN ADDITION, EVEN IN THE CASE EVOKED BY THE REFEREE, THE EFFECTS WILL DEPEND ON THE CONSUMPTION OF THE FEED BY THE ANIMALS

Line 159 - Please define acronyms (DM, OM) the first time you use them. 


\section{THIS HAS BEEN CORRECTED}

Line 197-198 - This sentence is unclear - consider rephrase

\section{WE THINK THAT THE SENTENCE IS CLEAR}

Line 215 -216 - 'By the overall, logical scheme/organisation and the objectives of each step, the procedure has been adapted...' I am not sure what this means? Please rephrase more clearly

\section{THE SENTENCE HAS BEEN MODIFIED IN ORDER TO CLARIFY THE MEANING}

Line 227 - '(see point 4)' it is unclear as to what this is referring to as there are so many points and sub-points in this review

\section{THIS HAS BEEN SUPPRESSED NOW TO AVOID ANY CONFUSION}

Line 245-253 - Other studies are referred to but there are no references

\section{REFERENCES HAVE BEEN ADDED}

Line 252-253 - This sentence is unclear, do you mean CTs? or Nutraceutical plants?

WE CAN NOT ADDRESS THIS POINT BECAUSE in the SUBMITTED MANUSCRIPT, WE DID NOT FIND REFERENCE NEITHER TO CT NOR TO NUTRACEUTICAL ON LINE 252-253

Line 256-268 - This section needs more references

\section{A REFERENCE HAS BEEN ADDED}

Line 268 - Could you discuss further which tests are likely to be most biologically relevant for GINs and why?

AS SPECIFIED IN THE FIRST VERSION (LINE 226 to 228 , NOW LINE 259 to 261 in the REVISED MANUSCRIPT) WE HAVE INDICATED THAT "Since the mode of action of tannin-containing nutraceuticals differs from synthetic chemical $A H s$, it may be of interest to examine the effects of the same plant extract on different key stages of the GIN life cycle (egg, infective larvae, adult worms)"

Line 270-279 - In light of this statement, what extraction technique would you recommend and why? WHAT WE WANT TO ILLUSTRATE WITH THIS SECTION IS THE STATEMENT THAT THE EXTRACTION PROCEDURE IS IMPORTANT TO ADAPT DEPENDING ON THE TYPE OF PSM SUSPECTED AND IN FACT, THAT THERE IS NO “BEST” EXTRACTION TECHNIQUE.

HOWEVER, IT HAS BEEN SPECIFIED (LINE 282-283 in the REVISED MANSCRIPT) THAT ACETONE:WATER IS THE MOST EFFICIENT SOLVENT FOR TANNINS

Line 282-292 - This section could be more concise. Are there any references to support these observations?

WE THINK THAT THE DIFFERENT POINTS MENTIONED IN THIS SECTION ARE IMPORTANT TO UNDERLINE WHY IT IS DIFFICULT TO INFER IN VIVO CONDITIONS FROM THE DATA OBTAINED FROM IN VITRO ASSAYS

Line 295-296 - 'In that case, such an approach would not be that of a nutraceutical material' - this sentence requires rephrasing, as it suggests that the nutraceutical material is taking an approach rather than the scientist. 
THE SENTENCE HAS BEEN REPHRASED (LINE 351-356 in the REVISED MANUSCRIPT)

Line 299-300 - Again, not sure about the definition of nutraceutical here - it is generally accepted that dietary supplements containing concentrated compounds from natural sources are also considered to be nutraceuticals - e.g. vitamins, concentrated herbal supplements, glucosamine

Line 315 - The same point as above

FOR THESE 2 LAST POINTS, See COMMENTS MADE TO THE REFEREE FOR LINE 152

Line 403-410 - Not particularly keen on being referred to other studies for this information, could the authors give a brief summary seeing as this is a review?

WE THINK THAT WE HAVEN GIVEN A SUMMARY OF THE MAIN RESULTS ON THE ANTHELMINTIC EFFECTS IN THE REST OF SECTION 4

Line 440-448 - Could the apparent host resilience be a direct result of the effect of CTs on infection intensity?

THE HYPOTHESIS HAS NOW BEEN MENTIONED

Line 457-459 - Is there any evidence for hypothesis no.2 ?

A SECTION WITH REFERENCES HAVE NOW BEEN ADDED (line 368-375) in the REVISED VERSION

Line 545 - 'a considerable amount of results has been' suggest reword to 'a considerable amount of data has been'

\section{CORRECTED}

Line 545-549 - Could the authors give an indication of the in vivo efficacy found in the studies referred to here?

SOME VALUES (and CORRESPONDING REFERENCES) HAVE BEEN ADDED IN THE LEGEND OF FIGURE 3 Lines 551-559 - Does this not contradict what was said in lines 293-306? i.e. of you concentrate the active compound and add it to the feed it is a plant extract - not a nutraceutical. N.B. I do not agree with this point anyway - but there is some inconsistency here

AGAIN WE HOPE TO HAVE BETTER DEFINE THE CONCEPT OF NUTRACEUTICALS THAT WE TRIED TO ILLUSTRATE IN THIS REVIEW

THE FACT THAT WE WILL CONSIDER THE POSSIBLE ADDITION OF CONCENTRATED FORM WA PREVIOUSLY MENTIONNED AND IS NOW INDICATED CLEARLY IN THE REVISED MANUSCRIPT ON LINE 95-96; see ALSO TABLE 1.

Lines 570-579 - The wine analogy is not necessary to make this point, suggest omit this paragraph THIS SECTION HAS NOW BEEN SUPPRESSED

Line 608 - suggest use 'areas' instead of 'axes' CORRECTED

Line 609 - Grammar - suggest 'targets for' instead of 'targets with' CORRECTED

Line 624- 625 - are not medicinal plants also technically nutraceuticals? 
THE TERM “MEDICINAL PLANTS"HAS BEEN REPLACED BY “HERBAL REMEDIES" AND REFERENCE MADE TO TABLE 1 WHERE THE DIFFERENCES BETWEEN HERBAL DRUGS AND NUTRACEUTICALS ARE EXPLAINED

Line 633 - spelling - sporulation CORRECTED

Lines 691-698 - Self-medication is mentioned a couple of times in this review, it is an interesting concept, could the authors briefly summarise the evidence for this taking place with plants containing CTs, even though there has been a recent review?

ACCORDING TO THE RECOMMENDATIONS OF THE FIRST REFEREE, WE HAVE NOW COMPLETED THIS SECTION 5.3 ON SELF MEDICATION WITH SEVERAL REFERENCES WHICH ILLUSTRATE THE DIFFERENT POINTS EVOKED. IN ADDITION, TWO REVIEWS ON THE SUBJECT ARE MENTIONNNED NOW WHERE THE READERS WILL FIND DETAILED INFORMATION. WE THINK THAT DEVELOPMENTS ON THE SELF MEDICATION IS NOT DIRECTLY RELEVANT TO THE OBJECTIVE OF THIS REVIEW.

Line 728 - spelling 'phytochemistry' CORRECTED 
TANNIN CONTAINING LEGUMES AS A MODEL FOR NUTRACEUTICALS AGAINST DIGESTIVE PARASITES IN LIVESTOCK

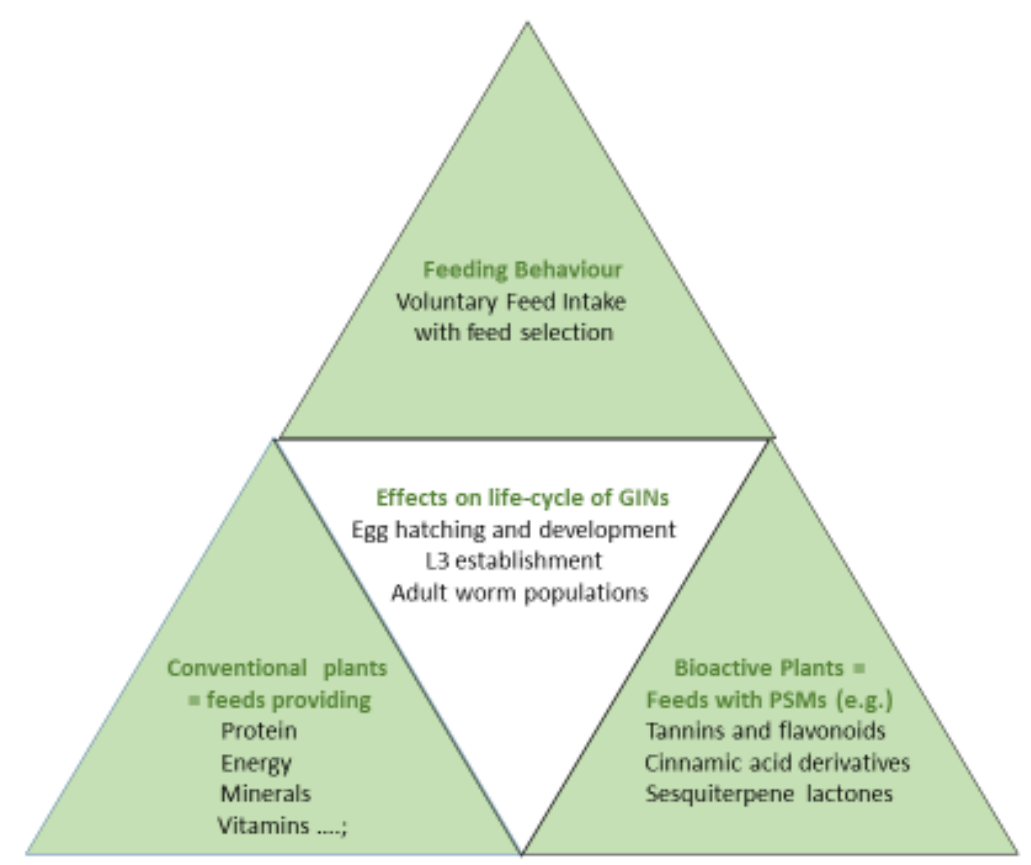

A proposed model of the components defining the concept of nutraceuticals against gastrointestinal parasites in livestock 
1 TANNIN CONTAINING LEGUMES AS A MODEL FOR NUTRACEUTICALS AGAINST DIGESTIVE

2 PARASITES IN LIVESTOCK

3 H.HOSTE ${ }^{1,2}$, J.F.J. TORRES -ACOSTA ${ }^{3}$, C.A. SANDOVAL-CASTRO ${ }^{3}$, I. MUELLER-HARVEY ${ }^{4}$, S. SOTIRAKI ${ }^{5}$,

4

5

6

7

8

9

10

11

12

13

14

15

16

17

H. LOUVANDINI ${ }^{6}$, S.M. THAMSBORG ${ }^{7}$, T.H. TERRILL: ${ }^{8}$

${ }^{1 /}$ INRA, UMR 1225 IHAP, 23 Chemin des Capelles, Toulouse F-31076, France

2/ Université de Toulouse, ENVT, 23 Chemin des Capelles, Toulouse F-31076, France

${ }^{3 /}$ Campus de Ciencias Biológicas y Agropecuarias, FMVZ, Universidad Autónoma de Yucatán, Km 15.5 Carretera Mérida-Xmatkuil, Merida, Yucatan, Mexico.

4/ University of Reading, School of Agriculture, Policy and Development, 1 Earley Gate, P.O. Box 236, Reading RG6 6AT, United Kingdom

${ }^{5 /}$ Veterinary Research Institute - Hellenic Agricultural Organization Demeter, 57001 Thermi, Thessaloniki, Greece

${ }^{6}{ }^{6}$ Laboratory of Animal Nutrition, Centre for Nuclear Energy in Agriculture, University of São Paulo, Piracicaba, São Paulo, Brazil,

${ }^{7 /}$ Department of Veterinary Disease Biology, Faculty of Health and Medical Sciences, University of Copenhagen, Frederiksberg, Denmark,

${ }^{8 /}$ Fort Valley State University, 1005 State University Drive Fort Valley, GA 31030, USA

Corresponding Author: (H.H.) phone/fax: + (33) 05-61-19-38-75 / + (33) 05-61-19-32-43. E-mail:

h.hoste@envt.fr 
Parasitic infections with gastrointestinal nematodes (GINs) still represent a worldwide major pathological threat associated with the outdoor production of various livestock species. Because of the widespread resistance to synthetic chemical anthelmintics, there is a strong impetus to explore novel approaches for a more integrated management of the infections. The use of nutraceuticals in the control of GINs is one of the alternatives which has been widely studied for since- 20 years. The objectives of this review are: i) to define and illustrate the concept of 'nutraceutical' in the context of veterinary parasitology based on data obtained on the most studied GIN models in small ruminants, the tannin-containing legumes (Fabaceae); ii) to illustrate how the 'nutraceutical concept' could be expanded to other plants, other livestock production systems and other GI parasitic diseases, and iii) to explain how this concept is opening up new research fields for better understanding the interactions between the host, the digestive parasites and the environment.

KEY WORDS: Nutraceuticals / Condensed tannins/ Polyphenols / Gastrointestinal nematodes / Antiparasitic effects / Small ruminants. 
Parasitic infections with gastrointestinal nematodes (GINs) represent a worldwide major pathological threat associated with the outdoor production of various livestock species, particularly ruminants. Up to now, the control of these parasitic helminth diseases has essentially relied on the repeated use of commercial anthelmintic (AH) drugs. However, resistance to these AH drugs is now widespread in worm populations, and the occurrence of multi-resistant strains has become a serious problem in some regions of the world (Kaplan, 2004; Torres-Acosta et al., 2012, Jackson et al., 2012). Moreover, as underscored by Waller (2006), resistance to xenobiotics develops quite rapidly and usually within 10 years. This has been illustrated since the recent launch of monepantel (Kaminsky et al., 2008), which is a drug belonging to the Amino Acetonitrile Derivatives (AADs). In spite of the novel mode of action, reports of monepantel resistant Haemonchus contortus have already appeared only seven years after the launch of this new drug (Van-den-Brom et al., 2015).

Therefore, modern parasite management involves an alternative approach seeking to achieve an integrated and more sustainable control of parasite infections by combining the 3 main principles for GIN control, namely i) management of grazing systems; ii) stimulation of host response and iii) modulation of worm biology (Hoste and Torres-Acosta, 2011). This also explains the strong impetus worldwide for exploring and adapting alternative options to different conditions. Among these novel approaches, the long tradition of using bioactive plants for their anti-parasitic properties has been reexplored. It is now and considered identified as one option for improving GIN control, and therefore, to counteract the negative pathophysiological consequences in hosts (Rochfort et al., 2008). Plants are widely used as phytotherapeutic drugs or herbal remedies, and their administration is based on a long tradition of ethno-veterinary or ethno-medicinal applications on all continents (Hammond et al., 1997; Sandoval-Castro et al., 2012). However, over the last 20 years, a novel, overall concept of nutraceutical plants (plants combining positive effects for both animal nutrition 
and health) has emerged in veterinary science and helminthology for improved controlling livestock parasites (Waller and Thamsborg, 2004; Hoste et al., 2006; Alonso-Diaz et al., 2010b).

The aim of this review is

$1 /$ to illustrate define the concept of 'nutraceutical' based on resources containing Plant Secondary Metabolites (PSMs) in the context of veterinary parasitology. We will mainly refer to the tannincontaining legumes (Fabaceae) and other plants, which is -one of byevaluating the most studied GIN-models to control GIN in $ө$ small ruminants, i.e. ts

2/ to showillustrate how the 'nutraceutical concept' could be expanded to other plants, other livestock production systems and other parasitic diseases of the digestive tract.

3/ to explain how this concept is opening up new research fields for probing the interactions between the host, the parasites of the digestive system, and the environment.

\section{DEFINITION OF NUTRACEUTICALS}

The term "nutraceutical" results from a portmanteau between the words "nutrition" and "pharmaceutical". It and has sometimes also been described as "functional food", which was first coined in the context of medical health (Hasler, 1998). Nutraceuticals are nutritional products that provide health and medicinal benefits. According to Andlauer and Fürst (2002), a nutraceutical is defined as "any substance that may be considered a food or part of a food which provides health benefits, including the prevention and treatment of disease". In a similar way, a nutraceutical in veterinary science can be defined as a livestock feed which combines nutritional value with beneficial effects on animal health. In contrast to pharmaceutical drugs, nutraceuticals are not synthetic compounds formulated for specific indications. Instead,

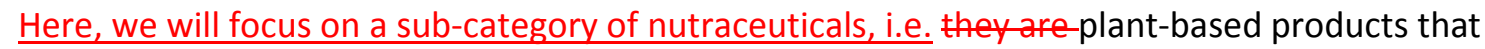
contain nutrients and bioactive compounds that can be used either directly as part of the 
animalplant diet or added in a concentrated form to another diet after extraction from the bioactive plant or resource. Simply put, a nutraceutical in veterinary science can be defined as a livestock feed which combines nutritional value with beneficial effects on animal health. This double action is suspected to relybased on the presence of various plant secondary metabolites (PSM) or bioactive compounds.

Although the nutraceutical concept sounds simple, it is important to recognise that there are several key differences compared to synthetic $\mathrm{AH}$ and phytotherapeutic drugs (Table 1). This makes studying their efficacy a rather complex task. The key points and differences between nutraceuticals and the other options for interfering with the parasite life cycle will be discussed below.

1/Nutrition: Compared to herbal drugs (phytotherapeutical remedies) or synthetic chemicals, a nutraceutical based on bio active plants is not imposed, but offered to animals over a relatively long period (from several days to weeks or months). Therefore, the efficacy of this sort of $z$ nutraceuticals will directly depend on the Voluntary Feed Intake (VFI) of the animal. The interaction between PSM ingested from different plants needs also be considered when nutraceutical feeds are supplemented, especially when animals are freely grazing/browsing on natural pastures or woodlands.

2/ Nature of the bioactive compounds (PSM): The bioactivity against the parasites is dependent on the presence of natural chemical compounds in plants, which are usually described as Plant Secondary Compounds (PSM). The concentrations of these compounds can be highly variable and may depend on environmental growing conditions, on the plant cultivar, or chemotype. In addition, technological factors (harvesting, processing methods) can also interfere with the preservation of the active compounds.

3/. Effect on animal health: The effects of nutraceutical feeds and of the associated bioactive

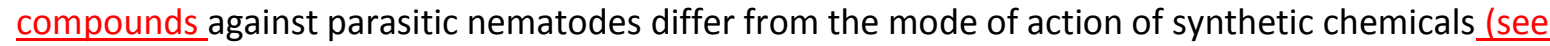
figure 3). This statement implies to develop specific methodologies of measurements of the AH effects.- 


\section{TANNIN CONTAINING LEGUMES WITH ANTHELMINTIC PROPERTIES AGAINST GINS IN SHEEP} AND GOATS: THE MOST STUDIED MODEL OF NUTRACEUTICALS IN VETERINARY PARASITOLOGY.

It is only recently (in the last 20 years) that researchers have obtained enough evidence that supports the use of plants as nutraceutical feeds against GIN. The first evidence originated from research in New Zealand based on empirical results that reported significant reduction of GIN faecal egg counts in sheep when grazing pastures with different legumes, i.e. birdsfoot trefoil and big trefoil (Lotus corniculatus, L. pedunculatus), sulla (Hedysarum coronarium) and sainfoin (Onobrychis viciifolia), which contain condensed tannins (CTs ) (Niezen et al., 1995, 1998, 2002). The information generated by these early field trials started the search for new legumes (Fabaceae) and for other plant candidates elsewhere in the world against GINs in small ruminants. This has become the subject of extensive studies and still represents an important model aiming to explore the concept of using nutraceutical plants against other parasites, with other hosts, and to identify other botanical families with nutraceutical properties (Sandoval-Castro et al., 2012).

These studies on tannin-containing legumes have led to:

$\mathbf{1 /}$ the development of several important methodological procedures that are based on in vitro and in vivo methods to evaluate plants as potential nutraceuticals;

2/ a better definition of the difference in effects between nutraceuticals, phytotherapeutic drugs, and synthetic $\mathrm{AH}$ chemicals.

\subsection{Identification/selection of future potential candidates of nutraceuticals against GINs.}

As illustrated in Figure 1, the effects of a nutraceutical against GIN depend on complex interactions. Hence, the selection of a plant candidate as a potential nutraceutical requires good knowledge and

142 interaction between different scientific disciplines, namely livestock nutrition and production, 143 phytochemistry, parasitology, and to some extent, ethology and toxicology. However, the presence of bioactive PSM is a key issue. 
Identifying viable nutraceutical candidates against parasites is a complex task, and the following steps need to be considered in the selection of nutraceutical materials. This procedure is intended to help in identifying candidate plant materials that can subsequently be explored under in vivo conditions.

\subsubsection{Nutritional issues.}

Even before the plant materials are tested in vitro or in vivo for AH activity, information should be gathered (or evaluated) in terms of nutritional value and palatability for the hosts. This information should include:

aA) A good macronutrient profile.

Ideally, the feed should have medium to high levels of protein or energy and low lignin. However, not all plants with tannins may have an optimal "nutritional"profile. Therefore, initial selection of such plants should not be based solely on their macronutrient profile, especially if such plants are selected by ruminants during grazing/browsing. The nutritional quality of the plant material that is intended for nutraceutical use should include the determination of its In Vitro Dry Matter Digestibility (IVDMD)IVDMD. This information can help to identify if the plant material could be useful under in vivo conditions.

$\underline{b} B$ ) A feed readily consumed by the animal host.

Since the general definition of a nutraceutical is linked to VFlvoluntary feed intake by animals, this key issue needs to be first considered and then measured during in vivo assays. Short intake or preference trials should be carried out before engaging with in vivo evaluation of the plant. If the plant is not eaten, it might still be useful in other ways, as PSM -could be extracted and then dosed (Phytotherapy).

cє) An acceptable in vivo apparent digestibility. 
Any plant material that will be used in large quantities or during long periods of time will require an evaluation of its impact on the apparent in vivo digestibility, including at least measurements of the dry matter $(\mathrm{DM})$ and the organic matter $(\mathrm{OM})$-measurements. These data may help to ensure that the nutraceutical material will not cause a severe digestibility reduction.

dㅁ) Little or no negative known impact on animal production.

Before selecting a nutraceutical plant for AH effects, it is important to collect information on the possible negative impact on production (i.e. growth, milk production, reproduction) or even clinical signs (e.g. abortions or foetus deformities, such as arthrogryposis due to phytoestrogens) or photosensitisation. In such cases, the plant material should not be considered as a viable nutraceutical.

\section{3.-1.2 PSM issues}

Since the early results in NZ, several tannin containing legumes (Fabaceae) have been subjected to a wide range of studies as potential nutraceuticals. The focus on these species was not based on prior ethno-botanic information about the action against signs of GIN parasitism (i.e. diarrhoea), or dewormers used for humans, as in both cases the information could be inadequate for ruminant species (Sandoval-Castro et al., 2012).

In contrast, they were mainly supported by knowledge and principles of pharmacognosy, based on the assumption that the presence of similar PSMs in the same botanical families (Fabaceae) should achieve similar antiparasitic effects. However, a few results have shown that some plant candidates, which were retained because of the presence of CTs, also corresponded to plants that had been identified based on ethnoveterinary knowledge. This double-sided approach can be of particular interest in many tropical countries.

A possible third approach could be based on detailed observational studies to identify plant selection (González-Pech et al, 2014), feeding behaviour, resource selection and possibly selfmedication under grazing or browsing conditions. However, such studies are laborious and few exist 
from tropical regions, where there is a large plant diversity (Novelo-Chi et al, 2014, Retama-Flores et al, 2010 and Ventura-Cordero et al, 2014a, 2014b).

The Fabaceae family is one of the richest botanical families in terms of species numbers (nearly 20,000 ) and tannin-containing legume and plant resources occur worldwide, just like GINs, and, therefore, the search for possible nutraceuticals has included temperate and tropical tannincontaining plants. These include herbaceous plants, trees, and shrubs, which are perennials or annuals, and which are used by small ruminants in a wide range of feeding systems.

In temperate areas, two legume species of the sub family Faboideae, have received special attention and and have been the focus of a number of studies. These are, namely sainfoin (Onobrychis viciifoliae) in Europe (Paolini et al., 2003a, 2005b; Heckendorn et al., 2006, 2007; Manolaraki et al., 2010; http://sainfoin.eu; www.legumeplus.eu) and Chinese bush clover or sericea lespedeza (Lespedeza cuneata) in the USA and South Africa (Shaik et al., 2006; Joshi et al., 2011; Kommuru et al., 2014; Terrill et al., 2009; 2012 http://www.acsrpc.org/). This special attention on these two herbaceous plants is explained by their ability to produce seeds, to be grown (cultivated) efficiently, and to organise their production for farm application on a large scale (see below).

It is worth underscoring that this scientific interest is also explained by their other beneficial effects in regards to nutrition and health of ruminants and environmental issues (see reviews by Rochfort et al., 2008, Waghorn, 2008, Mueller Harvey, 2006): i) a reduced use of chemical fertilisers because of biological nitrogen fixation; ii) high palatability for ruminants and feeding values; iii) positive effects to reduce ruminal methane emission and GHG; iv) anti bloat effects; v) switch of nitrogen excretion from urine to faeces. In contrast, it is also worth noting that some non-native species exploited for $\underline{\text { these properties are considered invasive by environmentalists and ecologists }}$

In tropical areas in Africa and Latin America, several genera (shrubs or trees) of the Fabaceae family have been particularly under focus and identified as possible nutraceuticals because of in vitro results 
or in vivo reductions in egg excretion; e.g. Leucaena leucocephala (Ademola et al., 2006), Lysiloma latisiliquum (Matínez-Ortíz de Montellano et al., 2010), Havardia albicans (Galicia-Aguilar et al., 2012; Méndez-Ortíz et al., 2012), or different Acacia species: Acacia pennatula , A. molissima , A. karroo, A. mearnsii, Mimosa tenuiflora (Kahiya et al., 2003; Alonso Diaz et al., 2008a; Minho et al., 2008; Cenci et al., 2007; Oliveira et al., 2013, Murare et al., 2012).

\subsection{A methodological procedure to confirm the antiparasitic effects.}

A methodological procedure has progressively emerged from scientific results from different studies to validate the possible efficiency of a wide range of tannin-containing plants as nutraceuticals against GINs. By itsthe overall, logical scheme_forganisation-and- by the objectives defined for $\theta$ feach step, the procedure has been widely adapted from the WAAVP guidelines to examine the efficiency of synthetic AHs (Wood et al., 1995).

The three successive steps are $\mathbf{1 /}$ the in vitro screening of plant extracts based on a wide range of assays (Figure 2); 2/ controlled in vivo studies on experimentally infected animals to confirm the efficiency of the selected plant candidates; $\mathbf{3}$ / holistic studies to examine how and when to apply the nutraceuticals in breeding/feeding systems for small ruminants.

However, because of the complexity and intrinsic variability of nutraceuticals, which are based on naturally occurring chemicals rather than synthetic anthelmintics (see Table 1, Quality of the compounds and mode of administration), this scheme requires adaptations and critical comments to interpret the results.

Since the mode of action of tannin-containing nutraceuticals differs from synthetic chemical $\mathrm{AHs}_{L}$ (see point 4) it may be of interest to examine the effects of the same plant extract on different key stages of the GIN life cycle (egg, infective larvae, adult worms) (Figure 2).

3.2.1 The in vitro screening of plant extracts. 
Most in vitro assays for the primary screening of plant products have been adapted from those

242 developed to assess the efficacy of synthetic AHs against GINs in ruminants (Wood et al., 1995). One

243 exception is the Larval Exsheathment Inhibition Assay, which has been set up specifically (Bahuaud et

244 al., 2006) to reproduce artificially, under in vitro conditions, disturbances related to the

establishment of infective larvae as measured in vivo in sainfoin-fed sheep (Brunet et al., 2007). The detailed methodologies of these different assays, when adapted to plant materials, can be found in Jackson and Hoste (2010). In addition, it is worth mentioning that the model represented by the free living nematode, Caenorhabditis elegans, is also increasingly being exploited to screen the $\mathrm{AH}$ properties of different plant resources (Katiki et al., 2012, 2013). nutraceutical candidates, have also been exploited for a second main objective: to better understand

252 the mode of action of PSM compounds against GINs. This has been achieved i) by applying either

253 isolated and purified tannins, which were selected because of their -different structural features

254 (Molan et al., 2004, Novobilsky et al., 2013, Quijada et al., 2015), or pure flavonoid compounds (Molan et al, 2003a; Brunet and Hoste, 2006), and ii) by performing detailed studies of the functional and structural changes induced in nematodes (Hoste et al., 2012). This allowed testing of the "direct" hypothesis (see section 4.1).

Most research groups started screening the $\mathrm{AH}$ activity of different plant materials under in vitro conditions. In most cases, the screening process was developed with plants that had been extracted with different solvents. When tannins are suspected as the main bioactive compounds, extraction

261 with acetone/water (70:30) is the most common and efficient solvent in regard of the yield of extraction. We note that several studies reported drying plant materials at high temperatures and that this may have reduced their AH activity. It is highly recommended that all plant samples should either be freeze-dried or dried below $40{ }^{\circ} \mathrm{C}$ in order to preserve polyphenols and tannins, as these are easily oxidised at higher temperatures. 
In addition, because of the intrinsic variability of the active compounds and/or mode of actions against GINs, many misunderstandings need to be clarified:

aa) If a plant extract shows an AH effect against a given life stage, it will also show a clear AH effect against other life stages of the same parasite, at roughly the same concentrations.

This is not the case. If the same extract from a single plant material is applied to different life stages of a nematodeparasite species under the respective in vitro conditions, the AH effect may differ between different life stages (Paolini et al, 2004). For instance, a plant extract may show a clear AH effect against $H$. contortus on a given life stage (i.e. $L_{3}$ larvae) and show a mild or no AH effect against another stage (i.e. eggs). Furthermore, the AH effect may only be evident on a certain aspect of the same life stage, such as inhibition of the $L_{3}$ exsheathment process, but have no clear effect on another aspect, such as the motility of the same $L_{3}$ larvae (Alonso-Díaz et al., 2011). This differential effect on different life stages of GIN has also been recorded for conventional anthelmintics, such as levamisole, that show a clear effect on $\mathrm{L}_{3}$ motility but fail to show any $\mathrm{AH}$ effect on the exsheathment of $L_{3}$ or the eclosion of GIN eggs. The latter imply that the selection of candidates for further in vivo tests could be judged either on the overall effective concentration (EC 50,90 or $99 \%$ ) of different in vitro tests with the different life stages tested., or, Azalternatively, the candidate should be the one showing the lowest EC in the most biologically relevant in vitro test chosen by the research group on valid biological grounds, depending on the stage of interest.

b) If the plant extract is obtained from the same plant material with a solvent of similar polarity, the potential AH effect against GIN will be similar.

This is also not the case. Different extraction procedures, even with solvents of similar polarity (i.e. methanol vs. acetone:water (70:30) applied to the same plant material, will result in different PSM being extracted. As a result, the extracts of the same plant material will show different $\mathrm{AH}$ activities even when applied to the same life stage. For example, acetone-water (70:30) extracts of Annonaceae leaves showed limited ovicidal activity and a clear exsheathment inhibition activity, 
while the methanolic extraction of the same plant material showed good ovicidal activity and less

292 clear exsheathment inhibition activity (Castañeda-Ramírez et al., 2014). Thus, the extraction

293 procedure, even with solvents of similar polarity, can result in marked differences in the extracted

294 PSM.

295

296

297

c) An in vitro screening test will help to decide on the dose or concentration of the nutraceutical material that needs to be consumed by the infected animals in order to control GIN infections.

The extrapolation of in vitro doses to in vivo conditions is more difficult to achieve for plants when used against parasites dwelling in the lumen of the gastrointestinal tract. A plant extract used in vitro contains a concentrated quantity of PSM from the experimental plant material. Those PSM will be present in the in vitro assaysystem at a certain quantity and quality that may not be comparable with the in vivo conditions, and also during a time span difficult to replicate under in vivo conditions. Besides, under in vivo conditions, the digestion processes and the conditions occurring in the digestive tract may affect the liberation of the PSM from the plant material. Also, the quantity or structure of PSM may be affected along the digestive tract after the plant is consumed, chewed, ruminated and digested by the ruminant host or gut microflora. Thus, research groups must remember that in vitro assays can help at identifying candidates with potential AH activities, but will not produce a dose level that can be used as a starting point for the in vivo dose level that should be applied to the various hosts.

With the limitations mentioned above, one may think that it might be easier to find a plant extract with excellent in vitro activity, validate its's in vivo AH activity against GIN in the relevant host, and then determineidentify a dose that can be used to control their GIN populations. SIn that case, such an approach would not be pertinent for that of a nutraceutical plant material but can-It might be considered for an herbal remedy or phytotherapeutical medicine, and, Azs such, this will need to be tested as a drug and its efficacy validated using the relevant guidelines for efficacy against GIN (Wood et al., 1995). 
Why can these extracts not be considered as a nutraceutical? The reason is simple: if the plant material is not providing macronutrients for the animal, then it is not a nutraceutical material. In reality, there may be a more straightforward method for identifying plant materials with potential nutraceutical effects and for investigating the dose level required to control the GIN population: letting the hosts eat the plant material, while evaluating the faecal GIN egg excretion. If animals are able to eat sufficient plant material in the chosen presentation and form and produce a visible $\mathrm{AH}$ effect, then such level of ingestion (or dosage) may be suggested against parasites in the test animals.

3.2. 2 Confirmation of potential nutraceutical candidates, under in vivo controlled conditions, based on in vitro results.

As for the $1^{\text {st }}$ step (i.e. in vitro screening), the in vivo procedures to assess the efficacy of nutraceuticals against GINs are also derived from the general guidelines described for synthetic chemical AHs (Wood et al., 1995). However; it is important to take into account several specificities of the nutraceutical concept (see Figure 1).

\section{a) A nutraceutical is at first a feed}

Therefore, it is essential to evaluate nutritional value by using conventional methodologies. The information should include the macronutrient content of crude protein (CP), metabolisable energy (ME), neutral detergent fibre (NDF), acid detergent fibre (FDA) and lignin. This information may help to identify plant materials fitting the nutritional characteristics of an edible ruminant feedstuff. The information generated from conventional nutritional methodologies could be correlated with the near infra-red (NIR) spectra. With time, when a large dataset of plant samples are tested, the NIR spectra can be linked with nutritional quality, presence of PSM and related AH effects. This may be automated with other NIR tools in the future. One key aspect of these measurements for controlled 
in vivo studies is to achieve iso-proteic and iso-energetic diets in the groups of animals receiving the control or the nutraceutical diets, in order to really evaluate the role of the PSM and to avoid any confounding effects because of differences in the amount of macronutrients (protein, energy or their balance) (Coop and Kyriazakis, 1999). However, differences in palatability may result in different feeding levels when feed on offer is not controlled.

Alternatively, assessing the trade-off of plant selection and intake could be an alternative for when iso-energetic and iso-proteic diets are not attainable. The working hypothesis should be carefully stated in all cases. Nutrient balance studies are needed to contribute to the understanding of parasitism and nutrient costs (for the host) and proper assessment of trade-off of nutraceutical plant intake.

b) A nutraceutical should be readily consumed by the relevant host. The effects on health depend on the animal feeding behaviour

Most plants materials meant to be used for nutraceutical purposes are not normally included in the diet of the relevant host. Since the general impact of nutraceuticals on animal health stems from the consumption of these materials, it is important: (1) to include in the experimental design of controlled in vivo studies a period for animal adaptation to the novel feed, lasting from 10 to 15 days, until experimental animals reach a plateau of consumption; and (2) once this plateau of consumption is reached, to estimate regularly the animal VFI. The evaluation can be as simple as measuring the plant material offered and refused, to determine intake. Under some circumstances, the ingestion of the plant material can be enhanced by means of some additives, such as sugar cane molasses. In such cases, the future use of these plant materials will depend on the availability of the plant per se, as well as the existence of the potential feed additive. This could mean an added difficulty for onfarm applications. If possible, plant intake should be evaluated with both infected and non-infected animals with the objective to provide information on self-medication (Martinez-Ortiz-de-Montellano et al, 2010). 
It is essential to obtain a measurement of the potential bioactive PSM before implementing the in vivo controlled studies. It is also important to describe the analytical methods used. In the case of condensed tannins, which cover the core of the current review, a critical description of the different analytical methods has been reviewed previously (Mueller-Harvey, 2006). One simple recommendation, when possible, is to try to obtain two different evaluations (usually one chemical assay and one biological assay in order to estimate the ability of tannins to complex proteins) (Makkar et al., 2003).

\section{d) The effects of tannin-containing nutraceuticals differ from synthetic $A H$}

And this requires adapted experimental designs and measurements. Once the information to characterise the nutritional value and the PSM content of a nutraceutical have been obtained, valid in vivo assays in controlled conditions can be implemented. Such studies could consider animals with natural GIN infections. However, artificial infection trials are preferred that focus on the most prevalent GIN genera and species in the areas of interest.

Within this general experimental context, several factors need to be explored which are specific to nutraceuticals

\section{- 1 The multivalent effects on a range of GIN species:}

-As a general recommendation, combined_infections with at least one species of the abomasal and one species of the small intestinal species should be encouraged. The reason for this is that i) as part of the overall objective, as for synthetic AHs, a multivalent effect can be expected from nutraceuticals and also, ii) variations in the effect of tannin-containing resources against different GIN species have been mentioned on several occasions (see Hoste et al., 2006, 2012). Of course, the choice of the GIN models should be based on epidemiological information, which needs to identify the most prevalent and pathogenic species in the regional areas. 

- $\quad$ ZThe multivalent effects on different GIN stages:

As shownillustrated in (section-4,Figure 3t, thee_-consequences of -nutraceuticals and related PSMs on GINs (at least for the tannin-containing legume models), result from a combination of effects on 3 key stages of the GIN life cycle. Therefore, when possible, it is important to design experimental studies that examine the effects on these different stages (Castañeda-Ramírez et al., 2014; Vargas-Magaña et al., 2014a, 2014b).

- 3 -The role of quantity and/or time period for offering tannin-containing resources in the diet to optimise effects against GINs in small ruminants

After completing initial simple experimental designs that validate the effects of tannin-containing nutraceuticals against different genera and/or stages of GINs in small ruminants, some additional studies are worth designing in order to help in evaluating the effect of two factors which can influence the efficacy of nutraceuticals against GINs, namely the proportions of nutraceuticals and the related concentration of CTs in the feed (Athanasiadou et al., 2001, Brunet et al., 2007, Terrill et al., 2009) and the length of distribution.

- 4 -Specificities in the evaluation of the parasitological and pathophysiological consequences

During the whole evaluation period in studies based on experimental infections, animals should be monitored regularly in terms of i) repeated parasitological measurements (faecal excretion of GIN eggs), ii) pathophysiological measurements to establish the effects on host resilience based on quantitative and/or semi-quantitative measurements of the (sub)clinical effects of infection (e.g. Packed Cell Volume $=$ PCV).

Because of the variations in the PSM effects, which can depend on the nematode species and/or stages (see Figure 3), two experimental measurements are worth considering to complete the information obtained from experimental in vivo studies: 1 / it is recommended that these methodologies need to differentiate effects from different GIN species in case of multispecific 

experimental infections; and 2/ whenever possible, to measure also effects on egg hatching and development.

Ideally, the studies in controlled conditions should be complemented with post-mortem evaluations of the worm populations. The latter will help to strengthen the parasitological protocol by defining if the effect on GIN egg excretion is due to the reduction of GIN populations, proportions of species, sex ratio, or reduction in female worm fecundity (Martinez-Ortiz de Montellano et al., 2010; GaliciaAguilar et al., 2012).

\section{TANNIN-CONTAINING LEGUME NUTRACEUTICALS AGAINST GINs ș IN RUMINANTS}

Several (recent) reviews have summarised the existing results on the potential of tannin containing legumes as nutraceuticals. Their focus concerns three different aspects:

- the overall effects on ruminant nutrition, health and production (e.g. Waghorn, 2008; Mueller-Harvey, 2006; Rochfort et al., 2008 ; Wang et al., 2015)

- the specific AH effects (Min and Hart, 2003; Hoste et al., 2006, 2012)

- the mode of action against the GINs by understanding the nature of active compounds (tannins and flavonoids) (Mueller-Harvey, 2006) and their possible effects on the worms (Hoste et al., 2012).

The readers are invited to refer to these different reviews. The aims of this section will be i) to provide an updated summary of the main results of basic research studies that describe the antiparasitic bioactivity of tannin-containing legumes against GIN nematodes in small ruminants and the current hypotheses on their mechanisms of action; and ii) to illustrate possible on-farm applications, which are starting to be developed.

\subsection{Updated summary of the main effects on the GIN life cycle and hypotheses on their modes of} action.

\footnotetext{
4.1.1. Impact on the GIN life cycle
} 
Three main potential impacts have been linked to the intake of tanniniferous plants by infected ruminants (Hoste et al., 2012) on the GIN life cycle (illustrated in Figure 3)

$1 /$ lower establishment of the infective third-stage larvae in the host.

2/ lower excretion of nematode eggs by adult worms, related either to a reduction in worm numbers or lower fertility of female worms; and

3/ impaired development of eggs into third-stage larvae.

Point 1 leads to reduced host invasion by third stage larvae. Steps 2 and 3 both contribute to reducing the environmental contamination with parasitic elements and thus to reduce the risks for hosts.

\section{7}

To summarise, tanniniferous nutraceuticals do not lead to a $100 \%$ elimination of worms, but they can interfere with the life cycle; whereas the main goal of synthetic AHs is to completely break the parasitic life cycle. The role of nutraceuticals can be linked to severely impairing several key biological stages of the life cycle (eggs, infective larvae, adult worms). The potential combined effect of these separate impacts contributes to slowing down the dynamics of the infection and to lowering the rate of infection to levels that enable acceptable productivity and animal welfare. This also provides an opportunity for the animal to develop its own immunity to the parasites.

454

Similar effects have been observed with the main nematode genera that infect the abomasum and small intestine of small ruminants (Haemonchus spp, Teladorsagia spp, Trichostrongylus spp). Some recent results (Gaudin et al, 2015 Abstract to WAAVP 2015 ) have demonstrated that significant reductions in egg excretion also occurred with a multi-resistant isolate of Haemonchus contortus in the presence of nutraceutical plants. This confirmed that tanniniferous nutraceuticals do indeed represent an alternative solution to $\mathrm{AH}$ resistance that is worth exploring further. It is worth mentioning that these AH effects that affect the worm biology have also repeatedly been 462 linked to positive effects on host resilience (e.g. better production parameters, less severe signs of diarrhoea or anaemia, lower mortality under parasitic challenge) ever since the early studies in NZ 
464 (Niezen et al, 1996). The mechanisms explaining this improved resilience remain obscure but can

465 partly be explained by the effects on reducing the worm population as well as by the nutritive value

466 of legumes (i.e. higher protein content) and the rumen-escape effect that occurs in the presence of

467 certain types of tannins, which are able to protect dietary proteins (Waghorn, 2008). Identification of

468 which particular tannins are best able to improve host resilience remains an outstanding research

469 goal. Therefore, it is of paramount importance to underline the need to achieve iso_proteic and iso-

470 energetic diets in control vs nutraceutical diets that are fed to sheep or goats in controlled in vivo

471 studies.

472

4.1.2. Hypotheses on the modes of action

473 Two non-exclusive general hypotheses have been proposed to explain the activity of bioactive tannin

474 containing feeds against gastrointestinal parasitic worms (Hoste et al., 2012):

4751 / The " direct" hypothesis is based on pharmacological-type of interactions between the various

476 polyphenols and the different stages of gastrointestinal nematodes.

4772 2/ The "indirect" hypotheses assumes a possible improvement of the host resistance (i.e. an

478 immunologically based response) because of the effects of tannin-containing feeds that can improve

479 the overall host protein nutrition by increasing the amount of by-pass proteins $=$

480 It is clear that the bulk of in vitro data obtained so far with different tannin-containing extracts

481 support the hypothesis of "pharmacological-like" effects.

482 As previously stated (Hoste et al, 2012), numerous studies on GIN from small ruminants strongly

483 suggest that both CTs and various flavonoids (at least some flavanols) contribute to the AH action

484 (Molan et al., 2004, Brunet and Hoste, 2006). This has been supported also by recent results on

485 another nematode model (e.g. Ascaris suum in pigs; Williams et al., 2014b). New evidence is also

486 starting to emerge that tannins and other flavonoids in combination can generate either favourable 
487 (synergistic) or unfavourable (e.g. antagonistic) interactions (Klongsiriwet et al., 2014; Vargas-

488

489

490

491

492

493

494

495

496

497

498

499

500

501

502

503

504

505

506

507

508

509

510 Magana et al., 2014a).

A dose-dependent relationship between tannins and/or flavonoid monomers and their in vitro effects has been found on several occasions with different assays and GIN species (see review by Hoste et al., 2012). A few in vivo studies have also described such relationships, where effects of a tanniniferous source on infective L3 larvae (Brunet et al., 2007) or on adult worm populations (Athanasiadou et al, 2001, Terrill et al., 2009) were examined. Taken together, it would appear that a CT threshold needs to be reached in the diet in order to achieve AH effects against the worms.

In addition, evidence is now accumulating from various in vitro studies which have sought to unravel the mode of action by tannins on the worms, that, besides quantitative factors (i.e. concentrations), qualitative factors (i.e. compound structures) can also modulate the bioactivity. Recent data obtained with GIN models from cattle, small ruminants, and pigs (Novobilsky et al., 2011, 2013; Quijada et al., 2014; Williams et al., 2014a) lend support to the hypothesis first raised by Molan et al. (2003) that bioactivity is linked to the prodelphinidin/procyanidin (PD/PC) ratio in plants. These recent studies have also revealed that tannin size is an important structural feature that contributes to the extent of the AH effects. As CTs usually occur in complex mixtures of closely related tannin compounds, their average polymer size is measured and reported as their mean degree of polymerisation (Gea et al., 2011).

Less studies have examined the "indirect" hypothesis, based on long -term studies and by measuring different effectors cells (mast cells, globule leucocytes, eosinophils, goblet cells) along the digestive tract in sheep (Tzamaloukas et al., 2006a and b; Martínez-Ortíz-De-Montellano et al., 2010; Rios de Alvarez et al., 2010) and goats (Paolini et al., 2003) when receiving different TR 
measurements indicating an enhanced local immune response (significantly higher numbers of mast cells and globule leucocytes) (Tzamaloukas et al.,2006) has been shown when lambs were consuming sulla or chicory and had a reduced development of worms.

Figure 3: Three key stages of the GIN life cycle have been identified as possible targets when

tanniniferous plants are consumed by infected small ruminants: 1/a reduced excretion of nematode eggs by the adult worms; $2 /$ a reduced establishment of the infective third-stage larvae in the host; and $3 /$ a reduced development of eggs to third-stage larvae.

\subsection{Strategies to apply tannin-containing nutraceutical materials on-farm}

The bulk of current data on potential nutraceuticals stems from in vitro assays. These results provided preliminary information on the future use of various plants or plant resources. However, gaps remain between in vitro results and on-farm application and these are outlined in section 3.

A few resources have been investigated more thoroughly through extensive approaches that included a succession or combination of in vitro assays, controlled in vivo studies and sometimes holistic studies in farming systems in order to prepare for implementation under field conditions. Fortunately, these specific plants illustrate various options that can be used to exploit tannincontaining resources as nutraceuticals.

\subsubsection{Cultivating legumes as nutraceuticals}

The availability of the plant material can be considered as the main constraint for using a nutraceutical material on-farm. If the plant material is not widely available, or the cost and effort of producing such material is high, then there will be insufficient quantities and it will be unlikely that farmers can adopt it. Up to now, very few plants exist that have potential for nutraceutical exploitations and that benefit from the availability of solid agronomic information suitable for largescale production. 
In some parts of the world, where nutraceutical legume plants can be sown in conventional pastures, animals may consume the nutraceutical plant together with the normal grass or herbs. In other areas, farmers may not be able to overseed their paddocks or may decide to dedicate a certain paddock to produce only the nutraceutical plant (i.e. monoculture). In that case, the nutraceutical material can be offered in the form of hay, silage or pellets. These types of R\&D studies have been developed or seem best suited for farmers who are looking for alternative GIN control measures. This is particularly the case of organic farming or milk production systems based on small ruminants.

In the temperate areas, as mentioned above, two legume forages have been the subject of extensive studies, namely sainfoin (Onobrychis viciifolia) in Europe and sericea lespedeza (Lespedeza cuneata) in South Africa and USA. These studies have involved a wide range of disciplines: phytochemistry, agronomy, animal production, ruminant physiology and parasitology. Both of these tanniniferous legume species have also been the preferred model for exploring the mode of action of polyphenols against the different stages of GINs (see Hoste et al., 2012). In addition, R\&D studies for nearly 20 years on $O$. vicifolia or L. cuneata have examined and compared different forms of exploitation, namely direct grazing, conservation as hay or silage (Paolini et al, 2005, Heckendorn et al, 2006, Shaik et al., 2006, Werne et al, 2013) or more recently with dehydrated pellets (Terrill et al., 2007, Gujja et al., 2013, Girard et al., 2013, Kommuru et al., 2014).

\subsubsection{Exploiting rangelands and their biodiversity of plant resources}

In most tropical parts of the world, the ecosystems present a wide plant biodiversity and include several plant species with nutraceutical potential as natural forage. However, for many of those plant species, there is no information on their agronomy or on possible propagation methods. There are, however, a few exceptions, such as Leucaena leucocephala, Arachis pintoi, Gliricidia sepium or Cratylia argentea (von son de Ferneix et al., 2014); all are from the Fabaceae family and are exploited i) in plantations, ii) in silvo-pastoral systems that consist of rows of grass and trees, or iii) in so-called "fodder banks" that are tree plantations in a very dense system that are not allowed to grow beyond 
approximately $2 \mathrm{~m}$ in height. Thus, nutraceutical forages in tropical areas could offer a variety of situations for their production. However, most farmers currently are relying on the natural availability of nutraceutical plants. Meanwhile, the few people who can invest money in their farms may also be able to build silvo-pastoral systems or fodder banks. Irrespective of the production strategy, such plants may be used for direct browsing or in a cut-and-carry system.

At the moment, most farmers let their animals browse the natural vegetation. Under such conditions, it is not possible to determine whether animals have consumed enough nutraceutical material to obtain the desired AH effect. Cut-and-carry systems could instead be the answer to ensure that animals are exposed to sufficient nutraceutical material. However, these systems are constrained by time spent by farmers to harvest enough plant material for all animals, the need for a vehicle to move sufficient plant material, and difficulties with harvesting (e.g. thorns). In any case, such management strategies could eventually deplete the resource. Thus, the creation of low-cost fodder banks represents a more sustainable option, but it poses considerable challenges in terms of investment and technical knowledge that is beyond the capability of most small farmers at present.

For the tropical areas, a considerable amount of dataresults has been acquired in Mexico for tannincontaining leguminous trees, such as Havardia albicans and Lysiloma latisiliquum. These materials were tested first under in vitro conditions (Alonso-Díaz et al., 2008a, 2008b; Hernández-Orduño et al., 2008) and their promising results led to subsequent in vivo studies with sheep (Martínez-Ortíz de Montellano et al., 2010; Galicia-Aguilar et al., 2012; Mendez-Ortíz et al., 2012) (see section 3.1.2).

\subsubsection{Exploring the value of agro industrial by-products}

In different areas of the world, interest has also been growing in exploring the potential of tannincontaining 'waste' or by-products from agro-industries. These represent an alternative option to "natural" nutraceuticals, in the sense that the PSM can be extracted from the by-products and then added to an existing feed (see Table 1). Transforming 'waste' tannin-rich materials into nutraceutical feeds with antiparasitic properties could have several advantages. First, this represents a viable 
alternative to add value to agro-industrial waste products; secondly, it may help to solve the problem of the inherent variability of PSM content (see below) in nutraceutical plants, as it would allow adjusting the bioactive PSM concentration(s) in feeds (Girard et al., 2013). Consequently, it may also help to avoid any negative consequences caused by an excess of PSM in the feed.

Some examples of tannin-containing plant by-products that have been under recent investigation for their AH activities are: 1 / by products from the nut industry in temperate areas (Desrues et al., 2012), 2/ carob pods (Manolaraki et al., 2010; Arroyo-Lopez et al., 2014) in the Mediterranean region, and 3/ coffee by-products and cocoa fruit husks and leaves in Yucatan, Mexico (Covarrubias-Cárdenas et al., 2013; Vargas-Magaña et al., 2014a, 2014b).

4.2.4 Inherent variability of nutraceutical plant materials

Whatever the mode of exploitation (grown, browsed, or by-products), once a plant species has been identified through in vitro and in vivo studies as a potential candidate for use as a nutraceutical, it is still important to consider the inherent variability caused by several factors which can influence the quantity and/or quality of PSMs-content and hence their antiparasitic effects of nutraceutical candidates.

Nutraceutical plants should be considered in the same manner as grapes that are produced for winemaking. It is evident that certain types of grapes result, generally speaking, in good wines. However, wine-makers and wine-connoisseurs are aware of the existence of many factors that affect the quality of the wine, some of which are not in the control of the producer. Thus, variation can result from the climate, amount of sun radiation and rainfall, timing of the rainfall, agronomic conditions of the vineyard, etc. This will result in varying contents of macronutrients, e.g. sugar in the case of grapes, which is a relatively stable feature of feeds, and variation of the content and composition of plant secondary compounds (e.g. tannins), which can be prone to a wide range of variation. Even the best vineyards in the world, with a long tradition of wine-making, accept that PSM variability will result in an excellent wine, a good wine or an average wine depending on the vear. 
Eandidates.Sainfoin (O. viciifolia) has been extensively studied to explore the factors that influence PSM contents and composition and related AH activities (Manolaraki et al., 2011). Three main factors have been identified: environmental conditions (e.g. phenological stages, areas or soil conditions for growth, climate and seasons), genetic factors (cultivars or chemotypes) (Azuhnwi et al., 2013; Stringano et al., 2012) and also technological processes (e.g. fresh versus hay, silage and pellet samples).

It is possible that this issue of variability caused by the different factors is also important for growing sericea lespedeza (Muir et al., 2014), or for the leaves of L. leucocephala or Manihot esculenta that originate from plantations in tropical zones. Variation of PSM contents may be even more evident in plants that grow in the native vegetation. Under such conditions, variation of PSM content is significant between individuals even during the same season in the geographical region (Alonso-Díaz et al., 2010b).

Further factors, which are frequently not considered include variation in harvesting methods by farmers, such as the leaf:stem ratio that results from pruning only young leaves (branch tip) or complete branches (often based on biomass feed requirement), and post-harvest practices, such as sun drying, wilting, which are often based on nutritional advice, but may not have considered the effects on the bioactive compounds, such as their reduced content or activity in the feed. As the common and traditional view is that PSMs are anti-nutritional factors, this type of advice will need to be modified for nutraceuticals.

However, as far as we are aware, hardly any research has been conducted on selecting or breeding for bioactive plants with stable tannin or other PSM compositions. This seems to be an opportunity that would be worth exploring as we have shown that a few relatively 'robust' sainfoin and sorghum chemovars chemotypes used earlier exist, where the PSM composition was much less dependent on the environment (Azuhnwi et al., 2013a; Mueller-Harvey and Dhanoa, 1991). 


\section{PERSPECTIVES}

635

636

637

638

639

640

641

642

643

644

645

646

647

648

649

650

651

652

653

654

655

656

657

658

Based on the previous description of tannin-containing legumes against GIN in small ruminants and the development of methodological approaches for exploring the nutraceutical concept, several areas*es for future research have been identified that focus on on-farm applications.

\subsection{What else? Novel parasitic "targets" forwith tannin-containing legumes}

5.1.1 Against GINs in other host species.

Several recent in vitro results have shown that tanniniferous legumes can also regulate worm biology of the main genera of GINs in cattle (see review by Sandoval-Castro et al., 2012). Significant results were obtained with extracts of sainfoin (O. viciifolia); L. corniculatus and L. pedunculatus against Ostertagia ostertagii and Cooperia oncophora (Novobilsky et al, 2011, 2013). These data are offering opportunities for in vivo studies and to promote the combined control of bloat and GINs in cattle production. Recently, a $50 \%$ reduction in worm burden was obtained in calves infected with $O$. ostertagi and fed sainfoin pellets (Desrues et al, 2015 WAAVP_2015 abstract).

In fact, attempts have been made in South Africa to regularly include wattle (A. karroo) as a supplementary feed for cattle that are infected with Haemonchus sp and Oesophagostomum columbianum. These studies reported a reduction in egg excretion (Xhomfulana et al., 2009). Two recent studies, based on in vitro assays, have also underscored that different tanniniferous plant sources could be used against GIN in monogastric livestock hosts given the positive assessment of AH effects against Oesophagostomum dentatum and Ascaris suum in pigs (Williams et al., 2014a and b). However, it remains to be seen whether these tannin resources will be used as herbal remedies medicinal plants or as nutraceuticals (see Table 1). However, these in vitro data are supported by a field observation study that examined the effects of acorns (Quercus robur) fed to outdoor pigs which had been raised with a natural nematode infection. The results indicated a dramatic reduction (> $90 \%$ ) in GIN faecal egg count (Salajpal et al., 2004). 
660 Recent investigations have also assessed the effects of tannin-containing plants against Eimeria

661 infections in small ruminants. Although results were disappointing from an in vitro assay that examined a wide range of sainfoin extracts for their capacity to inhibit oocyst sporulation (Saratsis et al., 2012), the results of in vivo studies on natural infection were much more encouraging. These studies evaluated sainfoin fed to lambs (Saratsis et al., 2012), and sericea lespedeza (Lespedeza cuneata) fed to either lambs (Burke et al., 2013) fed before and at weaning or kids (Kommuru et al., 2014). Moreover, some early results are also available that examined the effect of Pistacia lentiscus in young goats (Markovics et al., 2012).

668

In most of these trials, significant reductions in oocyst excretion were measured when young animals were fed with legumes, in particular, kids fed with L. cuneata showed reductions greater than $90 \%$. In addition, there was some evidence that sericea lespedeza had a positive effect on host resilience, 672 as it led to a lower requirement for anti-coccidian treatments. These promising results suggest that 673 tannin containing legumes, in particular pellets of sericea lespedeza, represent an option for a plantbased control of coccidiosis in small ruminants around weaning time.

675

The ability lambs and kids to consume sufficient nutraceutical amounts to prevent coccidiosis around weaning could be a limiting factor that will need to be considered. However, results of a recent experiment with calves, which were under 15-day old, are promising: supplementation of milk with concentrated pomegranate extract may, depending on the concentration, reduce faecal oocyst count and diarrhoea intensity and duration because of Cryptosporidium parvum infection (Weyl-Feinstein et al., 2014) [it should be noted, however, that pomegranate contains mostly ellagitannins - and not CTs]. 

PSMs.

The logical and successive steps described in section 3 have helped to identify other botanical resources, which could be exploited as nutraceuticals. Two examples that meet the general criteria of nutraceuticals as defined in Table 1 will be mentioned here to illustrate these issues:

An impressive range of studies has been performed in Spain that investigated the $\mathrm{AH}$ effects of different heather species that belong to three Erica spp and one Caluna sp (Ericeacae) and are browsed by Cashmere goats (Moreno-Gonzalo et al., 2012). This is a first example for which a whole series of results were obtained based on a range of studies that covered in vitro assays (e.g. MorenoGonzalo et al., 2013), controlled in vivo studies with experimental infections in confined conditions (Frutos et al., 2008; Moreno-Gonzalo et al., 2014) and systemic studies with natural infections (Osoro et al., 2009). These studies confirmed their AH effects. However. Caluna is known to contain CTs and other flavonoids and these are likely to contribute to their bioactivity.

Chicory (Cichorium intybus) (Asteraceae), when used as a forage for ruminants, represents another AH example, which has illustrated the "robustness" of the methodological approach described in section 3. Chicory has been shown to possess $\mathrm{AH}$ properties based on experiments that ranged from in vitro assays ( Molan et al., 2003b; Foster et al., 2011 a,b), simple in vivo studies (Peña-Espinoza et al., 2015 WAAVP2015 abstract), to systemic studies (Athanasiadou et al., 2007; Tzamaloukas et al., 2006 a,b; Nielsen et al., 2009).

Two other points are worth mentioning in comparison of chicory and the legume models and illustrate which additional studies are required to expand the nutraceutical concept for tackling digestive parasites in infected livestock. 
- Based on several in vitro results, the nature of the AH PSMs of chicory seems to stem from sesquiterpene lactones and not from CTs and related polyphenols (Molan et al., 2003b, Foster et al., 2006, 2011a and b).

- Despite the different PSMs, results acquired with chicory forages also illustrated that environmental and genetic factors affected the anti-parasitic activity and were linked to variations in PSM quantity or composition. This is evidenced by marked differences between cultivars (Miguel Peña-Espinoza, personal communication, 2015). Therefore, these factors require addressing before to seeking on-farm implementations for such nutraceuticals (Foster et al., 2006, 2011a).

\subsection{Self-medication and nutraceuticals: a novel field for basic researches on the host-gastro} intestinal nematode interactions.

Given that the antiparasitic effects of nutraceuticals depend on the PSM concentration in a feed and length of consumption by the infected host, the tannin-containing legumes provide a valuable model to explore the host-parasite (GIN) interactions in regard of regulation related to the host feeding $\underline{\text { behaviour and /or to assess the balance between host immunity and behaviour (Hoste et al., 2010) }}$ (especially when testing conserved forms, which can be used under controlled conditions)-.). Interesting studies can and have yet been performed that examine $1 /$ the ability of the host to select a feed with AH properties when hosts are infected or not with GINs (=self-medication)(Lisonbee et al, 2009; Villalba et al, 2013, Junkhe et al, 2012); 2/ the influence of various host or parasite factors on the self-medication behaviour (Amit et al, 2013); and 3/ the trade-offs between negative nutritional effects and beneficial health effects that accrue from the consumption of nutraceuticals (Frutos et al, 2008). 
It is important to indicate, however, that the influence of GIN on the ingestion of nutraceutical plant materials is not easy to evaluate in regard of methodological issues. Attempts to evaluate this phenomenon using cafeteria studies, where animals are exposed to different types of plant materials, or direct observation methods in the field, that compare animals with and without parasites, will be influenced by the quantity of parasites present in the animals (light to heavy burdens), the time that animals had been naturally infected with GIN before the study began (naïve or immune competent animals), the existing feeding experience, physiological adaptations (e.g. tannin binding saliva) of the animals investigated, amongst several other aspects that are difficult to control (Alonso-Díaz et al., 2010a; Vargas-Magaña et al., 2013). Because self-medication has been the subject of $\underline{2}$ arecent review (Villalba and Provenza, 2007; Villalba et al., 2014), this issue will not be developed further.

\section{CONCLUSIONS.}

- Because of the constant, worldwide, rapid development of resistance to synthetic chemical AHs, especially, and also because of societal demand, there is nowadays a clear and urgent need to explore and validate alternative options for specific livestock systems (e.g. organic farming systems, small dairy ruminant systems in EU or in caprine breeding).

- For these reasons, in regard of the control of GINs in livestock, as previously evoked (Thamsborg et al., 1999) in the $21^{\text {st }}$ century, we are now probably entering the postanthelmintic era and are moving from relatively simple solutions for on-farm applications (use of synthetic AHs) towards much more complex options.

- The development of nutraceutical products with real potential for the control of GIN in ruminants is a possibility that is well underway of becoming a reality in different parts of the world for different livestock breeding systems and relying on different plant materials.

- The complexity of the scientific questions which need to be addressed are intrinsic to nutraceuticals. Therefore, the possibility of developing on-farm applications against digestive 
parasites requires a multidisciplinary approach between scientists with expertise in parasitology, but also phytochemistry animal production, digestive physiology, ethology and others.

\section{CONFLICT OF INTEREST}

The authors declare that there is no conflict of interest.

\section{ACKNOWLEDGEMENTS}

The authors wish to acknowledge the financial support of the European Commission through the “LegumePlus" project (PITN-GA-2011-289377), the EMIDA ERANET project CARES, the CORE ORGANIC 2 ProPARA and the PCP France-Mexico project 2013-2017 (Fondo Institucional CONACYT No. 229330). We also acknowledge financial support from the IEPAC project (FEDER Convention No. 31439 - Programme INTERREG IV CARAIBES 2007-2013 - No. 41000140).

\section{REFERENCES}

1) Ademola, I. O., Idowu, S. O., 2006. Anthelmintic activity of Leucaena leucocephala seed extract on Haemonchus contortus infective larvae. Vet Rec.158, 485-486.

2) Alonso-Díaz, M.A., Torres-Acosta, J.F.J., Sandoval-Castro, C.A., Aguilar Caballero, A.J., Hoste, H., 2008a. In vitro larval migration and kinetics of exsheathment of Haemonchus contortus exposed to four tropical tanniniferous plant extracts. Vet. Parasitol. 153, 313-319.

3) Alonso-Díaz, M.A., Torres-Acosta, J.F.J., Sandoval-Castro, C.A., Capetillo-Leal, C.M., Brunet, S., Hoste, $H_{L_{L}} 2008 \mathrm{~b}$. Effects of four tropical tanniniferous plant extracts on the inhibition of larval migration and the exsheathment process of Trichostrongylus colubriformis infective stage. Vet. Parasitol. 153, 187-192

4) Alonso-Diaz, M.A., Torres-Acosta, J.F.J., Sandoval-Castro, C.A., Hoste, H., 2010a. Tannins in tanniniferous tree fodders fed to small ruminants: a friendly foe? Small Ruminant Res. 89, 164173. 
5) Alonso-Díaz M.A., Torres-Acosta J.F.J., Sandoval-Castro C.A., Capetillo-Leal, C.M., 2010b. Polyphenolic compounds of nutraceutical trees and the variability of their biological activity measured by two methods. Trop. Subtrop. Agroecosyst. 12, 649-656.

6) Alonso-Díaz, M.A., Torres-Acosta, J.F.J., Sandoval-Castro, C.A., Hoste, H., 2011. Comparing the sensitivity of two in vitro assays to evaluate the anthelmintic activity of tropical tannin rich plant extracts against Haemonchus contortus. Vet. Parasitol. 181, 360-364.

6)그=: Amit, M., Cohen, I., Marcovics, A., Muklada, H., Glasser, T.A., Ungar, E.D. Landau,S.Y., 2013. Self-medication with tannin-rich browse in goats infected with gastro-intestinal nematodes. Vet. Parasitol., 198, 305-311

7)으Andlauer, W., Fürst, P., 2002. Nutraceuticals: a piece of history, present status and outlook. Food Res.; 35, 171-176.

8)9)Arroyo-Lopez, C., Hoste, H ., Manolaraki, F., Saratsis A., Saratsi K., Stefanakis, A., Skampardonis, V., Voutzourakis, N., Sotiraki, S. ${ }_{2}$ 2014. Compared effects of two tannin rich resources carob (Ceratonia siliqua) and sainfoin (Onobrychis viciifolia) on the experimental trickle infections of lambs with Haemonchus contortus and Trichostrongylus colubriformis. Parasite 21, 71-80.

9)10) Athanasiadou, S., Kyriazakis, I., Jackson, F., Coop, R.L., 2001. Direct anthelmintic effects of condensed tannins towards different gastrointestinal nematodes of sheep: in vitro and in vivo studies. Vet. Parasitol. 99, 205-219.

10)11) Athanasiadou, S., Gray, D., Younie, D., Tzamaloukas, O., Jackson, F., Kyriazakis, I.. 2007. The use of chicory for parasite control in organic ewes and their lambs. Parasitology ${ }_{-7}$ 134, 299-307. 11)12) Azuhnwi, B.N., Boller, B., Dohme-Meier, F., Hess, H.D., Kreuzer, M., Stringano, E., MuellerHarvey, I., 2013a. Exploring variation in proanthocyanidin composition and content of sainfoin (Onobrychis viciifolia). J. Sci. Food Agric. 93, 2102-2109.

12)13) Azuhnwi, B. N., H. Hertzberg, H., Arrigo, Y., Gutzwiller, A., Hess, H. D., I. Mueller-Harvey, I., Torgerson, P.R., Kreuzer, M., Dohme-Meier, F., 2013b. Investigation of sainfoin (Onobrychis 
viciifolia) cultivar differences on nitrogen balance and fecal egg count in artificially infected lambs. J. An. Sci., 91, 2343-2354.

13)14) Bahuaud, D., Martinez-Ortiz-de-Montellano, C., Chauveau, S., Prevot, F., Torres-Acosta, J.F.J., Fouraste, I., Hoste, $H_{.}$, 2006. Effects of four tanniferous plant extracts on the in vitro exsheathment of third-stage larvae of parasitic nematodes. Parasitology 132, 545-554.

14)15) Brunet, S., Hoste, $H_{.2}$ 2006. Monomers of condensed tannins affect the larval exsheathment

16) Brunet, S., Aufrère, J., El Babili, F., Fouraste, I., Hoste, H., 2007.The kinetics of exsheathment of infective nematode larvae is disturbed in the presence of a tannin-rich plant extract (sainfoin) both in vitro and in vivo. Parasitology-, 134, 1253-1262.

15)17) Brunet, S., Martinez-Ortiz De Montellano, C. Torres-Acosta, J.F.J., Sandoval-Castro, C.A., 17)19) Castañeda-Ramírez, G.S-._Torres-Acosta, J.F J., Mendoza-de-Gives, P., Chan-Pérez, J.I., TunA.P., Abdalla, A.L., 2007. Effects of condensed tannin from Acacia mearnsii on sheep infected naturally with gastrointestinal helminthes. Vet Parasitol. 144, 132-137 

France.

21)23) Desrues, O., Vargas-Magaña, J.J., Girard, M., Manolaraki, F., Pardo, E., Mathieu, C., Vilarem, used to control gastrointestinal nematodes in goats? XIth International Goat Conference Las

22)24) Foster, J.G., Clapham, W.M., Belesky, D.P., Labreveux, M., Hall, M.H., Sanderson, M.A., 2006. Influence of cultivation site on sesquiterpene lactone composition of forage chicory (Cichorium intybus L.). J. Agric. Food Chem. 54, 1772-1778.

23)25) Foster, J.G., Cassida, K.A., Sanderson, M.A., 2011a . Seasonal variations in sesquiterpene

24)26) Foster, J.G., Joyce, G., Cassida, K.A., Turner K.E., 2011b. In vitro analysis of the anthelmintic activity of forage chicory (Cichorium intybus L.) - sesquiterpene lactones against a predominantly Ortega-Mora, L.M., Ferre, I., Osoro, K., 2008. Is the anthelmintic effect of heather supplementation to grazing goats always accompanied by anti-nutritional effects ? Animal. 2, $1449-1456$. biology of Haemonchus contortus. Anim. Feed Sci. Technol. 176, 178-184. 
27)29) Gea, A., Stringano, E., Brown, R.H., Mueller-Harvey, I-., 2011. In situ analysis and structural elucidation of sainfoin (Onobrychis viciifolia) tannins for high throughput germplasm screening. J. Agric. Food Chem. 2011, 59, 495-503.

28)30) Girard M., Gaid S., Mathieu C., Vilarem G., Gerfault V., Routier M., Gombault P., Pardo E., Manolaraki F., Hoste $H_{. L}$ 2013. Effects of different proportions of sainfoin pellets combined with hazel nut peels on infected lambs. 64th EAAP Nantes, 26th -30th August 2013, Page 506

29)31) Gujja S., Terrill, T.H., Mosjidis, J.A, Miller, J.E., Mechineni A., Kommuru D.S., Shaik S.A., Lambert B.D., Cherry, N.M., Burke, J.M., 2013. Effect of supplemental sericea lespedeza leaf meal pellets on gastro intestinal nematode infection in grazing goats. -Vet. Parasitol.; 191, 51-58.

30)32) Hammond, J.A., Fielding, D., Bishop, S.C., 1997. Prospects for plant anthelmintics in tropical veterinary medicine. Vet. Res. Commun. 21, 213-228.

31)33) Hasler, C.M, 1998. Functional foods: their role in disease prevention and health promotion. Food Tech. 52, 63-70.

32)34) Heckendorn, F., Häring, D.A.; Maurer, V., Zinsstag, J., Langhans W., Hertzberg, H., 2006.Effect of sainfoin (Onobrychis viciifolia) silage and hay on established populations of Haemonchus contortus and Cooperia curticei in lambs. Vet. Parasitol, 142, 293-300.

33)35) Heckendorn, F., Haring, D.A., Maurer, V., Senn, M., Hertzberg, H., 2007. Individual administration of three tanniferous forage plants to lambs artificially infected with Haemonchus contortus and Cooperia curticei. Vet. Parasitol. 146, 123-134.

34)36) Hernández-Orduño, G., Torres-Acosta, J.F.J., Sandoval-Castro, C., Aguilar-Caballero, A,J. Reyes-Ramirez, R.R., Hoste, H., Calderón-Quintal, J.A., 2008. In vitro anthelmintic effect of Acacia gaumeri, Havardia albicans and Quebracho tannin extracts on a Mexican strain of Haemonchus contortus L3 larvae. Trop. Subtrop. Agroecosystems. 8, 191-197.

37) Hoste, H., Jackson, F., Athanasiadou, S.; Thamsborg, S.M., Hoskin, S.2 2006. The effects of tanninrich plants on parasitic nematodes in ruminants. Trends Parasitol, 22, 253-261. 
35)38) Hoste, H., Sotiraki, S., Landau, S.Y., Jackson, F., Beveridge, I., 2010. Goat nematode interactions: Think differently! Trends Parasitol, 36, 376-381.

36)39) Hoste, H., Torres-Acosta, J.F.J. ${ }_{2}$ 2011. Non chemical control of helminths in ruminants: Adapting solutions for changing worms in a changing world. Vet. Parasitol., 180, 144-154.

37)40) Hoste, H., Martinez-Ortiz-de-Montellano, C., Manolaraki, F., Brunet, S., Ojeda-Robertos, N., Fourquaux, I., Torres-Acosta, J.F.J., Sandoval-Castro, C.A., 2012.Direct and indirect effects of bioactive tannin-rich tropical and temperate legumes against nematode infection. Vet. Parasitol., $186,18-27$.

38)41) Jackson, F., Varady, M., Bartley, D.J. 2012. Managing anthelmintic resistance in goats - Can we learn lessons from sheep_? Small Rum. Res.; 103, 3-9.

39)42) Jackson, F., Hoste, $\mathrm{H}_{\mathrm{L}_{2}}$ 2010. In vitro methods for the primary screening of plant products for direct activity against ruminant gastrointestinal nematodes. In: Vercoe, P.E.; Makkar, H.P.S.; Schlink, A.C. (Eds.), In vitro screening of Plant Resources for Extra Nutritional Attributes in Ruminants: Nuclear and Related Methodologies, FAO/IAEA Sppringer Edition. 2010, pp 24-45.

43) Joshi, B.R., Kommuru, D.S., Terrill, T.H., Mosjidis, J.A., Burke, J.M., Shakya, K.P., Miller, J.E., 2011. Effect of feeding sericea lespedeza leaf meal in goats experimentally infected with Haemonchus contortus. Vet. Parasitol $178,192-197$.

40)44) Juhnke J., Miller, J.E., Hall J.O., Provenza, F.D., Villalba, J.J., 2012. Preference for condensed $\underline{\text { tannins by sheep in response to challenge infection with Haemonchus contortus Vet. Parasitol, }}$ $\underline{188,104-114}$

41)45) Kahiya, C., Mukaratirwa, S.,Thamsborg, S.M. 2003 . Effects of Acacia nilotica and Acacia karroo diets on Haemonchus contortus infection in goats. Vet. Parasitol. 115, 265-274.

42)46) Kaplan, R.M., 2004. Drug resistance in nematodes of veterinary importance: a status report. Trends Parasitol. 20, 477-481.

43)47) Kaminsky, R., Gauvry, N., Schorderet Weber, S., Skripsky, T., Bouvier, J.,Wenger, A., Schroeder, F., Desaules, Y., Hotz, R., Goebel, T., Hosking, C.B., Pautrat, F., Wieland-Berghausen, 
S., Ducray, P., 2008. Identification of the amino-acetonitrile derivative monepantel (AAD 1566) as a new anthelmintic drug development candidate. Parasitol. Res. 103, 931-939.

909

910

911

912

913

914

915

916

917

918

919

920

921

922

923

924

925

926

927

928

929

930

931

932

44)48) Katiki, L.M., Ferreira J. F.S., Gonzalez Javier M., Zajac, A. M., Lindsay, D.S., Chagas A. C. S., Amarante A. F.T..$_{2}$ 2013. Anthelmintic effect of plant extracts containing condensed and hydrolyzable tannins on Caenorhabditis elegans, and their antioxidant capacity Vet. Parasitol $\overline{\bar{\tau}}$ $192,218-227$.

45)49) Katiki, L.M., Ferreira, J.F.S., Zajac, A.M., Masler, C., Lindsay, D.S., Chagas, A.C.S., Amarante, A.F.T., 2012. Caenorhabditis elegans as a model to screen plant extracts and compounds as natural anthelmintics for veterinary use. Vet. Parasitol. 182, 264-268.

50) Klongsiriwet, C., Quijada, J., Williams, A.R., Hoste, H., Williamson, E., Mueller-Harvey, I. $\underline{\text { Hoste, }}$ H., 20154. Synergistic effects between condensed tannins and luteolin on in vitro larval exsheathment inhibition of Hoemonchus contortus. In: Proceedings of XXVIIth International Conference on Polyphenols (ICP2014), Nagoya, Japan, 2 6 September 2014. (ISBN978-4-9907847 $0-6)$, p. 601-602. Synergistic inhibition of Haemonchus contortus exsheathment by flavonoid monomers and condensed tannins. Int. J. Parasitol, Drugs and Drug Resistance, Submitted for publication

46)

51) Kommuru, D.S., Barker, T., Desai, S., Burke, J.M., Ramsay, A., Mueller-Harvey, I., Miller, J.E., Mosjidis, J.A., Kamisetti, N., Terrill, T.H.. 2014. Use of pelleted sericea lespedeza (Lespedeza cuneata) for natural control of coccidian and gastrointestinal nematodes in weaned goats. Vet. Parasitol, 204, 191-198.

47)52) Lisonbee, L.D., Villalba, J.J, Provenza, F.D., Hall, J.O., 2009. Tannins and self-medication: $\underline{\text { Implications for sustainable parasite control in herbivores. Behav. Proc. 82,184-189 }}$

48)53) Makkar, H. P.. 2003. Quantification of tannins in tree and shrub foliages. In "A Laboratory Manual" Food and Agriculture Organization of the United Nations/ International Atomic Energy (FAO/IAEA), pp. 49-53. 
49)54) Manolaraki, F., Sotiraki, S., Skampardonis, V., Volanis, M., Stefanakis, A., Hoste, H., 2010. Anthelmintic activity of some Mediterranean browse plants against parasitic nematodes. Parasitology. 137, 685-696.

50)55) Manolaraki, F., 2011. Propriétés anthelminthiques du sainfoin (Onobrychis viciifoliae):

Analyse des facteurs de variations et du rôle des composés phénoliques impliqués. 21st Jan 2011. INP Toulouse

51)56) Markovics, A., Cohen, I., Muklada, H., Glasser, T.A., Dvash, L., Ungar,E.D., Azaizeh, H., Landau, S.Y., 2012. Consumption of Pistacia lentiscus foliage alleviates coccidiosis in young goats. Vet. Parasitol. 186,165-169.

52) 57) Martínez-Ortíz-De-Montellano, C., Vargas-Magana, J.J., Canul-Ku, H.L., Miranda-Soberanis, R., Capetillo-Leal, C., Sandoval-Castro, C.A., Hoste, H., Torres-Acosta, J.F.J., 2010. Effect of a tropical 53)58) tannin-rich plant, Lysiloma latisiliquum, on adult populations of Haemonchus contortus in sheep. Vet. Parasitol., 172, 283-290.

54)59) Mechineni, A., Kommuru, D.S., Gujja, S., Mosjidis, J.A., Miller, J.E., Burke, J.M., Ramsay, A., Mueller-Harvey, I., Kannan, G., Lee, J.H., Kouakou, B., Terrill, T.H.2 2014. Effect of fall-grazed sericea lespedeza (Lespedeza cuneata) on gastrointestinal nematode infections of growing goats. Vet. Parasitol.; 29, 221-228.

55)60) Méndez-Ortíz, F.A., Sandoval-Castro, C.A., Torres-Acosta, J.F.J., 2012. Short term consumption of Havardia albicans tannin rich fodder by sheep: Effects on feed intake, diet digestibility and excretion of Haemonchus contortus eggs. Anim. Feed Sci. Tech. 176, 185-191

56)61) Min, B.R., Hart, S.P., 2003. Tannins for suppression of internal parasites. J. Anim. Sci. 81, 102109.

57)62) Minho, A.P., Bueno, I.C.S., Louvandini, H., Jackson, F., Gennari, S.M., Abdalla A.L. 2008. Effect of Acacia molissima tannin extract on the control of gastrointestinal parasites in sheep. An. Feed Sci. Techn. 147, 172-181. 
58)63) Molan, A.L., Meagher, L.P., Spencer, P.A., Sivakumaran, S., 2003a.Effect of flavan-3-ols in vitro hatching, larval development and viability of infective larvae of Trichostrongy/us colubriformis. Int. J. Parasitol., 33, $1691-1698$.

59)64) Molan, A.L., Duncan, A.J., Barry, T.N., McNabb, W.C., 2003b. Effect of condensed tannins and crude sesquiterpene lactones extracted from chicory on the motility of larvae of deer lungworms and gastrointestinal nematodes. Parasitol. Int. 52, 209-218.

60)65) Molan, A.L., Sivakumaran, S., Spencer, P.A., Meagher, L.P., 2004. Green tea flavan-3-ols and oligomeric proanthocyanidins inhibit the motility of infective larvae of Teladorsagia circumcincta and Trichostrongylus colubriformis in vitro. Res Vet. Sci.-, 77, 239-243.

61)66) Moreno-Gonzalo, J, _Manolaraki, F., Frutos, P., Hervás, G., Celaya, R., Osoro, K., OrtegaMora, L.M., Hoste, H., Ferre, I. 2 2013. In vitro effect of heather (Ericaceae) extracts on different development stages of Teladorsagia circumcincta and Haemonchus contortus. Vet. Parasitol_. 197, 235-243.

62)67) Moreno-Gonzalo, J., Ferre, I., Celaya, R., Frutos, P., Ferreira, L.M.M., Hervás, G., García, U., Ortega-Mora, L.M., Osoro, K., 2012. Potential use of heather to control gastrointestinal nematodes in goats. Small Rumin. Res. 103, 60-68.

63)68) Moreno-Gonzalo, J., Osoro, K., García, U., Frutos, P., Celaya, R., Ferreira, L.M.M., OrtegaMora, L.M., Ferre, I., 2014.Anthelmintic effect of heather in goats experimentally infected with Trichostrongylus colubriformis. Parasitol Res. 113, 693-699.

64)69) Mueller-Harvey, I., Dhanoa, M.S., 1991. Varietal differences among sorghum crop residues in relation to their phenolic HPLC fingerprints and responses to different environments. J. Sci. Food Agric. 57, 199-216.

65)70) Mueller-Harvey, I. 2006 ${ }_{i \bar{\tau}}$ Unravelling the conundrum of tannins in animal nutrition and health. J. Sci. Food Agric. 86, 2010-2037.

66)71) Muir, J.P., Terrill, T.H., Kamisetti, N.R., Bow, J.R., 2014. Environment, Harvest Regimen, and Ontogeny Change Lespedeza cuneata Condensed Tannin and Nitrogen. Crop Sci. 54, 2903-2909. 
67) 72) Murare, U., Chimonyo, M, Dzama, K.. 2012. Influence of dietary supplementation with Acacia karroo on experimental haemonchosis in indigenous Xhosa lop-eared goats of South Africa. Livestock Sci. 144, 132-139.

68)73) Nielsen, B.K., Thamsborg, S.M., Hansen, H. Ranving, H., Hogh-Jensen, H., 2009. Effects of including chicory in perennial ryegrass-white clover on production and health in organic lambs. Livestock Sci.; 125, 66-73.

69)74) Niezen, J.H., Waghorn, T.S., Charleston, W.A.G., Waghorn, G.C.. 1995. Growth and gastrointestinal nematode parasitism in lambs grazing either lucerne (Medicago sativa) or sulla (Hedysarum coronarium) which contains condensed tannins. J. Agric. Sci. 125, 281-289.

70)75) Niezen, J.H., Warghorn, G.C., Charleston, W.A.G.2 1998. Establishment and fecundity of Ostertagia circumcincta and Trichostrongylus colubriformis in lambs fed lotus (Lotus pedunculatus) or perennial ryegrass (Lolium perenne). Vet. Parasitol. 78, 13-21.

71)76) Niezen, J.H., Waghorn, G.C., Graham, T., Carter, J.I., Leathwick, D.M., 2002. The effect of diet fed to lambs on subsequent development of Trichostrongylus colubriformis larvae in vitro and on pasture. Vet. Parasitol. 105, 269-283.

72)77) Novelo-Chi, L.K., González-Pech, P.G., Ventura-Cordero, J., Torres-Acosta, J.F.J., SandovalCastro, C.A. 2014 . Feeding behaviour in dewormed goats vs naturally infected by gastrointestinal nematodes at free grazing of a deciduous tropical forest. Trop. Subtrop.. Agroecosyst. 17, 332 333.

73)78) Novobilský, A., Mueller-Harvey, I., Thamsborg, S.M.2 2011. Condensed tannins act against cattle nematodes. Vet. Parasitol.; 182, 213-220.

74)79) Novobilský, A., Stringano, E., Hayot--Carbonero, C., Smith, L.M.J., Enemark, H.L., MuellerHarvey, I. Thamsborg, S.M. 2013. In vitro effect of extracts and purified tannins of sainfoin (Onobrychis viciifolia) against two cattle nematodes. Vet. Parasitol. 196, 532-537. 


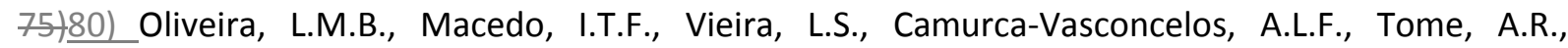
Sampaio, R.A., Louvandini, H., Bevilaqua, C.M.L.= 2013. Effects of Mimosa tenuiflora on larval establishment of Haemonchus contortus in sheep. Vet. Parasitol. 196, 341-346.

81) Osoro, K., Celaya, R., Moreno-Gonzalo, J., Ferreira, L.M.M., García, U., Frutos, P., Ortega-Mora, L.M., Ferre, I., 2009. Effects of stocking rate and heather supplementation on gastrointestinal nematode infections and host performance in naturally-infected Cashmere goats. Rangel. Ecol. Manage. 62, 127-135.

82) Paolini, V., Frayssines, A., De-La-Farge, F., Dorchies, Ph., Hoste, H., 2003. Effects of condensed $\underline{\text { tannins on established populations and on incoming larvae of Trichostrongylus colubriformis and }}$ Teladorsagia circumcincta in goats. Vet. Res. 34, 331-339.

76)83) Paolini, V., Fouraste, I., Hoste, H., 2004. In vitro effects of three woody plant and sainfoin extracts on two parasitic stage of three parasitic nematode species. Parasitology 129, 69 -77. 77) 84) Paolini, V., De-La-Farge, F., Prevot, F., Dorchies, Ph., Hoste, H., 2005. Effects of the repeated distribution of sainfoin hay on the resistance and the resilience of goats naturally infected with gastrointestinal nematodes. Vet. Parasitol. 127, 277-283.

78)85) Quijada, J., Fryganas, C., Ropiak, H., Ramsay, A., Mueller-Harvey, I., Hoste, H., 2015 4 ._Effect ef tannin-rich plant fractions against Haemonchus contortus and Trichostrongylus colubriformis. XIII th ICOPA conference Mexico city 10th-15th August 2014Anthelmintic activities against Haemonchus contortus or Trichostrongylus colubriformis are influenced by different structural features of condensed tannins J. Agr. Food Chem. Accepted for publication.

86) Retama-Flores, C., Torres-Acosta, J.F.J., Sandoval-Castro., C.A., Aguilar-Caballero, A.J., CámaraSarmiento, R., Canul-Ku, H.L.. 2012. Maize supplementation of Pelibuey sheep in a silvopastoral system: fodder selection, nutrient intake and resilience against gastrointestinal nematodes. Animal 6, 145-153. 
79)87) Rios de Alvarez, L., Greer, A.W., Jackson, F., Athanasiadou, S., Kyriazakis, I., Huntley, J.F., 2010. The effect of dietary sainfoin (Onobrychis viciifolia) on local cellular responses to

$\underline{\text { Trichostrongylus colubriformis in sheep. Parasitology 135, 1117-1124. }}$

80)88) Rochfort, S., Parker, A.J., Dunshea, F.R., 2008. Plant bioactives for ruminant health and productivity. Phytochemistry 69, 299-322.

81)89) Salajpal, K., Karolyi, D., Beck, R., Kis, G., Vickovic, I., Điki c, M., Kovacic, D., 2004. Effect of acorn (Quercus robur) intake on faecal egg count in outdoor reared black slavonian pig. Acta Agric. Slovenica (supplement) 1, 173-178.

82)90) Sandoval-Castro C.A., Torres-Acosta, J.F.J., Hoste, H., Salem, A.F., Chan-Pérez, J.I._ 2012. Using plant bioactive materials to control gastrointestinal tract helminths in livestock. An. Feed Sci. Techn. 176, 192-201.

83)91) Saratsis, A., Regos, I., Tzanidakis, N., Voutzourakis, N., Stefanakis, A., Treuter, D., Joachim, A., Sotiraki, S. 2012 . In vivo and in vitro efficacy of sainfoin (Onobrychis viciifolia) against Eimeria spp pin lambs. Vet. Parasitol. 188, 1-9.

84)92) Shaik, S.A., Terrill, T.H., Miller, J.E., Kouakou, B., Kannan, G., Kaplan, R.M., Burke, J.M., Mosjidis, J.A., 2006. Sericea lespedeza hay as a natural deworming agent against gastrointestinal nematode infection in goats. Vet. Parasitol. 139, 150-157.

85)93) Stringano,_-E., Hayot Carbonero, C., Smith, L.M.J., Brown, R.H., Mueller-Harvey, I., 2012. Proanthocyanidin diversity in the EU 'HealthyHay'sainfoin (Onobrychis viciifolia) germplasm collection. Phytochemistry, 77, 197-208.

86)94) Terrill, T.H., Miller, J.E., Burke, J.M., Mosjidis, J.A., Kaplan, R.M.L 2012. Experiences with integrated concepts for the control of Haemonchus contortus in sheep and goats in the United States. Vet. Parasitol. 186, 28-37.

87)95) Terrill, T.H., Mosjidis, J.A., Moore, D.A., Shaik, S.A., Miller, J.E., Burke, J.M., Muir, J.P., Wolfe, R., 2007. Effect of pelleting on efficacy of sericea lespedeza hay as a natural dewormer in goats. Vet. Parasitol. 146:117-122. 
88)96) Terrill, T.H., Dykes, G.S., Shaik, S.A., Miller, J.E., Kouakou, B., Kannan, G., Burke, J.M., Mosjidis, J.A.. 2009. Efficacy of sericea lespedeza hay as a natural dewormer in goats: dose titration study. Vet. Parasitol. 163, 52-56.

89)97) Thamsborg, S.M., Roepstorff, A., Larsen M.L $_{._{L}}$ 1999. Integrated and biological control of parasites in organic and conventional production systems. Vet. Parasitol. 84, 169-186.

90이근 Torres-Acosta, J.F.J., Mendoza-de-Gives, P., Aguilar-Caballero, A.J., Cuéllar-Ordaz, J.A., 2012. Anthelmintic resistance in sheep farms: update of the situation in the American continent. Vet. Parasitol. 189, 89-96.

91)99) Tzamaloukas, O., Athanasiadou, S., Kyriazakis, I., Huntley, J., 2006. The effect of chicory (Cichorium intybus) and sulla (Hedysarum coronarium) on larval development and mucosal cell respponses of growing lambs challenged with Teladorsagia circumcincta. Parasitology 132, 419426.

92)100)Tzamaloukas, $\mathrm{O}_{2}$ 2006ㅁ․ The use of bioactive forages towards organic/sustainable control of gastrointestinal parasites in sheep. PhD -University of Edinburgh 19th Sept. 2006.

93)101)Van-den-Brom, R., Moll, L., Kappert, C., Vellema, P., 2015. Haemonchus contortus resistance to monepantel in sheep. Vet. Parasitol. 209, 278-280.

94)102)Vargas-Magaña, J.J., Aguilar-Caballero, A.J., Torres-Acosta, J.F.J., Sandoval-Castro, C.A., Hoste, H., Capetillo-Leal, C.M., 2013. Tropical tannin rich fodder intake modifies saliva-binding capacity in growing sheep. Animal- 7, 1921-1924.

95)103)Vargas-Magaña, J.J., Torres-Acosta, J.F.J., Aguilar-Caballero, A.J., Sandoval-Castro, C.A., Hoste, H., Chan-Pérez, J.I..$_{2}$ 2014a. Anthelmintic activity of acetone-water extracts against Haemonchus contortus eggs: Interactions between tannins and other plant secondary compounds. Vet Parasitol. 206, 322-327.

96)104)Vargas-Magaña, J.J.; Torres-Acosta, J.F.J.; Aguilar-Caballero, A.J.; Sandoval-Castro, C.A.; Hoste,

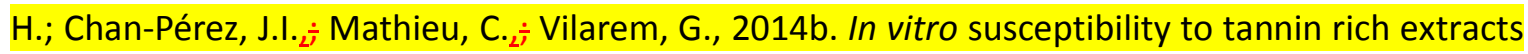



International Congress of Parasitology. August 10-15, 2014. México city, México.

97)105)Ventura-Cordero, J., González-Pech, P.G., Novelo-Chi, L.K., Torres-Acosta, J.F.J., SandovalCastro, C.A., 2014a. Resource selection by browsing of criollo goats in the decideous tropical forest of Yucatan, Mexico. Trop. Subtrop. Agroecosyst. 17, 328-329.

98)106)Ventura-Cordero, J., González-Pech, P.G., Torres-Acosta, J.F.J., Sandoval-Castro, C.A.\& 2014b. Feeding behaviour of sheep and goats in the decideous tropical forest during the rainy season. Trop. Subtrop. Agroecosyst. 17, 330-331.

99)107)Villalba, J.J., Provenza, F. D.- ${ }_{2}$ 2007. Self-medication and homeostatic behaviour in herbivores:

learning about the benefits of nature's pharmacy. Animal 1, 1360-1370.

108) Villalba J.J., Miller J., Hall J.O., Clemensen A.K., Stott R., Snyder D., Provenza F.D., 2013 Preference for tanniferous (Onobrychis viciifolia) and non-tanniferous (Astragalus cicer) forage plants by sheep in response to challenge infection with Haemonchus contortus. Small Rum. Res. 112, 199-207.

100)109) Villalba, J.J, Miller, J., Ungar, E., Landau S.Y., Glendinning, J., 2014. Ruminant selfmedication against gastrointestinal nematodes: evidence, mechanism and origins. Parasite, 21, 31.

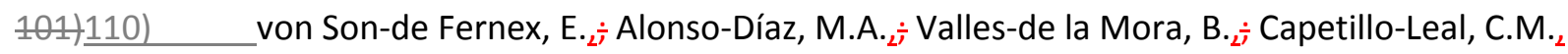
2012. In vitro anthelmintic activity of five tropical legumes on the exsheathment and motility of Haemonchus contortus infective larvae. Exp. Parasitol. 131, 413-418

102)111) Waghorn, G., 2008. Beneficial and detrimental effects of dietary condensed tannins for sustainable sheep and goat production-Progress and challenges. An. Feed Sci. Technol. 147, 116-139.

103)112) Waller, P.J., Thamsborg, S.M. 2004. Nematode control in "green" ruminant production system. Trends Parasitol ${ }_{-\bar{\prime}} 20$, 493-497. 
104)113) Waller, P.J. 2006. From discovery to development: current industry perspectives for the development of novel methods of helminth control in livestock. Vet. Parasitol. 139, 1-14.

105)114) Wang, Y., McAllister, T.A., Acharya, S.L 2015. Condensed tannins in sainfoin: composition, concentration and effects on nutritive and feeding value of sainfoin forage. Crop Science, 55, 13-22.

106)115) Weyl-Feinstein, S., Markovics, A., Eitam, H., Orlov, A., Yishay, M., Agmon, R., Miron, J., Izhaki, I., Shabtay, A., 2014. Effect of pomegranate-residue supplement on Cryptosporidium parvum oocyst shedding in neonatal calves. J. Dairy Sci. 97, 5800-5805.

107)116) Werne, S. Perler, E., Maurer, V., Probst, J., Drewek, A., Hoste, H., Heckendorn F. 2013. Effect of sainfoin and faba bean on gastrointestinal nematodes in periparturient ewes. Small Rum. Res. 113, 454-460.

108)117) Williams, A.R., -Ropiak, H.M., Fryganas, C., Desrues, O., Mueller-Harvey, I. Thamsborg, S.M.L 2014a. Assessment of the anthelmintic activity of medicinal plant extracts and purified condensed tannins against free-living and parasitic stages of Oesophagostomum dentatum. Parasites \& Vectors 2014, 7:518 http://www.parasitesandvectors.com/content/7/1/518 109)118) Williams, A.R., Fryganas, C., Ramsay, A., Mueller-Harvey, I., Thamsborg, S.M., 2014b. Direct anthelmintic effects of condensed tannins from diverse plant sources against Ascaris suum. PLos ONE. 9(5):e97053.doi:10.1371/journal.pone.0097053

110)119) Wood, I.B., Amaral, N.K., Bairden, K., Duncan, J.L., Kassai, T., Malone Jr., J.B., Pankavich, J.A., Reinecke, R.K., Slocombe, O., Taylor, S.M., Vercruysse, J., 1995. World Association for the Advancement of Veterinary Para- sitology (W.A.A.V.P.) second edition of guidelines for evaluating the efficacy of anthelmintics in ruminants (bovine, ovine, caprine). Vet. Parasitol. 58, 181-213. 
111)120) Xhomfulana, V., Mapiye, C., Chimonyo, M., Marufu, M.C., 2009. Supplements containing Acacia karroo foliage reduce nematode burdens in Nguni and crossbred cattle. Anim. Prod. Sci. 49, 646-653.

(1) 


\begin{tabular}{|l|c|c|c|c|}
\hline $\begin{array}{l}\text { Mode of } \\
\text { action }\end{array}$ & $\begin{array}{c}\text { Usually, well } \\
\text { identified }\end{array}$ & $\begin{array}{c}\text { Usually, well } \\
\text { identified }\end{array}$ & Unknown & Hypotheses \\
\hline $\begin{array}{l}\text { Development } \\
\text { of resistance }\end{array}$ & High & High & Unknown & Suspected \\
\hline
\end{tabular}

1145

1146 
1 TANNIN CONTAINING LEGUMES AS A MODEL FOR NUTRACEUTICALS AGAINST DIGESTIVE

2 PARASITES IN LIVESTOCK

3 H.HOSTE ${ }^{1,2}$, J.F.J. TORRES -ACOSTA ${ }^{3}$, C.A. SANDOVAL-CASTRO ${ }^{3}$, I. MUELLER-HARVEY ${ }^{4}$, S. SOTIRAKI ${ }^{5}$,

4 H. LOUVANDINI ${ }^{6}$, S.M. THAMSBORG ${ }^{7}$, T.H. TERRILL. ${ }^{8}$

$51 /$ INRA, UMR 1225 IHAP, 23 Chemin des Capelles, Toulouse F-31076, France

$6 \quad{ }^{2 /}$ Université de Toulouse, ENVT, 23 Chemin des Capelles, Toulouse F-31076, France

$7 \quad{ }^{3 /}$ Campus de Ciencias Biológicas y Agropecuarias, FMVZ, Universidad Autónoma de Yucatán, Km 15.5

8 Carretera Mérida-Xmatkuil, Merida, Yucatan, Mexico.

94 4/ University of Reading, School of Agriculture, Policy and Development, 1 Earley Gate, P.O. Box 236, 10 Reading RG6 6AT, United Kingdom

$11{ }^{5 /}$ Veterinary Research Institute - Hellenic Agricultural Organization Demeter, 57001 Thermi,

12 Thessaloniki, Greece

$13{ }^{6 /}$ Laboratory of Animal Nutrition, Centre for Nuclear Energy in Agriculture, University of São Paulo, 14 Piracicaba, São Paulo, Brazil,

$15{ }^{7 /}$ Department of Veterinary Disease Biology, Faculty of Health and Medical Sciences, University of 16 Copenhagen, Frederiksberg, Denmark,

$17{ }^{8 /}$ Fort Valley State University, 1005 State University Drive Fort Valley, GA 31030, USA 
Parasitic infections with gastrointestinal nematodes (GINs) still represent a worldwide major pathological threat associated with the outdoor production of various livestock species. Because of the widespread resistance to synthetic chemical anthelmintics, there is a strong impetus to explore novel approaches for a more integrated management of these infections. The use of nutraceuticals in the control of GINs is one of the alternatives which has been widely studied for 20 years. The objectives of this review are: i) to define and illustrate the concept of 'nutraceutical' in the context of veterinary parasitology based on data obtained on the most studied models to control GINs in small ruminants, the tannin-containing legumes (Fabaceae); ii) to illustrate how the 'nutraceutical concept' could be expanded to other plants, other livestock production systems and other GI parasitic diseases, and iii) to explain how this concept is opening up new research fields for better understanding the interactions between the host, the digestive parasites and the environment.

KEY WORDS: Nutraceuticals / Condensed tannins/ Polyphenols / Gastrointestinal nematodes / Antiparasitic effects / Small ruminants. 
Parasitic infections with gastrointestinal nematodes (GINs) represent a worldwide major pathological threat associated with the outdoor production of various livestock species, particularly ruminants. Up to now, the control of these parasitic helminth diseases has essentially relied on the repeated use of commercial anthelmintic (AH) drugs. However, resistance to these AH drugs is now widespread in worm populations, and the occurrence of multi-resistant strains has become a serious problem in some regions of the world (Kaplan, 2004; Torres-Acosta et al., 2012, Jackson et al., 2012). Moreover, as underscored by Waller (2006), resistance to xenobiotics develops quite rapidly in pathogens and usually within 10 years. This has been illustrated since the recent launch of monepantel (Kaminsky et al., 2008), which is a drug belonging to the Amino Acetonitrile Derivatives (AADs). In spite of the novel mode of action, reports of monepantel resistant Haemonchus contortus have already appeared only seven years after the launch of this new drug (Van-den-Brom et al., 2015).

Therefore, modern parasite management involves alternative approaches seeking to achieve an integrated and more sustainable control of helminth infections by combining the 3 main principles for GIN control, namely i) management of grazing systems; ii) stimulation of host response and iii) modulation of worm biology (Hoste and Torres-Acosta, 2011). This also explains the strong impetus worldwide for exploring and adapting alternative options to different conditions. Among these novel approaches, the long tradition of using bioactive plants for their anti-parasitic properties has been reexplored. It is now considered as one option for improving GIN control, and therefore, to counteract the negative pathophysiological consequences in hosts (Rochfort et al., 2008). Plants are widely used as phytotherapeutic drugs or herbal remedies, and their administration is based on a long tradition of ethno-veterinary or ethno-medicinal applications on all continents (Hammond et al., 1997; Sandoval-Castro et al., 2012). However, over the last 20 years, a novel, overall concept of nutraceutical plants (plants combining positive effects for both animal nutrition and health) has 
emerged in veterinary science and helminthology for improved controlling livestock parasites (Waller and Thamsborg, 2004; Hoste et al., 2006; Alonso-Diaz et al., 2010b).

The aim of this review is

1/ to illustrate the concept of 'nutraceutical' based on resources containing Plant Secondary Metabolites (PSMs) in the context of veterinary parasitology. We will mainly refer to the tannincontaining legumes (Fabaceae) and other plants, which is one of the most studied models of nutraceuticals to control GIN in small ruminants.

2/ to show how the 'nutraceutical concept' could be expanded to other plants, other livestock production systems and other parasitic diseases of the digestive tract.

3/ to explain how this concept is opening up new research fields for probing the interactions between the host, the parasites of the digestive system, and the environment.

\section{DEFINITION OF NUTRACEUTICALS}

The term "nutraceutical" results from a portmanteau between the words "nutrition" and "pharmaceutical". It has sometimes also been described as "functional food", which was first coined in the context of medical health (Hasler, 1998). According to Andlauer and Fürst (2002), a nutraceutical is defined as "any substance that may be considered a food or part of a food which provides health benefits, including the prevention and treatment of disease". In a similar way, a nutraceutical in veterinary science can be defined as a livestock feed which combines nutritional value with beneficial effects on animal health. This double action is suspected to rely on the presence of various plant secondary metabolites (PSM) or bioactive compounds. In contrast to pharmaceutical drugs, nutraceuticals are not synthetic compounds formulated for specific indications. 
Here, we will focus on a sub-category of nutraceuticals, i.e. plant-based products that contain nutrients and bioactive compounds that can be used either directly as part of the animal diet or added in a concentrated form to another diet after extraction from the bioactive plant or resource. Although the nutraceutical concept sounds simple, it is important to recognise that there are several key differences compared to synthetic $\mathrm{AH}$ and phytotherapeutic drugs (Table 1). This makes studying their efficacy a rather complex task. The key points and differences between nutraceuticals and the other options for interfering with the parasite life cycle will be discussed below.

\section{1/Nutrition: Compared to herbal drugs (phytotherapeutical remedies) or synthetic chemicals, a} nutraceutical based on bio active plants is not imposed, but offered to animals over a relatively long period (from several days to weeks or months). Therefore, the efficacy of this sort of nutraceuticals will directly depend on the Voluntary Feed Intake (VFI) of the animal.

2/ Nature of the bioactive compounds (PSM): The bioactivity against the parasites is dependent on the presence of natural chemical compounds in plants, which are usually Plant Secondary Compounds (PSM). The concentrations of these compounds can be highly variable and may depend on environmental growing conditions, on the plant cultivar, or chemotypes. In addition, technological factors (harvesting, processing methods) can also interfere with the preservation of the active compounds.

3/ Effect on animal health: The effects of nutraceutical feeds and of the associated bioactive compounds against parasitic nematodes differ from the mode of action of synthetic chemicals (see figure 3). This statement implies to develop specific methodologies of measurements of the AH effects.

\section{TANNIN CONTAINING LEGUMES WITH ANTHELMINTIC PROPERTIES AGAINST GINS IN SHEEP} AND GOATS: THE MOST STUDIED MODEL OF NUTRACEUTICALS IN VETERINARY PARASITOLOGY. 
It is only recently (in the last 20 years) that researchers have obtained enough evidence that supports the use of plants as nutraceutical feeds against GIN. The first evidence originated from research in New Zealand based on empirical results that reported significant reduction of GIN faecal egg counts in sheep when grazing pastures with different legumes, i.e. birdsfoot trefoil and big trefoil (Lotus corniculatus, L. pedunculatus), sulla (Hedysarum coronarium) and sainfoin (Onobrychis viciifolia), which contain condensed tannins (CTs ) (Niezen et al., 1995, 1998, 2002). The information generated by these early field trials started the search for new legumes (Fabaceae) containing the same PSMs and for other plant candidates elsewhere in the world against GINs in small ruminants. This has become the subject of extensive studies and still represents an important model aiming to explore the concept of using nutraceutical plants against other parasites, with other hosts, and to identify other botanical families with nutraceutical properties (Sandoval-Castro et al., 2012).

These studies on tannin-containing legumes have led to:

1/ the development of several important methodological procedures that are based on in vitro and in vivo methods to evaluate plants as potential nutraceuticals;

2/ a better definition of the difference in effects between nutraceuticals, phytotherapeutic remedies, and synthetic $\mathrm{AH}$ chemical drugs.

\subsection{Identification/selection of future potential candidates of nutraceuticals against GINs.}

As illustrated in Figure 1, the effects of a nutraceutical against GIN depend on complex interactions. Hence, the selection of a plant candidate as a potential nutraceutical requires good knowledge and interaction between different scientific disciplines, namely livestock nutrition and production, phytochemistry, parasitology, and to some extent, ethology and toxicology. However, the presence of bioactive PSM is a key issue.

Identifying viable nutraceutical candidates against parasites is a complex task, and the following steps need to be considered in the selection of potential materials. This procedure is intended to 
help in identifying candidate plant materials that can subsequently be explored under in vivo conditions.

\subsubsection{Nutritional issues.}

Even before the plant materials are tested in vitro or in vivo for AH activity, information should be gathered in terms of nutritional value and palatability for the hosts. This information should include:

\section{a) A good macronutrient profile.}

Ideally, the feed should have medium to high levels of protein or energy and low lignin. However, not all plants with tannins may have an optimal "nutritional"_profile. Therefore, initial selection of such plants should not be based solely on their macronutrient profile, especially if such plants are selected by ruminants during grazing/browsing. The nutritional quality of the plant material that is intended for nutraceutical use should include the determination of its In Vitro Dry Matter Digestibility (IVDMD). This information can help to identify if the plant material could be further useful under in vivo conditions.

\section{b) A feed readily consumed by the animal host.}

Since the general definition of a nutraceutical is linked to VFI by animals, this key issue needs to be first considered and then measured during in vivo assays. Short intake or preference trials should be carried out before engaging with in vivo evaluation of the plant. If the plant is not eaten, it might still be useful in other ways, as the active PSMs could be extracted and then dosed to animals (Phytotherapy).

\section{c) An acceptable in vivo apparent digestibility.}

Any plant material that will be used in large quantities or during long periods of time will require an evaluation of its impact on the apparent in vivo digestibility, including at least measurements of the dry matter (DM) and the organic matter (OM). These data may help to ensure that the nutraceutical material will not cause a severe reduction of digestibility. 
Before selecting a nutraceutical plant for AH effects, it is important to collect information on the possible negative impact on production (i.e. growth, milk production, reproduction) or even clinical signs (e.g. abortions or foetus deformities, such as arthrogryposis due to phytoestrogens) or photosensitisation. In such cases, the plant material should not be considered as a viable nutraceutical.

Since the early results in NZ, several tannin containing legumes (Fabaceae) have been subjected to a wide range of studies as potential nutraceuticals. The focus on these species was usually not based on prior ethno-botanic information about the action against signs of GIN parasitism (i.e. diarrhoea), or de-wormers used for humans, as in both cases the information could be inadequate for ruminant species (Sandoval-Castro et al., 2012). In contrast, they were mainly supported by knowledge and principles of pharmacognosy, based on the assumption that the presence of similar PSMs in the same botanical families (Fabaceae) should achieve similar antiparasitic effects. However, a few results have shown that some plant candidates, which were retained because of the presence of CTs, also corresponded to plants that had been identified based on ethnoveterinary knowledge. This double-sided approach can be of particular interest in many tropical countries.

A possible third approach could be based on detailed observational studies to identify plant selection

185 (González-Pech et al, 2014), feeding behaviour, resource selection and possibly self-medication 186 under grazing or browsing conditions. However, such studies are laborious and few exist from 187 tropical regions, where there is a large plant diversity (Novelo-Chi et al, 2014, Retama-Flores et al, 2010 and Ventura-Cordero et al, 2014a, 2014b). 
The Fabaceae family is one of the richest botanical families in terms of species numbers (nearly 20,000) and tannin-containing legume and plant resources occur worldwide, just like GINs.

Therefore, the search for possible nutraceuticals has included temperate and tropical tannincontaining plants. These include herbaceous plants, trees, and shrubs, which are perennials or annuals, and which are used by small ruminants in a wide range of feeding systems.

In temperate areas, two legume species of the sub family Faboideae, have received special attention and have been the focus of a number of studies. These are the sainfoin (Onobrychis viciifoliae) in Europe (Paolini et al., 2003a, 2005b; Heckendorn et al., 2006, 2007; Manolaraki et al., 2010;

http://sainfoin.eu; www.legumeplus.eu) and the Chinese bush clover or sericea lespedeza (Lespedeza cuneata) in the USA and South Africa (Shaik et al., 2006; Joshi et al., 2011; Kommuru et al., 2014; Terrill et al., 2009; 2012 http://www.acsrpc.org/). This special attention on these two herbaceous plants is explained by their ability to produce seeds, to be grown (cultivated) efficiently, and to organise their production for farm application on a large scale (see below).

It is worth underscoring that this scientific interest is also explained by their other beneficial effects in regards to nutrition and health of ruminants and environmental issues (see reviews by Rochfort et al., 2008, Waghorn, 2008, Mueller Harvey, 2006) which are : i) a reduced use of chemical fertilisers because of biological nitrogen fixation; ii) high palatability for ruminants and feeding values; iii) positive effects to reduce ruminal methane emission and GHG; iv) anti bloat effects; v) switch of nitrogen excretion from urine to faeces. In contrast, it is also worth noting that some non-native species exploited for these properties are considered invasive by environmentalists and ecologists In tropical areas in Africa and Latin America, several genera (shrubs or trees) of the Fabaceae family have been particularly under focus and identified as possible nutraceuticals because of in vitro results or in vivo data indicating reductions in egg excretion; e.g. Leucaena leucocephala (Ademola et al., 2006), Lysiloma latisiliquum (Matínez-Ortíz de Montellano et al., 2010), Havardia albicans (GaliciaAguilar et al., 2012; Méndez-Ortíz et al., 2012), or different Acacia species: Acacia pennatula , A. 
molissima , A. karroo, A. mearnsii, Mimosa tenuiflora (Kahiya et al., 2003; Alonso Diaz et al., 2008a;

Minho et al., 2008; Cenci et al., 2007; Oliveira et al., 2013, Murare et al., 2012).

\subsection{A methodological procedure to confirm the antiparasitic effects.}

An overall methodological procedure has progressively emerged from scientific results from different studies to validate the possible efficiency of a wide range of tannin-containing plants as nutraceuticals against GINs. By its logical scheme and by the objectives defined for each step, the procedure has been widely derived from the WAAVP guidelines to examine the efficiency of synthetic AHs (Wood et al., 1995).

The three successive steps are $\mathbf{1 /}$ the in vitro screening of plant extracts based on a wide range of assays (Figure 2); 2 / controlled in vivo studies on experimentally infected animals in confined conditions to confirm the efficiency of the selected plant candidates; $\mathbf{3} /$ holistic studies to examine how and when to apply the nutraceuticals in breeding/feeding systems for small ruminants.

However, because of the complexity and intrinsic variability of nutraceuticals, which are based on naturally occurring chemicals rather than synthetic anthelmintics (see Table 1, Quality of the compounds and mode of administration), this scheme requires adaptations and critical comments to interpret the results.

Since the mode of action of tannin-containing nutraceuticals differs from synthetic chemical AHs, it is of interest to examine the effects of the same plant extract on different key stages of the GIN life cycle (egg, infective larvae, adult worms) (Figure 2).

3.2.1 The in vitro screening of plant extracts.

Most in vitro assays for the primary screening of plant products have been adapted from those developed to assess the efficacy of synthetic AHs against GINs in ruminants (Wood et al., 1995). One exception is the Larval Exsheathment Inhibition Assay, which has been set up specifically (Bahuaud et 
al., 2006) to reproduce artificially, under in vitro conditions, the disturbances related to the establishment of infective larvae as measured in vivo in sainfoin-fed sheep (Brunet et al., 2007).

The detailed methodologies of these different assays, when adapted to plant materials, can be found in Jackson and Hoste (2010). In addition, it is worth mentioning that the model represented by the free living nematode, Caenorhabditis elegans, is also increasingly being exploited to screen the AH properties of different plant resources (Katiki et al., 2012, 2013).

It is important to emphasise that these different in vitro assays, first used to screen potential nutraceutical candidates, have also been exploited for a second main objective: to better understand the mode of action of PSM compounds against GINs. This has been achieved i) by applying either isolated and purified tannins, which were selected because of their different structural features (Molan et al., 2004, Novobilsky et al., 2013, Quijada et al., 2015), or pure flavonoid compounds (Molan et al, 2003a; Brunet and Hoste, 2006), and ii) by performing detailed studies of the functional and structural changes induced in nematodes (Hoste et al., 2012). This allowed testing of the "direct" hypothesis (see section 4.1).

Most research groups started screening the $\mathrm{AH}$ activity of different plant materials under in vitro conditions. In most cases, the screening process was developed with plants that had been extracted with different solvents. When tannins are suspected as the main bioactive compounds, extraction with acetone/water (70:30) is the most common and efficient solvent in regard of the yield of extraction. We note that several studies reported drying plant materials at high temperatures and that this may have reduced the AH activity. It is highly recommended that all plant samples should either be freeze-dried or dried below $40{ }^{\circ} \mathrm{C}$ in order to preserve polyphenols and tannins, as these are easily oxidised at higher temperatures. against GINs, many misunderstandings need to be clarified: 

against other life stages of the same parasite, at roughly the same concentrations.

This is not the case ! If the same extract from a single plant material is applied to different life stages of a nematode species under the respective in vitro conditions, the AH effect may differ between different life stages (Paolini et al, 2004). For instance, a plant extract may show a clear AH effect against $H$. contortus on a given life stage (i.e. $L_{3}$ larvae) and show a mild or no AH effect against another stage (i.e. eggs). Furthermore, the AH effect may only be evident on a certain aspect of the same life stage, such as inhibition of the $L_{3}$ exsheathment process, but have no clear effect on another aspect, such as the motility of the same $L_{3}$ larvae (Alonso-Díaz et al., 2011).

Such differential effects depending on the life stages of GIN have also been recorded for conventional anthelmintics, such as levamisole, that shows a clear effect on $\mathrm{L}_{3}$ motility but fails to show any $\mathrm{AH}$ effect on the exsheathment of $\mathrm{L}_{3}$ or the eclosion of GIN eggs.

These comments imply that the selection of candidates for further in vivo tests could be judged either on the overall effective concentration (EC 50, 90 or 99\%) of different in vitro tests with the different life stages tested or alternatively, that the candidate should be the one showing the lowest EC in the most biologically relevant in vitro test chosen based on valid biological grounds, depending on the stage of interest for the designed study.

b) If the plant extract is obtained from the same plant material with a solvent of similar polarity, the potential AH effect against GIN will be similar.

Again, this is not the case ! Different extraction procedures, even with solvents of similar polarity [i.e. methanol vs. acetone:water (70:30)] applied to the same plant material, can result in different profiles of PSMs being extracted. As a result, the extracts of the same plant material will show different $\mathrm{AH}$ activities when applied to the same life stage. For example, acetone-water (70:30) extracts of Annonaceae leaves showed limited ovicidal activity and a clear exsheathment inhibition activity, while the methanolic extracts of the same plant material showed significant ovicidal activity 
but was less efficient to inhibit the exsheathment of larvae (Castañeda-Ramírez et al., 2014). Thus, the extraction procedure and the choice of solvent, even with similar polarity, can result in marked differences in the extracted PSMs.

\section{c) An in vitro screening test will help to decide on the dose or concentration of the nutraceutical} material that needs to be consumed by the infected animals in order to control GIN infections.

The extrapolation of in vitro doses to in vivo conditions is more difficult to achieve for plants when used against parasites dwelling in the lumen of the gastrointestinal tract. A plant extract prepared for in vitro use contains a concentrated quantity of PSM from the experimental plant material. Hence, those PSMs will be present in the in vitro assay at a certain quantity and quality that may not be comparable with the in vivo conditions, and also during a time span difficult to replicate under in vivo conditions. Moreover, under in vivo conditions, the digestion processes and the conditions occurring in the digestive tract may affect the liberation of the bioactive PSMs from the plant material. Also, the quantity or structure of PSM may be affected along the digestive tract after the plant is consumed, chewed, ruminated and digested by the ruminant host or gut microflora. Thus, it should be remembered that in vitro assays can help at identifying candidates with potential AH activities, but will not produce indications on a dose level that can be used as a starting point for the in vivo dose level that should be applied to the various hosts.

With the limitations mentioned above, one may think that it might be easier to find a plant extract with excellent in vitro activity, validate its in vivo AH activity against GIN in the relevant host, and then determine a dose that can be used to control their GIN populations. Such an approach would not be pertinent for a nutraceutical plant material but can be considered for an herbal remedy or phytotherapeutical medicine. As such, this will need to be tested as a drug and its efficacy validated using the relevant guidelines for efficacy against GIN (Wood et al., 1995).

Why can these extracts not be considered as a nutraceutical? The reason is simple: if the plant material is not providing macronutrients for the animal, then it is not a nutraceutical material. In 
reality, there may be a more straightforward method for identifying plant materials with potential nutraceutical effects and for investigating the dose level required to control the GIN population: letting the hosts eat the plant material, while evaluating the faecal GIN egg excretion. If animals are able to eat sufficient plant material in the chosen presentation and form and produce a visible $\mathrm{AH}$ effect, then such level of ingestion (or dosage) may be suggested against parasites in the test animals.

3.2. 2 Confirmation of potential nutraceutical candidates, under in vivo controlled conditions, based on in vitro results.

As for the $1^{\text {st }}$ step (i.e. in vitro screening), the in vivo procedures to assess the efficacy of nutraceuticals against GINs are also derived, to some extent, from the general guidelines described for synthetic chemical AHs (Wood et al., 1995). However; it is important to take into account several specificities of the nutraceutical concept (see Figure 1).

\section{a) A nutraceutical is at first a feed}

Therefore, it is essential to evaluate its nutritional value by using conventional methodologies. The information should include the macronutrient content of crude protein (CP), metabolisable energy (ME), neutral detergent fibre (NDF), acid detergent fibre (FDA) and lignin. This information may help to identify plant materials fitting the nutritional characteristics of an edible ruminant feedstuff. The information generated from conventional nutritional methodologies could be correlated with near infra-red (NIR) spectra. With time, when a large dataset of plant samples are tested, the NIR spectra can be linked with nutritional quality, presence of PSM and related AH effects. This may be automated with other NIR tools in the future.

One key aspect of these measurements for controlled in vivo studies is to achieve iso-proteic and isoenergetic diets in the groups of animals receiving the control or the nutraceutical diets, in order to specifically evaluate the role of the PSMs and to avoid any confounding effects because of differences in the amount of macronutrients (protein, energy or their balance) (Coop and Kyriazakis, 

is not controlled.

339 Alternatively, assessing the trade-off of plant selection and intake could be an alternative for when iso-energetic and iso-proteic diets are not attainable. The working hypothesis should be carefully stated in all cases. Nutrient balance studies are needed to contribute to the understanding of parasitism and nutrient costs (for the host) and proper assessment of trade-off of nutraceutical plant intake.

b) A nutraceutical should be readily consumed by the relevant host since the effects on health depend on the animal feeding behaviour

Most plants materials meant to be used for nutraceutical purposes are not normally included in the diet of the relevant host. Since the general impact of nutraceuticals on animal health stems from the consumption of these materials, it is important: (1) to include in the experimental design of controlled in vivo studies a period for animal adaptation to the novel feed, lasting from 10 to 15 days, until experimental animals reach a plateau of consumption; and (2) once this plateau of consumption is reached, to estimate regularly the animal VFI. The evaluation can be as simple as measuring the plant material offered and refused, to determine intake. Under some circumstances, the ingestion of the plant material can be enhanced by means of some additives, such as sugar cane molasses. In such cases, the future use of these plant materials will depend on the availability of the plant per se, as well as the existence of the potential feed additive. This could mean an added difficulty for onfarm applications. If possible, plant intake should be evaluated with both infected and non-infected animals with the objective to provide information on self-medication (Martinez-Ortiz-de-Montellano et al, 2010).

\section{c) The impact of nutraceuticals against the parasite depends on the presence of PSM}

It is essential to obtain a measurement of the potential bioactive PSM before implementing the in vivo controlled studies. It is also important to describe the analytical methods used. In the case of 
condensed tannins, which cover the core of the current review, a critical description of the different analytical methods has been reviewed previously (Mueller-Harvey, 2006). One simple recommendation, when possible, is to try to obtain two different evaluations (usually one chemical assay and one biological assay in order to estimate the ability of tannins to complex proteins) (Makkar et al., 2003).

\section{d) The effects of tannin-containing nutraceuticals differ from synthetic $A H$}

This requires adapted experimental designs and measurements. Once the information to characterise the nutritional value and the PSM content of a nutraceutical have been obtained, valid in vivo assays in controlled conditions can be implemented. Such studies could consider animals with natural GIN infections. However, artificial infection trials are preferred that focus on the most prevalent GIN genera and species in the areas of interest.

Within this general experimental context, several factors need to be explored which are specific to nutraceuticals

\section{- The multivalent effects on a range of GIN species:}

As a general recommendation, combined infections with at least one species of the abomasal plus one species of the small intestinal species should be encouraged. The reason for this is that $i$ ) as part of the overall objective, as for synthetic AHs, a multivalent effect can be expected from nutraceuticals and also, ii) variations in the effect of tannin-containing resources against different GIN species have been mentioned on several occasions (see Hoste et al., 2006, 2012). Of course, the choice of the GIN models should be based on epidemiological information, which needs to identify the most prevalent and pathogenic species in the regional areas.

\section{- The multivalent effects on different GIN stages:}

As shown in Figure 3, the consequences of nutraceuticals and related PSMs on GINs (at least for the tannin-containing legume models), result from a combination of effects on 3 key stages of the GIN 
life cycle. Therefore, when possible, it is important to design experimental studies that examine the effects on these different stages (Castañeda-Ramírez et al., 2014; Vargas-Magaña et al., 2014a, 2014b).

- The role of quantity and/or time period for offering tannin-containing resources in the diet to optimise effects against GINs in small ruminants

After completing initial simple experimental designs that validate the effects of tannin-containing nutraceuticals against different genera and/or stages of GINs in small ruminants, some additional studies are worth designing in order to help in evaluating the effect of two factors which can influence the efficacy of nutraceuticals against GINs, namely the proportions of nutraceuticals and the related concentration of CTs in the feed (Athanasiadou et al., 2001, Brunet et al., 2007, Terrill et al., 2009) and the length of distribution.

\section{- Specificities in the evaluation of the parasitological and pathophysiological consequences}

During the whole evaluation period in studies based on experimental infections, animals should be monitored regularly in terms of i) repeated parasitological measurements (faecal excretion of GIN eggs), ii) pathophysiological measurements to establish the effects on host resilience based on quantitative and/or semi-quantitative measurements of the (sub)clinical effects of infection (e.g. Packed Cell Volume $=$ PCV, FAMACHA Score) .

Because of the variations in the PSM effects, which can depend on the nematode species and/or stages (see Figure 3), two experimental measurements are worth considering to complete the information obtained from experimental in vivo studies: $1 /$ it is recommended that these methodologies need to differentiate effects from different GIN species in case of multispecific experimental infections; and 2/ whenever possible, to measure also effects on egg hatching and development. 
Ideally, the studies in controlled conditions should be complemented with post-mortem evaluations of the worm populations. The latter will help to strengthen the parasitological protocol by defining if the effect on GIN egg excretion is due to the reduction of GIN populations, proportions of species, sex ratio, or reduction in female worm fecundity (Martinez-Ortiz de Montellano et al., 2010; GaliciaAguilar et al., 2012).

\section{4 . TANNIN-CONTAINING LEGUME NUTRACEUTICALS AGAINST GINS IN RUMINANTS}

Several (recent) reviews have summarised the existing results on the potential of tannin containing legumes as nutraceuticals. Their focus concerns three different aspects:

- the overall effects on ruminant nutrition, health and production (e.g. Waghorn, 2008; Mueller-Harvey, 2006; Rochfort et al., 2008 ; Wang et al., 2015)

- the specific AH effects (Min and Hart, 2003; Hoste et al., 2006, 2012)

- the mode of action against the GINs by understanding the nature of active compounds (tannins and flavonoids) (Mueller-Harvey, 2006) and their possible effects on the worms (Hoste et al., 2012).

The readers are invited to refer to these different reviews. The aims of the current section will be i) to provide an updated summary of the main results of basic research studies that describe the antiparasitic bioactivity of tannin-containing legumes against GIN nematodes in small ruminants and the current hypotheses on their mechanisms of action; and ii) to illustrate possible on-farm applications, which are starting to be developed.

\subsection{Updated summary of the main effects on the GIN life cycle and hypotheses on their modes of} action.

4.1.1. Impact on the GIN life cycle

Three main potential impacts have been linked to the intake of tanniniferous plants by infected ruminants (Hoste et al., 2012) on the GIN life cycle (illustrated in Figure 3) 
1/ lower establishment of the infective third-stage larvae_(L3) in the host.

4342 / lower excretion of nematode eggs by adult worms, related either to a reduction in worm numbers

435 or lower fertility of female worms; and

$436 \quad 3 /$ impaired development of eggs into third-stage larvae.

437 Point 1 leads to reduced host invasion by L3. Steps 2 and 3 both contribute to reducing the

438 environmental contamination with parasitic elements and thus to reduce the risks for hosts.

439 To summarise, tanniniferous nutraceuticals do not lead to a $100 \%$ elimination of worms, but they

440 can interfere with the life cycle; whereas the main goal of synthetic AHs is to completely break the

441 parasitic life cycle. The role of nutraceuticals can be linked to severely impairing several key biological

442 stages of the life cycle (eggs, infective larvae, adult worms). The potential combined effect of these

443 separate impacts contributes to slowing down the dynamics of the infection and to lowering the rate

444 of infection to levels that enable acceptable productivity and animal welfare. This also provides an

445 opportunity for the animal to develop its own immunity to the parasites. Similar effects have been

446 observed with the main nematode genera that infect the abomasum and small intestine of small

447 ruminants (Haemonchus spp, Teladorsagia spp, Trichostrongylus spp). Some recent results (Gaudin et

448 al, 2015 Abstract to WAAVP 2015 ) have demonstrated that significant reductions in egg excretion

449 also occurred with a multi-resistant isolate of Haemonchus contortus in the presence of nutraceutical

450 plants. This confirmed that tanniniferous nutraceuticals do indeed represent an alternative solution

451 to $\mathrm{AH}$ resistance that is worth exploring further.

452 It is worth mentioning that these AH effects that affect the worm biology have also repeatedly been

453 linked to positive effects on host resilience (e.g. better production parameters, less severe signs of

454 diarrhoea or anaemia, lower mortality under parasitic challenge) ever since the early studies in NZ

455 (Niezen et al, 1996). The mechanisms explaining this improved resilience remain obscure but can

456 partly be explained by the effects on reducing the worm population as well as by the nutritive value

457 of legumes (i.e. higher protein content) and the rumen-escape effect that occurs in the presence of

458 certain types of tannins, which are able to protect dietary proteins (Waghorn, 2008). Identification of 
which particular tannins are best able to improve host resilience remains an outstanding research goal. Therefore, it is of paramount importance to underline the need to achieve iso-proteic and isoenergetic diets in control vs nutraceutical diets that are fed to sheep or goats in controlled in vivo studies.

\subsubsection{Hypotheses on the modes of action}

Two non-exclusive general hypotheses have been proposed to explain the activity of bioactive tannin containing feeds against gastrointestinal parasitic worms (Hoste et al., 2012):

$1 /$ The " direct" hypothesis is based on pharmacological-type of interactions between the various polyphenols and the different stages of gastrointestinal nematodes.

2/ The "indirect" hypotheses assumes a possible improvement of the host resistance (i.e. an immunologically based response) because of the effects of tannin-containing feeds that can improve the overall host protein nutrition by increasing the amount of by-pass proteins

It is clear that the bulk of in vitro data obtained so far with different tannin-containing extracts support the hypothesis of "pharmacological-like" effects.

As previously stated (Hoste et al, 2012), numerous studies on GIN from small ruminants strongly suggest that both CTs and various flavonoids (at least some flavanols) contribute to the $\mathrm{AH}$ action (Molan et al., 2004, Brunet and Hoste, 2006). This has been supported also by recent results on another nematode model (e.g. Ascaris suum in pigs; Williams et al., 2014b). New evidence is also starting to emerge that tannins and other flavonoids in combination can generate either favourable (synergistic) or unfavourable (e.g. antagonistic) interactions (Klongsiriwet et al., 2014; VargasMagana et al., 2014a).

A dose-dependent relationship between tannins and/or flavonoid monomers and their in vitro effects has been found on several occasions with different assays and GIN species (see review by Hoste et al., 2012). A few in vivo studies have also described such relationships, where effects of a 
tanniniferous source on infective L3 larvae (Brunet et al., 2007) or on adult worm populations (Athanasiadou et al, 2001, Terrill et al., 2009) were examined. Taken together, it would appear that a $\mathrm{CT}$ threshold needs to be reached in the diet in order to achieve AH effects against the worms.

In addition, evidence is now accumulating from various in vitro studies which have sought to unravel the mode of action by tannins on the worms, that, besides quantitative factors (i.e. concentrations), qualitative factors (i.e. compound structures) can also modulate the bioactivity. Recent data obtained with GIN models from cattle, small ruminants, and pigs (Novobilsky et al., 2011, 2013; Quijada et al., 2015; Williams et al., 2014a) lend support to the hypothesis first raised by Molan et al. (2003) that bioactivity is linked to the prodelphinidin/procyanidin (PD/PC) ratio in plants. These recent studies have also revealed that tannin size is an important structural feature that contributes to the extent of the AH effects. As CTs usually occur in complex mixtures of closely related tannin compounds, their average polymer size is measured and reported as their mean degree of polymerisation (Gea et al., 2011).

Less studies have examined the "indirect" hypothesis, based on long -term studies and by measuring different effectors cells (mast cells, globule leucocytes, eosinophils, goblet cells) along the digestive tract in sheep (Tzamaloukas et al., 2006a and b; Martínez-Ortíz-De-Montellano et al., 2010; Rios de Alvarez et al., 2010) and goats (Paolini et al., 2003) when receiving different TR resources. Some of the most convincing evidence to support this "indirect hypothesis" is that some measurements indicating an enhanced local immune response (significantly higher numbers of mast cells and globule leucocytes) (Tzamaloukas et al.,2006) has been shown when lambs were consuming sulla or chicory and had a reduced development of worms.

\subsection{Strategies to apply tannin-containing nutraceutical materials on-farm}


507 provided preliminary information on the future use of various plants or plant resources. However, gaps remain between in vitro results and on-farm application. These are outlined in section 3.

A few resources have been investigated more thoroughly through extensive approaches that included a succession or combination of in vitro assays, controlled in vivo studies and sometimes holistic studies in farming systems in order to prepare for implementation under field conditions. Fortunately, these specific plants illustrate various options that can be used to exploit tannincontaining resources as nutraceuticals.

\subsubsection{Cultivating legumes as nutraceuticals}

The availability of the plant material can be considered as the main constraint for using a nutraceutical material on-farm. If the plant material is not widely available, or the cost and effort of producing such material is high, then there will be insufficient quantities and it will be unlikely that farmers can adopt it. Up to now, very few plants exist that have potential for nutraceutical exploitations and that benefit from the availability of solid agronomic information suitable for largescale production.

In some parts of the world, where nutraceutical legume plants can be sown in conventional pastures, animals may consume the nutraceutical plant together with the normal grass or herbs. In other areas, farmers may not be able to overseed their paddocks or may decide to dedicate a certain paddock to produce only the nutraceutical plant (i.e. monoculture). In that case, the nutraceutical material can be offered in the form of hay, silage or pellets. These types of R\&D studies have been developed or seem best suited for farmers who are looking for alternative GIN control measures. This is particularly the case of organic farming or milk production systems based on small ruminants. In the temperate areas, as mentioned above, two legume forages have been the subject of extensive studies, namely sainfoin (Onobrychis viciifolia) in Europe and sericea lespedeza (Lespedeza cuneata) in South Africa and USA. These studies have involved a wide range of disciplines: phytochemistry, 
agronomy, animal production, ruminant physiology and parasitology. Both of these tanniniferous legume species have also been the preferred model for exploring the mode of action of polyphenols against the different stages of GINs (see Hoste et al., 2012). In addition, R\&D studies for nearly 20 years on $O$. vicifolia or L. cuneata have compared different forms of exploitation, namely direct grazing, conservation as hay or silage (Paolini et al, 2005, Heckendorn et al, 2006, Shaik et al., 2006, Werne et al, 2013) or more recently with dehydrated pellets (Terrill et al., 2007, Gujja et al., 2013, Girard et al., 2013, Kommuru et al., 2014).

\subsubsection{Exploiting rangelands and their biodiversity of plant resources}

In most tropical parts of the world, the ecosystems present a wide plant biodiversity and include several plant species with nutraceutical potential as natural forages. However, for many of those plant species, there is no information on their agronomy or on possible propagation methods. There are, however, a few exceptions, such as Leucaena leucocephala, Arachis pintoi, Gliricidia sepium or Cratylia argentea (von son de Ferneix et al., 2014). All are from the Fabaceae family and are exploited i) in plantations, ii) in silvo-pastoral systems that consist of rows of grass and trees, or iii) in so-called "fodder banks" that are tree plantations in a very dense system that are not allowed to grow beyond approximately $2 \mathrm{~m}$ in height. Thus, nutraceutical forages in tropical areas could offer a variety of situations for their production. However, most farmers currently are relying on the natural availability of nutraceutical plants. Meanwhile, the few people who can invest money in their farms may also be able to build silvo-pastoral systems or fodder banks. Irrespective of the production strategy, such plants may be used for direct browsing or in a cut-and-carry system.

At the moment, most farmers let their animals browse the natural vegetation. Under such conditions, it is not possible to determine whether animals have consumed enough nutraceutical material to obtain the desired AH effect. Cut-and-carry systems could instead be the answer to ensure that animals are exposed to sufficient nutraceutical material. However, these systems are constrained by time spent by farmers to harvest enough plant material for all animals, the need for a 
vehicle to move sufficient plant material, and difficulties with harvesting (e.g. thorns). In any case, such management strategies could eventually deplete the resource. Thus, the creation of low-cost fodder banks represents a more sustainable option. However, it poses considerable challenges in terms of investment and technical knowledge that is beyond the capability of most small farmers at present.

For the tropical areas, a considerable amount of data has been acquired in Mexico for tannincontaining leguminous trees, such as Havardia albicans and Lysiloma latisiliquum. These materials were tested first under in vitro conditions (Alonso-Díaz et al., 2008a, 2008b; Hernández-Orduño et al., 2008) and their promising results led to subsequent in vivo studies with sheep (Martínez-Ortíz de Montellano et al., 2010; Galicia-Aguilar et al., 2012; Mendez-Ortíz et al., 2012) (see section 3.1.2).

\subsubsection{Exploring the value of agro industrial by-products}

In different areas of the world, interest has been growing in exploring the potential of tannincontaining 'waste' or by-products from agro-industries. These represent an alternative option to "natural" nutraceuticals, in the sense that the PSM can be extracted from the by-products and then added to an existing feed (see Table 1). Transforming 'waste' tannin-rich materials into nutraceutical feeds with antiparasitic properties could have several advantages. First, this represents a viable alternative to add value to agro-industrial waste products; secondly, it may help to solve the problem of the inherent variability of PSM content (see below) in nutraceutical plants, as it would allow adjusting the bioactive PSM concentration(s) in feeds (Girard et al., 2013). Third and consequently, it may also help to avoid any negative consequences caused by an excess of PSM in the feed.

Some examples of tannin-containing plant by-products that have been under recent investigation for their AH activities are: 1 / by products from the nut industry in temperate areas (Desrues et al., 2012, Girard et al, 2013), 2/ carob pods (Manolaraki et al., 2010; Arroyo-Lopez et al., 2014) in the Mediterranean region, and 3/ coffee by-products and cocoa fruit husks and leaves in Yucatan, Mexico (Covarrubias-Cárdenas et al., 2013; Vargas-Magaña et al., 2014a, 2014b). 
582

583

584

585

Whatever the mode of exploitation (grown, browsed, or by-products), once a plant species has been identified through in vitro and in vivo studies as a potential candidate for use as a nutraceutical, it is still important to consider the inherent variability caused by several factors which influence the quantity and/or quality of PSMs and hence the antiparasitic effects of nutraceutical candidates.

Sainfoin (O. viciifolia) has been extensively studied to explore such factors that influence PSM contents and composition and the related AH activities (Manolaraki et al., 2011). Three main factors have been identified: environmental conditions (e.g. phenological stages, areas or soil conditions for growth, climate and seasons), genetic factors (cultivars or chemotypes) (Azuhnwi et al., 2013; Stringano et al., 2012) and also technological processes (e.g. fresh versus hay, silage and pellet samples).

It is possible that this issue of variability caused by the different factors is also important for growing sericea lespedeza (Muir et al., 2014), or for the leaves of L. leucocephala or Manihot esculenta that originate from plantations in tropical zones. Variation of PSM contents may be even more evident in plants that grow in the native vegetation. Under such conditions, variation of PSM content is significant between individual plants even during the same season in the same geographical region (Alonso-Díaz et al., 2010b).

Further factors, which are frequently not considered, include variation in harvesting methods by farmers, such as the leaf:stem ratio that results from pruning only young leaves (branch tip) or complete branches (often based on biomass feed requirement), and post-harvest practices, such as sun drying, wilting, which are often based on nutritional advice, but may not have considered the effects on the bioactive PSMs, such as their reduced content or activity in the feed. As the common and traditional view is that PSMs are anti-nutritional factors, this type of advice will need to be revised for nutraceuticals. 
However, as far as we are aware, hardly any research has been conducted on selecting or breeding for bioactive plants with stable tannin or other PSM compositions. This seems to be an opportunity that would be worth exploring as we have shown that a few relatively 'robust' sainfoin and sorghum chemovars used earlier exist, where the PSM composition was much less dependent on the environment (Azuhnwi et al., 2013a; Mueller-Harvey and Dhanoa, 1991).

\section{PERSPECTIVES}

Based on the previous description of tannin-containing legumes against GIN in small ruminants and the development of methodological approaches for exploring the nutraceutical concept, several areas for future research have been identified that focus on on-farm applications.

\subsection{What else? Novel parasitic "targets" for tannin-containing legumes}

5.1.1 Against GINs in other host species.

Several recent in vitro results have shown that tanniniferous legumes can also regulate worm biology of the main genera of GINs in cattle (Sandoval-Castro et al., 2012). Significant results were obtained with extracts of sainfoin (O. viciifolia); L. corniculatus and L. pedunculatus against Ostertagia ostertagii and Cooperia oncophora (Novobilsky et al, 2011, 2013). These data are offering opportunities for in vivo studies and to promote the combined control of bloat and GINs in cattle production. Recently, a 50\% reduction in worm burden was obtained in calves infected with $O$. ostertagi and fed sainfoin pellets (Desrues et al, 2015 WAAVP 2015 abstract).

Attempts have been made in South Africa to regularly include wattle extracts ( $A$. karroo) as a supplementary feed for cattle that are infected with Haemonchus sp and Oesophagostomum columbianum. These studies reported a reduction in egg excretion (Xhomfulana et al., 2009).

Two recent studies, based on in vitro assays, have also underscored that different tanniniferous plant sources could also be used against GIN in monogastric livestock hosts given the positive assessment 
of AH effects against Oesophagostomum dentatum and Ascaris suum in pigs (Williams et al., 2014a and b). However, it remains to be seen whether these tannin resources will be used as herbal remedies or as nutraceuticals (Table 1). These in vitro data are supported by a field observation study that examined the effects of acorns (Quercus robur) fed to outdoor pigs which had been raised with natural nematode infections. The results indicated a dramatic reduction (>90\%) in GIN faecal egg count (Salajpal et al., 2004).

\subsubsection{Against other digestive parasites}

Recent investigations have also explored the effects of tannin-containing plants against Eimeria infections in small ruminants. Although early results were disappointing from an in vitro assays that examined a wide range of sainfoin extracts for their capacity to inhibit oocyst sporulation (Saratsis et al., 2012), the results of in vivo studies on natural infection were much more encouraging. These studies evaluated sainfoin fed to lambs (Saratsis et al., 2012), and sericea lespedeza (Lespedeza cuneata) fed to either lambs (Burke et al., 2013) fed before and at weaning or kids (Kommuru et al., 2014). Moreover, some early results are also available that examined the effect of Pistacia lentiscus in young goats (Markovics et al., 2012).

In most of these in vivo trials, significant reductions in oocyst excretion were measured when young animals were fed with legumes. In particular, kids fed with L. cuneata showed reductions greater than $90 \%$. In addition, there was some evidence that sericea lespedeza had a positive effect on host resilience, as it led to a lower requirement for anti-coccidian treatments. These promising results suggest that tannin containing legumes, in particular pellets of sericea lespedeza, represent an option for a plant-based control of coccidiosis in small ruminants around weaning time.

\section{The ability of lambs and kids to consume sufficient nutraceutical amounts to prevent coccidiosis} around weaning could be a limiting factor that will need to be considered. However, results of a 
recent experiment with calves, which were under 15-day old, are promising: supplementation of milk with concentrated pomegranate extract may, depending on the concentration, reduce faecal oocyst count and diarrhoea intensity and duration because of Cryptosporidium parvum infection (WeylFeinstein et al., 2014) [it should be noted, however, that pomegranate contains mostly ellagitannins - and not CTs].

\subsection{Exploring plant resources as nutraceuticals: example of other plant families, other bioactive} PSMs.

The logical and successive steps described in section 3 have helped to identify other botanical resources, which could be exploited as nutraceuticals. Two examples that meet the general criteria of nutraceuticals as defined in Table 1 will be mentioned here to illustrate these issues.

An impressive range of studies has been performed in Spain that investigated the AH effects of different heather species that belong to three Erica spp and one Caluna sp (Ericeacae) and are browsed by Cashmere goats (Moreno-Gonzalo et al., 2012). This is a first example for which a whole series of consistent results were obtained that covered in vitro assays (e.g. Moreno-Gonzalo et al., 2013), controlled in vivo studies with experimental infections in confined conditions (Frutos et al., 2008; Moreno-Gonzalo et al., 2014) and systemic studies with natural infections (Osoro et al., 2009).

Chicory (Cichorium intybus) (Asteraceae), when used as a forage for ruminants, represents another example of potential nutraceutical with AH properties, which has illustrated the "robustness" of the methodological approach described in section 3. Chicory has been shown to possess AH properties based on experiments that ranged from in vitro assays ( Molan et al., 2003b; Foster et al., 2011 a,b), simple in vivo studies (Peña-Espinoza et al., 2015 WAAVP2015 abstract), to systemic studies (Athanasiadou et al., 2007; Tzamaloukas et al., 2006 a,b; Nielsen et al., 2009). 
679 Two other points are worth mentioning in comparison of chicory and the legume models and 680 illustrate which additional studies are required to expand the nutraceutical concept for tackling digestive parasites in infected livestock.

682

- Based on several in vitro results, the nature of the AH PSMs of chicory seems to stem from sesquiterpene lactones and not from CTs and related polyphenols (Molan et al., 2003b, Foster et al., 2006, 2011a and b).

- Despite the different PSMs, results acquired with chicory forages also illustrated that

\subsection{Self-medication and nutraceuticals: a novel field for basic researches on the host-gastro} intestinal nematode interactions.

Given that the antiparasitic effects of nutraceuticals depend on the PSM concentration in a feed and on the length of consumption by the infected host, the tannin-containing legumes provide a valuable model to explore the host-parasite (GIN) interactions in regard of regulation of infection related to the host feeding behaviour and /or to assess the balance between host immunity and nutritional behaviour (Hoste et al., 2010). Interesting studies can and have yet been performed that examine 1 / the ability of the host to select a feed with AH properties when hosts are infected or not with GINs (=self-medication) (Lisonbee et al, 2009; Villalba et al, 2013, Junkhe et al, 2012); 2/ the influence of various host or parasite factors on the self-medication behaviour (Amit et al, 2013); and 3/ the tradeoffs between negative nutritional effects and beneficial health effects that accrue from the consumption of nutraceuticals (Frutos et al, 2008). 
705 It is important to indicate, however, that the influence of GIN on the ingestion of nutraceutical plant 706 materials is not easy to evaluate in regard of methodological issues. Attempts to evaluate this phenomenon using cafeteria studies, where animals are exposed to different types of plant materials, or direct observation methods in the field, that compare animals with and without parasites, will be influenced by the quantity of parasites present in the animals (light to heavy burdens), the time that animals had been naturally infected with GIN before the study began (naïve or immune competent animals), the existing feeding experience, physiological adaptations (e.g. tannin binding saliva) of the animals investigated, amongst several other aspects, many of them being difficult to control (Alonso-Díaz et al., 2010a; Vargas-Magaña et al., 2013). Because selfmedication has been the subject of 2 recent review (Villalba and Provenza, 2007; Villalba et al., 2014), this issue will not be developed further.

\section{CONCLUSIONS.}

- Because of the constant, worldwide, rapid development of resistance to synthetic chemical $\mathrm{AHs}$, and also because of the increasing societal demand, there is nowadays a clear and urgent need to explore and validate alternative options for specific livestock systems (e.g. organic farming systems, small dairy ruminant systems in EU or in caprine breeding).

- For these reasons, in regard of the control of GINs in livestock, as previously evoked

- The development of nutraceutical products with real potential for the control of GIN in ruminants is a possibility that is well underway of becoming a reality in different parts of the world for different livestock breeding systems and relying on different plant materials. 
- The complexity of the scientific questions which need to be addressed are intrinsic to nutraceuticals. Therefore, the possibility of developing on-farm applications against digestive parasites requires a multidisciplinary approach between scientists with expertise in parasitology, as well as phytochemistry animal production, digestive physiology, ethology and other.

\section{CONFLICT OF INTEREST}

The authors declare that there is no conflict of interest.

\section{ACKNOWLEDGEMENTS}

The authors wish to acknowledge the financial support of the European Commission through the “LegumePlus" project (PITN-GA-2011-289377), the EMIDA ERANET project CARES, the CORE

ORGANIC 2 ProPARA and the PCP France-Mexico project 2013-2017 (Fondo Institucional CONACYT No. 229330). We also acknowledge financial support from the IEPAC project (FEDER Convention No. 31439 - Programme INTERREG IV CARAIBES 2007-2013 - No. 41000140).

\section{REFERENCES}

1) Ademola, I. O., Idowu, S. O., 2006. Anthelmintic activity of Leucaena leucocephala seed extract on Haemonchus contortus infective larvae. Vet Rec.158, 485-486.

2) Alonso-Díaz, M.A., Torres-Acosta, J.F.J., Sandoval-Castro, C.A., Aguilar Caballero, A.J., Hoste, H., 2008a. In vitro larval migration and kinetics of exsheathment of Haemonchus contortus exposed to four tropical tanniniferous plant extracts. Vet. Parasitol. 153, 313-319.

3) Alonso-Díaz, M.A., Torres-Acosta, J.F.J., Sandoval-Castro, C.A., Capetillo-Leal, C.M., Brunet, S., Hoste, H., 2008b. Effects of four tropical tanniniferous plant extracts on the inhibition of larval migration and the exsheathment process of Trichostrongylus colubriformis infective stage. Vet. Parasitol. 153, 187-192 
4) Alonso-Diaz, M.A., Torres-Acosta, J.F.J., Sandoval-Castro, C.A., Hoste, H., 2010a. Tannins in tanniniferous tree fodders fed to small ruminants: a friendly foe? Small Ruminant Res. 89, 164 173.

5) Alonso-Díaz M.A., Torres-Acosta J.F.J., Sandoval-Castro C.A., Capetillo-Leal, C.M., 2010b. Polyphenolic compounds of nutraceutical trees and the variability of their biological activity measured by two methods. Trop. Subtrop. Agroecosyst. 12, 649-656.

6) Alonso-Díaz, M.A., Torres-Acosta, J.F.J., Sandoval-Castro, C.A., Hoste, H., 2011. Comparing the sensitivity of two in vitro assays to evaluate the anthelmintic activity of tropical tannin rich plant extracts against Haemonchus contortus. Vet. Parasitol. 181, 360-364.

7) Amit, M., Cohen, I., Marcovics, A., Muklada, H., Glasser, T.A., Ungar, E.D. Landau,S.Y., 2013. Self-medication with tannin-rich browse in goats infected with gastro-intestinal nematodes. Vet. Parasitol., 198, 305-311

8) Andlauer, W., Fürst, P., 2002. Nutraceuticals: a piece of history, present status and outlook. Food Res. 35, 171-176.

9) Arroyo-Lopez, C., Hoste, H ., Manolaraki, F., Saratsis A., Saratsi K., Stefanakis, A., Skampardonis, V., Voutzourakis, N., Sotiraki, S., 2014. Compared effects of two tannin rich resources carob (Ceratonia siliqua) and sainfoin (Onobrychis viciifolia) on the experimental trickle infections of lambs with Haemonchus contortus and Trichostrongylus colubriformis. Parasite 21, 71-80.

10) Athanasiadou, S., Kyriazakis, I., Jackson, F., Coop, R.L., 2001. Direct anthelmintic effects of condensed tannins towards different gastrointestinal nematodes of sheep: in vitro and in vivo studies. Vet. Parasitol. 99, 205-219.

11) Athanasiadou, S., Gray, D., Younie, D., Tzamaloukas, O., Jackson, F., Kyriazakis, I., 2007. The use of chicory for parasite control in organic ewes and their lambs. Parasitology 134, 299-307.

12) Azuhnwi, B.N., Boller, B., Dohme-Meier, F., Hess, H.D., Kreuzer, M., Stringano, E., Mueller-Harvey, I., 2013a. Exploring variation in proanthocyanidin composition and content of sainfoin (Onobrychis viciifolia). J. Sci. Food Agric. 93, 2102-2109. 
13) Azuhnwi, B. N., H. Hertzberg, H., Arrigo, Y., Gutzwiller, A., Hess, H. D., I. Mueller-Harvey, I., Torgerson, P.R., Kreuzer, M., Dohme-Meier, F., 2013b. Investigation of sainfoin (Onobrychis viciifolia) cultivar differences on nitrogen balance and fecal egg count in artificially infected lambs. J. An. Sci., 91, 2343-2354.

14) Bahuaud, D., Martinez-Ortiz-de-Montellano, C., Chauveau, S., Prevot, F., Torres-Acosta, J.F.J., Fouraste, I., Hoste, H., 2006. Effects of four tanniferous plant extracts on the in vitro exsheathment of third-stage larvae of parasitic nematodes. Parasitology 132, 545-554.

15) Brunet, S., Hoste, H., 2006. Monomers of condensed tannins affect the larval exsheathment of parasitic nematodes of ruminants. J. Agri. Food Chem. 54, 7481-7487.

16) Brunet, S., Aufrère, J., El Babili, F., Fouraste, I., Hoste, H., 2007.The kinetics of exsheathment of infective nematode larvae is disturbed in the presence of a tannin-rich plant extract (sainfoin) both in vitro and in vivo. Parasitology 134, 1253-1262.

17) Brunet, S., Martinez-Ortiz De Montellano, C. Torres-Acosta, J.F.J., Sandoval-Castro, C.A., Aguilar Caballero, A.J., Capetillo-Leal, C.M., Hoste, H., 2008. Effect of the consumption of Lysiloma latisilliquum on the larval establishment of parasitic nematodes in goats Vet Parasitol, 157, 8188.

18) Burke, J.M, Miller, J.E., Terrill, T.H., Orlik, S.T, Acharya, M, Garza, J.J, Mosjidis, J.A., 2013. Sericea lespedeza as an aid in the control of Eimeria spp. in lambs. Vet. Parasitol.193, 39-46.

19) Castañeda-Ramírez, G.S.,Torres-Acosta, J.F J., Mendoza-de-Gives, P., Chan-Pérez, J.I., Tun-Garrido, J., Rosado-Aguilar, J.A., 2014. In vitro anthelmintic effect of the foliage from three plant species of the Annonaceae family against Haemonchus contortus. $13^{\text {th }}$ International Congress of Parasitology. August 10-15, 2014. México city, México.

20) Cenci, F.B, Louvandini, H., McManus, C.M. , Dell'Porto, A., Costa, D.M., Arau'jo, S.C., Minho, A.P., Abdalla, A.L., 2007. Effects of condensed tannin from Acacia mearnsii on sheep infected naturally with gastrointestinal helminthes. Vet Parasitol. 144, 132-137

21) Coop, R.L., Kyriazakis, I.K., 1999. Nutrition-parasite interactions. Vet. Parasitol. 84, 187-204. 
22) Covarrubias-Cárdenas, A.G., Torres-Acosta, J.F.J, Sandoval-Castro, C.A., Hoste, H., 2013. In vitro anthelmintic effect of Acacia pennatula and Coffea arabica extracts on Haemonchus contortus sensitive to tannins. 7th Novel Approaches to the Control of Helminths of Livestock "Bridges between scientific advances and farm development". 25-28th March. Toulouse, France.

23) Desrues, O., Vargas-Magaña, J.J., Girard, M., Manolaraki, F., Pardo, E., Mathieu, C., Vilarem, G., Torres-Acosta, J.F.J., Sandoval-Castro, C.A., Jean, H., Hoste H., 2012. Can hazel-nut peels be used to control gastrointestinal nematodes in goats? XIth International Goat Conference Las Canarias Sept 2012

24) Foster, J.G., Clapham, W.M., Belesky, D.P., Labreveux, M., Hall, M.H., Sanderson, M.A., 2006. Influence of cultivation site on sesquiterpene lactone composition of forage chicory (Cichorium intybus L.). J. Agric. Food Chem. 54, 1772-1778.

25) Foster, J.G., Cassida, K.A., Sanderson, M.A., 2011a . Seasonal variations in sesquiterpene lactone concentrations and composition of forage chicory (Cichorium intybus L.) cultivars. Grass Forage Sci. $66,424-433$.

26) Foster, J.G., Joyce, G., Cassida, K.A., Turner K.E., 2011b. In vitro analysis of the anthelmintic activity of forage chicory (Cichorium intybus L.) sesquiterpene lactones against a predominantly Haemonchus contortus egg populations. Vet Parasitol. 180, 296-306.

27) Frutos, P., Moreno-Gonzalo, J., Hervás, G., García, U., Ferreira, L.M.M., Celaya, R., Toral, P.G., Ortega-Mora, L.M., Ferre, I., Osoro, K., 2008. Is the anthelmintic effect of heather supplementation to grazing goats always accompanied by anti-nutritional effects ? Animal. 2, $1449-1456$.

28) Galicia-Aguilar, H.H., Rodríguez-González, L.A., Capetillo-Leal, C.M., Cámara-Sarmiento, R., Aguilar-Caballero, A.J., Sandoval-Castro, C.A., Torres-Acosta, J.F.J., 2012. Effect of Havardia albicans supplementation on feed consumption and dry matter digestibility of sheep and the biology of Haemonchus contortus. Anim. Feed Sci. Technol. 176, 178-184. 
29) Gea, A., Stringano, E., Brown, R.H., Mueller-Harvey, I., 2011. In situ analysis and structural elucidation of sainfoin (Onobrychis viciifolia) tannins for high throughput germplasm screening. J. Agric. Food Chem. 59, 495-503.

30) Girard M., Gaid S., Mathieu C., Vilarem G., Gerfault V., Routier M., Gombault P., Pardo E., Manolaraki F., Hoste H., 2013. Effects of different proportions of sainfoin pellets combined with hazel nut peels on infected lambs. 64th EAAP Nantes, 26th -30th August 2013, Page 506

31) Gujja S., Terrill, T.H., Mosjidis, J.A, Miller, J.E., Mechineni A., Kommuru D.S., Shaik S.A., Lambert B.D., Cherry, N.M., Burke, J.M., 2013. Effect of supplemental sericea lespedeza leaf meal pellets on gastro intestinal nematode infection in grazing goats. Vet. Parasitol. 191, 51-58.

32) Hammond, J.A., Fielding, D., Bishop, S.C., 1997. Prospects for plant anthelmintics in tropical veterinary medicine. Vet. Res. Commun. 21, 213-228.

33) Hasler, C.M, 1998. Functional foods: their role in disease prevention and health promotion. Food Tech. 52, 63-70.

34) Heckendorn, F., Häring, D.A.; Maurer, V., Zinsstag, J., Langhans W., Hertzberg, H., 2006.Effect of sainfoin (Onobrychis viciifolia) silage and hay on established populations of Haemonchus contortus and Cooperia curticei in lambs. Vet. Parasitol, 142, 293-300.

35) Heckendorn, F., Haring, D.A., Maurer, V., Senn, M., Hertzberg, H., 2007. Individual administration of three tanniferous forage plants to lambs artificially infected with Haemonchus contortus and Cooperia curticei. Vet. Parasitol. 146, 123-134.

36) Hernández-Orduño, G., Torres-Acosta, J.F.J., Sandoval-Castro, C., Aguilar-Caballero, A,J. ReyesRamirez, R.R., Hoste, H., Calderón-Quintal, J.A., 2008. In vitro anthelmintic effect of Acacia gaumeri, Havardia albicans and Quebracho tannin extracts on a Mexican strain of Haemonchus contortus L3 larvae. Trop. Subtrop. Agroecosystems. 8, 191-197.

37) Hoste, H., Jackson, F., Athanasiadou, S.; Thamsborg, S.M., Hoskin, S., 2006. The effects of tanninrich plants on parasitic nematodes in ruminants. Trends Parasitol, 22, 253- 261. 
38) Hoste, H., Sotiraki, S., Landau, S.Y., Jackson, F., Beveridge, I., 2010. Goat nematode interactions: Think differently! Trends Parasitol, 36, 376-381.

39) Hoste, H., Torres-Acosta, J.F.J., 2011. Non chemical control of helminths in ruminants: Adapting solutions for changing worms in a changing world. Vet. Parasitol., 180, 144-154.

40) Hoste, H., Martinez-Ortiz-de-Montellano, C., Manolaraki, F., Brunet, S., Ojeda-Robertos, N., Fourquaux, I., Torres-Acosta, J.F.J., Sandoval-Castro, C.A., 2012.Direct and indirect effects of bioactive tannin-rich tropical and temperate legumes against nematode infection. Vet. Parasitol., $186,18-27$.

41) Jackson, F., Varady, M., Bartley, D.J., 2012. Managing anthelmintic resistance in goats - Can we learn lessons from sheep ? Small Rum. Res. 103, 3-9.

42) Jackson, F., Hoste, H., 2010. In vitro methods for the primary screening of plant products for direct activity against ruminant gastrointestinal nematodes. In: Vercoe, P.E.; Makkar, H.P.S.; Schlink, A.C. (Eds.), In vitro screening of Plant Resources for Extra Nutritional Attributes in Ruminants: Nuclear and Related Methodologies, FAO/IAEA Springer Edition. 2010, pp 24-45.

43) Joshi, B.R., Kommuru, D.S., Terrill, T.H., Mosjidis, J.A., Burke, J.M., Shakya, K.P., Miller, J.E., 2011. Effect of feeding sericea lespedeza leaf meal in goats experimentally infected with Haemonchus contortus. Vet. Parasitol. 178, 192-197.

44) Juhnke J., Miller, J.E., Hall J.O., Provenza, F.D., Villalba, J.J., 2012. Preference for condensed tannins by sheep in response to challenge infection with Haemonchus contortus Vet. Parasitol, $188,104-114$.

45) Kahiya, C., Mukaratirwa, S.,Thamsborg, S.M., 2003. Effects of Acacia nilotica and Acacia karroo diets on Haemonchus contortus infection in goats. Vet. Parasitol. 115, 265-274.

46) Kaplan, R.M., 2004. Drug resistance in nematodes of veterinary importance: a status report. Trends Parasitol. 20, 477-481.

47) Kaminsky, R., Gauvry, N., Schorderet Weber, S., Skripsky, T., Bouvier, J.,Wenger, A., Schroeder, F., Desaules, Y., Hotz, R., Goebel, T., Hosking, C.B., Pautrat, F., Wieland-Berghausen, S., Ducray, P., 

2008. Identification of the amino-acetonitrile derivative monepantel (AAD 1566) as a new anthelmintic drug development candidate. Parasitol. Res. 103, 931-939.

48) Katiki, L.M., Ferreira J. F.S., Gonzalez Javier M., Zajac, A. M., Lindsay, D.S., Chagas A. C. S., Amarante A. F.T., 2013. Anthelmintic effect of plant extracts containing condensed and hydrolyzable tannins on Caenorhabditis elegans, and their antioxidant capacity Vet. Parasitol. $192,218-227$.

49) Katiki, L.M., Ferreira, J.F.S., Zajac, A.M., Masler, C., Lindsay, D.S., Chagas, A.C.S., Amarante, A.F.T., 886 2012. Caenorhabditis elegans as a model to screen plant extracts and compounds as natural anthelmintics for veterinary use. Vet. Parasitol. 182, 264-268.

50) Klongsiriwet, C., Quijada, J., Williams, A.R., Williamson, E., Mueller-Harvey, I., Hoste, H., 2015. Synergistic inhibition of Haemonchus contortus exsheathment by flavonoid monomers and condensed tannins. Int. J. Parasitol, Drugs and Drug Resistance, Submitted for publication

51) Kommuru, D.S., Barker, T., Desai, S., Burke, J.M., Ramsay, A., Mueller-Harvey, I., Miller, J.E., Mosjidis, J.A., Kamisetti, N., Terrill, T.H., 2014. Use of pelleted sericea lespedeza (Lespedeza cuneata) for natural control of coccidian and gastrointestinal nematodes in weaned goats. Vet.

52) Lisonbee, L.D., Villalba, J.J, Provenza, F.D., Hall, J.O., 2009. Tannins and self-medication: Implications for sustainable parasite control in herbivores. Behav. Proc. 82,184-189

53) Makkar, H. P., 2003. Quantification of tannins in tree and shrub foliages. In "A Laboratory (FAO/IAEA), pp. 49-53.

54) Manolaraki, F., Sotiraki, S., Skampardonis, V., Volanis, M., Stefanakis, A., Hoste, H., 2010. 
55) Manolaraki, F., 2011. Propriétés anthelminthiques du sainfoin (Onobrychis viciifoliae): Analyse des facteurs de variations et du rôle des composés phénoliques impliqués. 21st Jan 2011. INP Toulouse

56) Markovics, A., Cohen, I., Muklada, H., Glasser, T.A., Dvash, L., Ungar,E.D., Azaizeh, H., Landau, S.Y., 2012. Consumption of Pistacia lentiscus foliage alleviates coccidiosis in young goats. Vet. Parasitol. 186,165-169.

57) Martínez-Ortíz-De-Montellano, C., Vargas-Magana, J.J., Canul-Ku, H.L., Miranda-Soberanis, R., Capetillo-Leal, C., Sandoval-Castro, C.A., Hoste, H., Torres-Acosta, J.F.J., 2010. Effect of a tropical 58) tannin-rich plant, Lysiloma latisiliquum, on adult populations of Haemonchus contortus in sheep. Vet. Parasitol. 172, 283-290.

59) Mechineni, A., Kommuru, D.S., Gujja, S., Mosjidis, J.A., Miller, J.E., Burke, J.M., Ramsay, A., Mueller-Harvey, I., Kannan, G., Lee, J.H., Kouakou, B., Terrill, T.H., 2014. Effect of fall-grazed sericea lespedeza (Lespedeza cuneata) on gastrointestinal nematode infections of growing goats. Vet. Parasitol. 29, 221-228.

60) Méndez-Ortíz, F.A., Sandoval-Castro, C.A., Torres-Acosta, J.F.J., 2012. Short term consumption of Havardia albicans tannin rich fodder by sheep: Effects on feed intake, diet digestibility and excretion of Haemonchus contortus eggs. Anim. Feed Sci. Tech. 176, 185-191

61) Min, B.R., Hart, S.P., 2003. Tannins for suppression of internal parasites. J. Anim. Sci. 81, 102109.

62) Minho, A.P., Bueno, I.C.S., Louvandini, H., Jackson, F., Gennari, S.M., Abdalla A.L., 2008. Effect of Acacia molissima tannin extract on the control of gastrointestinal parasites in sheep. An. Feed Sci. Techn. 147, 172-181.

63) Molan, A.L., Meagher, L.P., Spencer, P.A., Sivakumaran, S., 2003a.Effect of flavan-3-ols in vitro hatching, larval development and viability of infective larvae of Trichostrongylus colubriformis. Int. J. Parasitol. 33, $1691-1698$. 
64) Molan, A.L., Duncan, A.J., Barry, T.N., McNabb, W.C., 2003b. Effect of condensed tannins and crude sesquiterpene lactones extracted from chicory on the motility of larvae of deer lungworms and gastrointestinal nematodes. Parasitol. Int. 52, 209-218.

65) Molan, A.L., Sivakumaran, S., Spencer, P.A., Meagher, L.P., 2004. Green tea flavan-3-ols and oligomeric proanthocyanidins inhibit the motility of infective larvae of Teladorsagia circumcincta and Trichostrongylus colubriformis in vitro. Res Vet. Sci. 77, 239-243.

66) Moreno-Gonzalo, J, Manolaraki, F., Frutos, P., Hervás, G., Celaya, R., Osoro, K., Ortega-Mora, L.M., Hoste, H., Ferre, I., 2013. In vitro effect of heather (Ericaceae) extracts on different development stages of Teladorsagia circumcincta and Haemonchus contortus. Vet. Parasitol. 197, 235-243.

67) Moreno-Gonzalo, J., Ferre, I., Celaya, R., Frutos, P., Ferreira, L.M.M., Hervás, G., García, U., Ortega-Mora, L.M., Osoro, K., 2012. Potential use of heather to control gastrointestinal nematodes in goats. Small Rumin. Res. 103, 60-68.

68) Moreno-Gonzalo, J., Osoro, K., García, U., Frutos, P., Celaya, R., Ferreira, L.M.M., Ortega-Mora, L.M., Ferre, I., 2014.Anthelmintic effect of heather in goats experimentally infected with Trichostrongylus colubriformis. Parasitol Res. 113, 693-699.

69) Mueller-Harvey, I., Dhanoa, M.S., 1991. Varietal differences among sorghum crop residues in relation to their phenolic HPLC fingerprints and responses to different environments. J. Sci. Food Agric. 57, 199-216.

70) Mueller-Harvey, I., 2006. Unravelling the conundrum of tannins in animal nutrition and health. J. Sci. Food Agric. 86, 2010-2037.

71) Muir, J.P., Terrill, T.H., Kamisetti, N.R., Bow, J.R., 2014. Environment, Harvest Regimen, and Ontogeny Change Lespedeza cuneata Condensed Tannin and Nitrogen. Crop Sci. 54, 2903-2909.

72) Murare, U., Chimonyo, M, Dzama, K., 2012. Influence of dietary supplementation with Acacia karroo on experimental haemonchosis in indigenous Xhosa lop-eared goats of South Africa. Livestock Sci. 144, 132-139. 
73) Nielsen, B.K., Thamsborg, S.M., Hansen, H. Ranving, H., Hogh-Jensen, H., 2009. Effects of including chicory in perennial ryegrass-white clover on production and health in organic lambs. Livestock Sci. 125, 66-73.

74) Niezen, J.H., Waghorn, T.S., Charleston, W.A.G., Waghorn, G.C., 1995. Growth and gastrointestinal nematode parasitism in lambs grazing either lucerne (Medicago sativa) or sulla (Hedysarum coronarium) which contains condensed tannins. J. Agric. Sci. 125, 281-289.

75) Niezen, J.H., Warghorn, G.C., Charleston, W.A.G., 1998. Establishment and fecundity of Ostertagia circumcincta and Trichostrongylus colubriformis in lambs fed lotus (Lotus pedunculatus) or perennial ryegrass (Lolium perenne). Vet. Parasitol. 78, 13-21.

76) Niezen, J.H., Waghorn, G.C., Graham, T., Carter, J.I., Leathwick, D.M., 2002. The effect of diet fed to lambs on subsequent development of Trichostrongylus colubriformis larvae in vitro and on pasture. Vet. Parasitol. 105, 269-283.

77) Novelo-Chi, L.K., González-Pech, P.G., Ventura-Cordero, J., Torres-Acosta, J.F.J., Sandoval-Castro, C.A., 2014. Feeding behaviour in dewormed goats vs naturally infected by gastrointestinal nematodes at free grazing of a deciduous tropical forest. Trop. Subtrop. Agroecosyst. 17, 332333.

78) Novobilský, A., Mueller-Harvey, I., Thamsborg, S.M., 2011. Condensed tannins act against cattle nematodes. Vet. Parasitol. 182, 213-220.

79) Novobilský, A., Stringano, E., Hayot-Carbonero, C., Smith, L.M.J., Enemark, H.L., Mueller-Harvey, I. Thamsborg, S.M., 2013. In vitro effect of extracts and purified tannins of sainfoin (Onobrychis viciifolia) against two cattle nematodes. Vet. Parasitol. 196, 532-537.

80) Oliveira, L.M.B., Macedo, I.T.F., Vieira, L.S., Camurca-Vasconcelos, A.L.F., Tome, A.R., Sampaio, R.A., Louvandini, H., Bevilaqua, C.M.L., 2013. Effects of Mimosa tenuiflora on larval establishment of Haemonchus contortus in sheep. Vet. Parasitol. 196, 341-346.

81) Osoro, K., Celaya, R., Moreno-Gonzalo, J., Ferreira, L.M.M., García, U., Frutos, P., Ortega-Mora, L.M., Ferre, I., 2009. Effects of stocking rate and heather supplementation on gastrointestinal 
nematode infections and host performance in naturally-infected Cashmere goats. Rangel. Ecol. Manage. 62, 127-135.

982

983

984

985

986

987

988

989

990

991

992

993

994

995

996

997

998

82) Paolini, V., Frayssines, A., De-La-Farge, F., Dorchies, Ph., Hoste, H., 2003. Effects of condensed tannins on established populations and on incoming larvae of Trichostrongylus colubriformis and Teladorsagia circumcincta in goats. Vet. Res. 34, 331-339.

83) Paolini, V., Fouraste, I., Hoste, H., 2004. In vitro effects of three woody plant and sainfoin extracts on two parasitic stage of three parasitic nematode species. Parasitology 129, 69-77.

84) Paolini, V., De-La-Farge, F., Prevot, F., Dorchies, Ph., Hoste, H., 2005. Effects of the repeated distribution of sainfoin hay on the resistance and the resilience of goats naturally infected with gastrointestinal nematodes. Vet. Parasitol. 127, 277-283.

85) Quijada, J., Fryganas, C., Ropiak, H., Ramsay, A., Mueller-Harvey, I., Hoste, H., 2015.

Anthelmintic activities against Haemonchus contortus or Trichostrongylus colubriformis are influenced by different structural features of condensed tannins J. Agr. Food Chem. Accepted for publication.

86) Retama-Flores, C., Torres-Acosta, J.F.J., Sandoval-Castro., C.A., Aguilar-Caballero, A.J., CámaraSarmiento, R., Canul-Ku, H.L., 2012. Maize supplementation of Pelibuey sheep in a silvopastoral system: fodder selection, nutrient intake and resilience against gastrointestinal nematodes. Animal 6, 145-153.

87) Rios de Alvarez, L., Greer, A.W., Jackson, F., Athanasiadou, S., Kyriazakis, I., Huntley, J.F., 2010. The effect of dietary sainfoin (Onobrychis viciifolia) on local cellular responses to Trichostrongylus colubriformis in sheep. Parasitology 135, 1117-1124.

88) Rochfort, S., Parker, A.J., Dunshea, F.R., 2008. Plant bioactives for ruminant health and productivity. Phytochemistry 69, 299-322.

89) Salajpal, K., Karolyi, D., Beck, R., Kis, G., Vickovic, I., Điki c, M., Kovacic, D., 2004. Effect of acorn (Quercus robur) intake on faecal egg count in outdoor reared black slavonian pig. Acta Agric. Slovenica (supplement) 1, 173-178. 
90) Sandoval-Castro C.A., Torres-Acosta, J.F.J., Hoste, H., Salem, A.F., Chan-Pérez, J.I., 2012. Using plant bioactive materials to control gastrointestinal tract helminths in livestock. An. Feed Sci. Techn. 176, 192-201.

91) Saratsis, A., Regos, I., Tzanidakis, N., Voutzourakis, N., Stefanakis, A., Treuter, D., Joachim, A., Sotiraki, S., 2012. In vivo and in vitro efficacy of sainfoin (Onobrychis viciifolia) against Eimeria spp in lambs. Vet. Parasitol. 188, 1-9.

92) Shaik, S.A., Terrill, T.H., Miller, J.E., Kouakou, B., Kannan, G., Kaplan, R.M., Burke, J.M., Mosjidis, J.A., 2006. Sericea lespedeza hay as a natural deworming agent against gastrointestinal nematode infection in goats. Vet. Parasitol. 139, 150-157.

93) Stringano, E., Hayot Carbonero, C., Smith, L.M.J., Brown, R.H., Mueller-Harvey, I., 2012. Proanthocyanidin diversity in the EU 'HealthyHay'sainfoin (Onobrychis viciifolia) germplasm collection. Phytochemistry, 77, 197-208.

94) Terrill, T.H., Miller, J.E., Burke, J.M., Mosjidis, J.A., Kaplan, R.M., 2012. Experiences with integrated concepts for the control of Haemonchus contortus in sheep and goats in the United States. Vet. Parasitol. 186, 28-37.

95) Terrill, T.H., Mosjidis, J.A., Moore, D.A., Shaik, S.A., Miller, J.E., Burke, J.M., Muir, J.P., Wolfe, R., 2007. Effect of pelleting on efficacy of sericea lespedeza hay as a natural dewormer in goats. Vet. Parasitol. 146:117-122.

96) Terrill, T.H., Dykes, G.S., Shaik, S.A., Miller, J.E., Kouakou, B., Kannan, G., Burke, J.M., Mosjidis, J.A., 2009. Efficacy of sericea lespedeza hay as a natural dewormer in goats: dose titration study. Vet. Parasitol. 163, 52-56.

97) Thamsborg, S.M., Roepstorff, A., Larsen M., 1999. Integrated and biological control of parasites in organic and conventional production systems. Vet. Parasitol. 84, 169-186.

98) Torres-Acosta, J.F.J., Mendoza-de-Gives, P., Aguilar-Caballero, A.J., Cuéllar-Ordaz, J.A., 2012. Anthelmintic resistance in sheep farms: update of the situation in the American continent. Vet. Parasitol. 189, 89-96. 
1032

1033

1034

1035

1036

1037

1038

1039

1040

1041

1042

1043

1044

1045

1046

1047

1048

1049

1050

1051

1052

1053

1054

1055

1056

1057

99) Tzamaloukas, O., Athanasiadou, S., Kyriazakis, I., Huntley, J., 2006. The effect of chicory (Cichorium intybus) and sulla (Hedysarum coronarium) on larval development and mucosal cell responses of growing lambs challenged with Teladorsagia circumcincta. Parasitology 132, 419426.

100) Tzamaloukas, O., 2006b. The use of bioactive forages towards organic/sustainable control of gastrointestinal parasites in sheep. PhD University of Edinburgh 19th Sept. 2006.

101) Van-den-Brom, R., Moll, L., Kappert, C., Vellema, P., 2015. Haemonchus contortus resistance to monepantel in sheep. Vet. Parasitol. 209, 278-280.

102) Vargas-Magaña, J.J., Aguilar-Caballero, A.J., Torres-Acosta, J.F.J., Sandoval-Castro, C.A., Hoste, H., Capetillo-Leal, C.M., 2013. Tropical tannin rich fodder intake modifies saliva-binding capacity in growing sheep. Animal 7, 1921-1924.

103) Vargas-Magaña, J.J., Torres-Acosta, J.F.J., Aguilar-Caballero, A.J., Sandoval-Castro, C.A., Hoste, H., Chan-Pérez, J.I., 2014a. Anthelmintic activity of acetone-water extracts against Haemonchus contortus eggs: Interactions between tannins and other plant secondary compounds. Vet Parasitol. 206, 322-327.

104) Vargas-Magaña, J.J.; Torres-Acosta, J.F.J.; Aguilar-Caballero, A.J.; Sandoval-Castro, C.A.; Hoste, H.; Chan-Pérez, J.I., Mathieu, C., Vilarem, G., 2014b. In vitro susceptibility to tannin rich extracts differs amongst Haemonchus contortus isolates from tropical and temperate regions. $13^{\text {th }}$ International Congress of Parasitology. August 10-15, 2014. México city, México.

105) Ventura-Cordero, J., González-Pech, P.G., Novelo-Chi, L.K., Torres-Acosta, J.F.J., SandovalCastro, C.A., 2014a. Resource selection by browsing of criollo goats in the decideous tropical forest of Yucatan, Mexico. Trop. Subtrop. Agroecosyst. 17, 328-329.

106) Ventura-Cordero, J., González-Pech, P.G., Torres-Acosta, J.F.J., Sandoval-Castro, C.A., 2014b. Feeding behaviour of sheep and goats in the decideous tropical forest during the rainy season. Trop. Subtrop. Agroecosyst. 17, 330-331.

107) Villalba, J.J., Provenza, F. D., 2007. Self-medication and homeostatic behaviour in herbivores: 
108) Villalba J.J., Miller J., Hall J.O., Clemensen A.K., Stott R., Snyder D., Provenza F.D., 2013 Preference for tanniferous (Onobrychis viciifolia) and non-tanniferous (Astragalus cicer) forage plants by sheep in response to challenge infection with Haemonchus contortus. Small Rum. Res. 112, 199-207.

109) Villalba, J.J, Miller, J., Ungar, E., Landau S.Y., Glendinning, J., 2014. Ruminant self-medication against gastrointestinal nematodes: evidence, mechanism and origins. Parasite 21, 31 .

110) von Son-de Fernex, E., Alonso-Díaz, M.A., Valles-de la Mora, B., Capetillo-Leal, C.M., 2012. In vitro anthelmintic activity of five tropical legumes on the exsheathment and motility of Haemonchus contortus infective larvae. Exp. Parasitol. 131, 413-418

111) Waghorn, G., 2008. Beneficial and detrimental effects of dietary condensed tannins for sustainable sheep and goat production-Progress and challenges. An. Feed Sci. Technol. 147, 116-139.

112) Waller, P.J., Thamsborg, S.M., 2004. Nematode control in "green" ruminant production system. Trends Parasitol. 20, 493-497.

113) Waller, P.J., 2006. From discovery to development: current industry perspectives for the development of novel methods of helminth control in livestock. Vet. Parasitol. 139, 1-14.

114) Wang, Y., McAllister, T.A., Acharya, S., 2015. Condensed tannins in sainfoin: composition, concentration and effects on nutritive and feeding value of sainfoin forage. Crop Science, 55, $13-$

115) Weyl-Feinstein, S., Markovics, A., Eitam, H., Orlov, A., Yishay, M., Agmon, R., Miron, J., Izhaki, 
117) Williams, A.R., Ropiak, H.M., Fryganas, C., Desrues, O., Mueller-Harvey, I., Thamsborg, S.M., 2014a. Assessment of the anthelmintic activity of medicinal plant extracts and purified condensed tannins against free-living and parasitic stages of Oesophagostomum dentatum. Parasites \& Vectors 2014, 7:518 http://www.parasitesandvectors.com/content/7/1/518

118) Williams, A.R., Fryganas, C., Ramsay, A., Mueller-Harvey, I., Thamsborg, S.M., 2014b. Direct anthelmintic effects of condensed tannins from diverse plant sources against Ascaris suum. PLos ONE. 9(5):e97053.doi:10.1371/journal.pone.0097053

119) Wood, I.B., Amaral, N.K., Bairden, K., Duncan, J.L., Kassai, T., Malone Jr., J.B., Pankavich, J.A., Reinecke, R.K., Slocombe, O., Taylor, S.M., Vercruysse, J., 1995. World Association for the Advancement of Veterinary Parasitology (W.A.A.V.P.) second edition of guidelines for evaluating the efficacy of anthelmintics in ruminants (bovine, ovine, caprine). Vet. Parasitol. 58, 181-213.

120) Xhomfulana, V., Mapiye, C., Chimonyo, M., Marufu, M.C., 2009. Supplements containing Acacia karroo foliage reduce nematode burdens in Nguni and crossbred cattle. Anim. Prod. Sci. $49,646-653$. 
Table 1: The criteria defining the main concepts of xenobiotics and plant secondary metabolites for controlling gastrointestinal nematodes of livestock (VFI = voluntary feed intake).

\begin{tabular}{|c|c|c|c|c|}
\hline $\begin{array}{l}\text { Nature of the } \\
\text { bioactive } \\
\text { compounds }\end{array}$ & \multicolumn{2}{|c|}{ Synthetic chemical compounds } & \multicolumn{2}{|c|}{$\begin{array}{l}\text { Natural chemical compounds } \\
\text { (Plant secondary metabolites) }\end{array}$} \\
\hline Formulations & $\begin{array}{l}\text { Therapeutic } \\
\text { drugs }\end{array}$ & $\begin{array}{c}\text { Chemical additives } \\
\text { (supplements) }\end{array}$ & Herbal drugs & Nutraceuticals \\
\hline \multirow[t]{3}{*}{$\begin{array}{l}\text { Mode of } \\
\text { administration }\end{array}$} & $\begin{array}{c}\text { Forced } \\
\text { Administration }\end{array}$ & $\begin{array}{l}\text { Added to the } \\
\text { feed }\end{array}$ & $\begin{array}{c}\text { Forced } \\
\text { administration }\end{array}$ & $\begin{array}{l}\text { PSMs Included in and/or } \\
\text { added to the feed }\end{array}$ \\
\hline & $\begin{array}{c}\text { Independent } \\
\text { of VFI }\end{array}$ & Dependent of VFI & $\begin{array}{l}\text { Independent of } \\
\text { VFI }\end{array}$ & $\begin{array}{l}\text { Dependent of Voluntary Feed } \\
\text { Intake (VFI) }\end{array}$ \\
\hline & $\begin{array}{l}\text { Short term } \\
\text { Well defined } \\
\text { posology }\end{array}$ & $\begin{array}{l}\text { Long term } \\
\text { Posology defined by a } \\
\text { range within the feed }\end{array}$ & Short term & Long term \\
\hline Objective & $\begin{array}{l}\text { Curative / } \\
\text { (preventive) }\end{array}$ & Preventive & $\begin{array}{c}\text { Curative/ } \\
\text { (preventive) }\end{array}$ & $\begin{array}{l}\text { Preventive/ } \\
\text { ( curative) }\end{array}$ \\
\hline $\begin{array}{l}\text { Quality of the } \\
\text { active } \\
\text { compounds }\end{array}$ & $\begin{array}{c}\text { Standardised } \\
\text { Identified }\end{array}$ & $\begin{array}{l}\text { Standardised } \\
\text { Identified }\end{array}$ & $\begin{array}{l}\text { Variable } \\
\text { Usually non } \\
\text { identified }\end{array}$ & $\begin{array}{l}\text { Variable } \\
\text { Identification of the family of } \\
\text { phytochemical compounds }\end{array}$ \\
\hline $\begin{array}{l}\text { Mode of } \\
\text { action }\end{array}$ & $\begin{array}{l}\text { Usually, well } \\
\text { identified }\end{array}$ & $\begin{array}{l}\text { Usually, well } \\
\text { identified }\end{array}$ & Unknown & Hypotheses \\
\hline $\begin{array}{l}\text { Development } \\
\text { of resistance }\end{array}$ & High & High & Unknown & Suspected \\
\hline
\end{tabular}


FIGURE 1: A proposed model of the components defining the concept of nutraceuticals against gastrointestinal parasites in livestock

FIGURE 2: The different in vitro assays available to screen the AH effects of potential nutraceuticals (see Jackson and Hoste, 2010), EHA: Egg Hatching Assay; LFIA: Larval Feeding Inhibition Assay; LDIA: Larval Development Inhibition Assay; LMIA: Larval Migration Inhibition Assay; LEAI : Larval Exsheathment Inhibition Assay; AMIA: Adult Motility Inhibition Assay; C. elegans: Assays developed using the $C$. elegans model of free living nematodes.

FIGURE 3: Three key stages of the GIN life cycle have been identified as possible targets when tanniniferous plants are consumed by infected small ruminants: 1 / a reduced excretion of nematode eggs by the adult worms (maximum values up to $80 \%$ reduction) (Shaik et al., 2006); 2 / a reduced establishment of the infective third-stage larvae in the host (up to $70 \%$ ) (Brunet et al, 2008); and 3/ a reduced development of eggs to third-stage larvae (maximum values of reduction up to $90 \%$ ) (Niezen et al., 2002). 
FIGURE 1

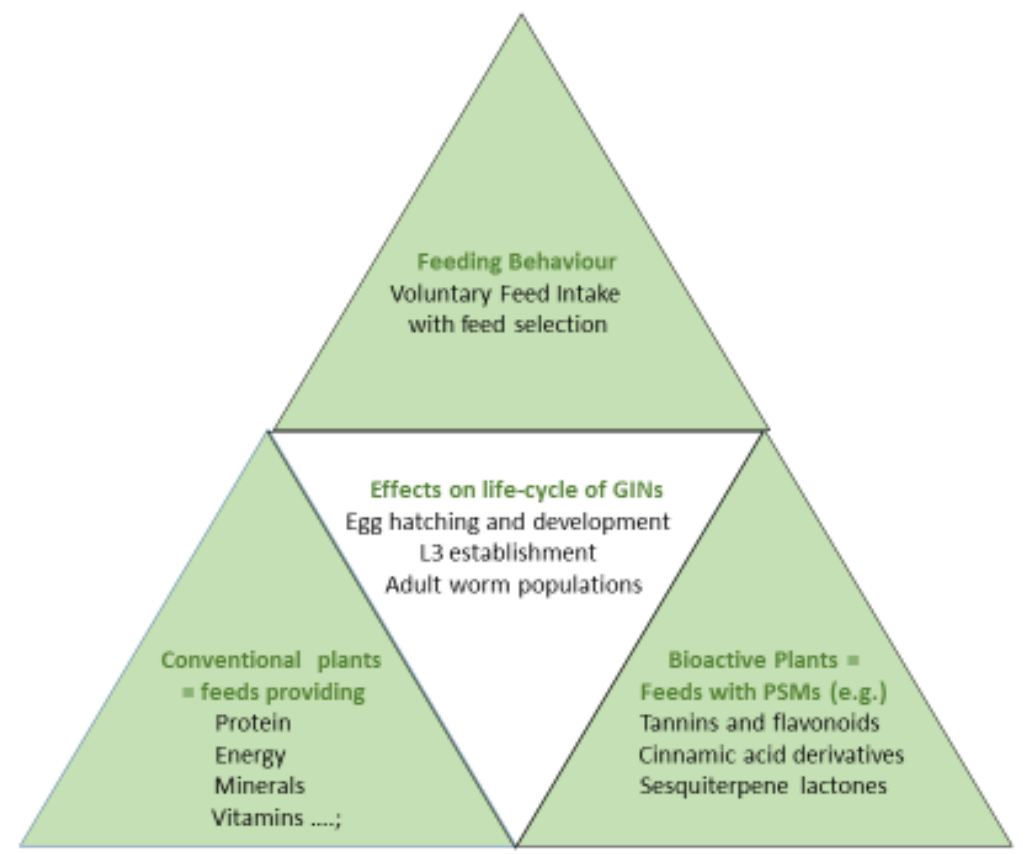


FIGURE 2

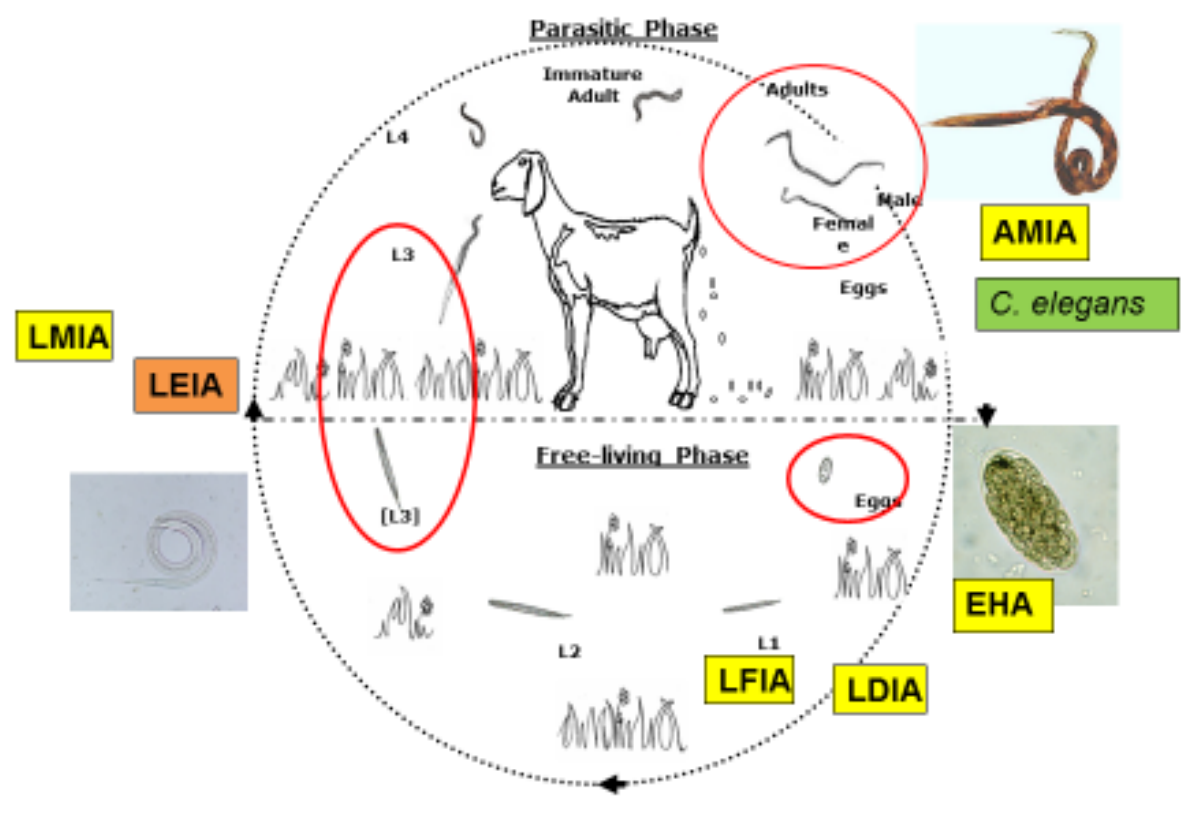

FIGURE 3 


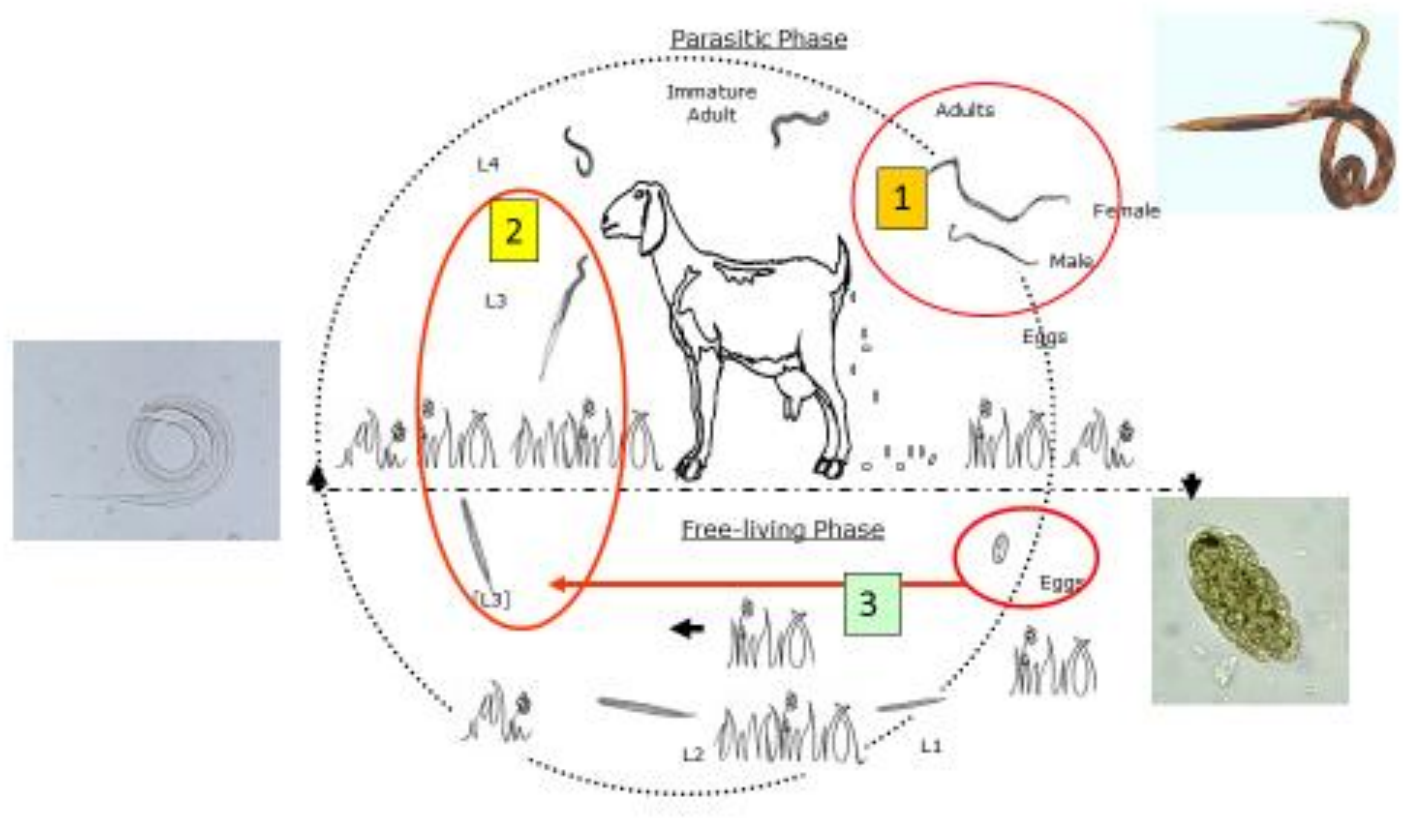

